This is the peer reviewed version of the following article: Kompanizare M, Petrone RM, Shafii M, Robinson DT, Rooney RC. Effect of climate change and mining on hydrological connectivity of surficial layers in the Athabasca Oil Sands Region. Hydrological Processes. 2018;32:36983716. https://doi.org/10.1002/hyp.13292, which has been published in final form at https://doi.org/10.1002/hyp.13292. This article may be used for non-commercial purposes in accordance with Wiley Terms and Conditions for Use of Self-Archived Versions.

\title{
Effect of climate change and mining on hydrological connectivity of surficial layers in the Athabasca Oil Sands Region
}

Kompanizare, M. ${ }^{1,{ }^{*}}$, Petrone, R.M. ${ }^{1}$, Shafii, M. ${ }^{2}$, Robinson, D.T. ${ }^{1}$, Rooney, R.C. ${ }^{3}$

${ }^{1}$ Dept. of Geography \& Environmental Management, University of Waterloo, 200 University Ave West, Waterloo, Ontario, Canada, N2L 3G1

${ }^{2}$ Dept. of Earth \& Environmental Sciences, University of Waterloo, 200 University Ave West, Waterloo, Ontario, Canada, N2L 3G1

${ }^{3}$ Dept. of Biology, University of Waterloo, 200 University Ave West, Waterloo, Ontario, Canada, N2L 3G1.

*Corresponding Author: Mazda Kompanizare, mkompani@uwaterloo.ca

\section{Abstract}

This research analyzes the impact of climate change and surface mining activities on the hydrologic connectivity of surficial (soil and geological) layers located in a watershed in the Athabasca Oil Sands Region. Surface water and groundwater flow are simulated for the period 2014 - 2080 under four climate scenarios: Median (M), Double precipitation (DP), No change in precipitation (NP) and Double temperature (DT); and with the assumption of no change in the extent of mine activities after 2013. The results demonstrate that the annual growing season duration is longer and snowmelt happens earlier in the year 2080. During the growing season, the daily proportion of connected hydrologic units (DPCUs) remains approximately the same in the future under the different climate scenarios. It appears that around $68 \%$ of watershed area, mostly in western and central eastern portions, will be frequently connected (annual proportion of connected days, $\mathrm{APCD} \geq 20 \%$ ) in the future. This area remains hydrologically connected for more than $20-50 \%$ of the year. Results also show that mining areas are located in infrequently connected areas (APCD $<20 \%$ ), where DPCU values are significantly lower than other areas. DPCUs in forestlands are more stable with a growing-season that is $\sim 15$ days longer than in wetlands. Comparisons between hydrologic responses in 2016 and 2080 show that, in 2080, maximum snow depths are about 0.7 times smaller, evapotranspiration is $\sim 0.05 \mathrm{~mm}$ higher, capillary soil moisture 
in DT and NP scenarios are $1.01-1.52 \mathrm{~mm}$ lower, and the ratio of precipitation to potential evapotranspiration is almost the same during the growing season. However, at the end of growing season, the ratio is $\sim 1$ unit less in 2080 in DT and NP scenarios. Results also demonstrate that thinner surficial geological layers in the mining areas (located mostly in downstream part of the watershed) lead to their lower HCs. Therefore, these areas are more vulnerable to mining activity impacts, and their hydrologic response under a changing climate should be considered in reclamation planning. 


\section{Introduction}

Surface mining in the Athabasca Oil Sands Region (AOSR) in the western boreal zone of Canada has significantly disturbed the hydrology and ecology of the vegetation and soils. The extent of one of the largest mining areas in the Lower Athabasca region has increased from $290 \mathrm{~km}^{2}$ in 1980 to $1030 \mathrm{~km}^{2}$ in 2013 (Alberta Environment and Park, 2016). Legally, the disturbed lands must be reclaimed upon mine closure, and returned to a naturally appearing and self-sustaining state representative of pre-disturbance conditions. The AOSR is located within the Western Boreal Plain, a landscape that is characterized by gently rolling relief as well as a mosaic of fragmented upland forests, riparian ecosystems, and pond-peatland complexes (Petrone et al., 2008; Rizzo and Wiken, 1989). Understanding of hydrologic connectivity (HC) and its controlling mechanisms is key to successful reclamation in this region because any disruption to $\mathrm{HC}$ will impact the recovery of ecosystem productivity.

We define $\mathrm{HC}$ as the water-mediated transport of matter, energy and organisms within or between elements of the hydrologic cycle (Freeman et al., 2007). As such, HC can serve as a framework for understanding spatial variation of runoff and run-on, illustrating how parts of the watershed are interconnected (Bracken and Croke, 2007; Ali and Roy, 2009). In wetlands, hydrologic connectivity and near-surface runoff processes are controlled by dynamically expanding and contracting riparian saturated zones (Tetzlaff et al., 2007a, 2007b; Birkel et al., 2010). In our study area, whose dominant runoff process is saturation-excess overland flow, climate and topography interact with surficial geology and differences in soil texture and permeability to influence hydrological flow paths and $\mathrm{HC}$, and consequently, to affect soil and plant development and water use in both wetland and forest land units (Devito et al., 2017; Bridge and Johnson, 2000; Winter, 2001). 
To simulate the hydrological response of a surficial layer to surficial mining activities at the watershed scale, groundwater and surface-water interactions must be characterized. The Royal Society of Canada (RSC, 2010) previously pointed out that, to ameliorate environmental issues related to oil sands development, an integrated Surface water - Groundwater (SW-GW) approach that considers the interaction between groundwater with rivers, lakes and wetlands is required. We postulate that, in the context of our case study, an accurate surface-groundwater model is urgently needed for accurately predicting HC under different climatic scenarios for the AOSR. The points that have to be taken into consideration for developing such a modeling platform include the selection of a relevant $\mathrm{HC}$ indicator, the identification of influential topographic components of the landscape, e.g.: surface micro-topography and surface depression storage (Antoine et al., 2009; Ali and Roy, 2010a) and fill-and-spill mechanisms (e.g. Hayashi et al., 2016; Hubbard and Linder, 1986; Shaw et al., 2012). Additionally, we must consider which future climate and land-use scenarios to apply.

The interaction between lakes, wetlands and groundwater in the Lower Athabasca Region has been investigated by the analysis of stable isotope mass balance (Bennett et al., 2008; Gibson et al., 2009). Other studies that address the interaction of surface and groundwater at watershed scales have been underway since 2003 (Birks et al., 2012). However, to the best of our knowledge, the results of these studies have not been published yet. Previous studies on groundwater modeling in the AOSR have been limited only to the local scale, e.g., predicting flow from tailings ponds to surface water (Ferguson et al., 2009; Yasuda et al., 2010), or modeling groundwater quality (Worley Parsons Canada Ltd, 2010), thus, using SW-GW models for HC analysis in the AOSR is novel. 
The most widely used SW-GW interaction models are GSFLOW (Markstrom et al., 2008), MIKE SHE (DHI, 2009), HydroGeoSphere (Therrien et al., 2010), and Parflow (Maxwell et al., 2009). GSFLOW is a coupled surface-groundwater flow model, which couples PRMS (surface water model; Leavesley et al., 1983, 2005) and MODFLOW-2005 (groundwater flow model; Harbaugh, 2005). Previous studies (Vining, 2002; Viger et al., 2010; Golden et al., 2014) demonstrated that GSFLOW and PRMS are applicable to the simulation of hydrologic processes in wetlands and to answer questions related to wetland HC (Golden et al., 2014). GSFLOW thus has a high potential to address the gap in our understanding of SW-GW interactions in the AOSR by shedding light on how land use and climate change might influence HC. The capacity for the simulation of different climate inputs in a surface-groundwater model is vital in the context of HC prediction, because climate change has the potential to significantly affect $\mathrm{HC}$, and subsequently reclamation efforts, especially for wetlands (Devito et al., 2017; Rooney et al., 2015; Petrone et al., 2007). Although climate change analysis based on developing numerical models is common in the literature (e.g., De Roo and Jetten, 1999; Callow and Smettem, 2009; Lane et al., 2009; Meerkerk et al., 2009; McGuire and McDonnell, 2010, Blackwell et al., 1999), few studies have looked at the effect of climate change on HC specifically (e.g., Bracken et al., 2013). Wainwright and Parsons (2002) and Reaney et al. (2007) examined the influence of spatial and temporal variability in precipitation $(\mathrm{P})$ on $\mathrm{HC}$ within a watershed and revealed that the surface flow models that do not incorporate temporal variability of P intensities under-predict runoff significantly.

Our research aims to evaluate the impact of climate change (characterized as spatiotemporal changes in $\mathrm{P}$, temperature, and solar radiation) and mining on $\mathrm{HC}$ in the AOSR using an integrated modeling approach. The main objectives of this paper are to: 1) employ a semidistributed SW-GW model to assess HC in the AOSR where the post-glacial terrain and surficial 
geology complicate estimates of $\mathrm{HC}$ occurrence; and 2) predict how the temporal and spatial variation of $\mathrm{HC}$ in the region will change as a consequence of projected climate change. Two major advances incorporated in our model include: 1) more realistic P inputs generated by Markov Random Space (MRS) instead of mean P intensity; and 2) an approach to assess the influence of microtopographical characteristics of post-glacial landforms through the use of a cascade routing tool. To achieve our two main objectives, we also develop a method for the generation of climate data using 40 climate points by considering the lateral transition probability in wet and dry days in different points.

\section{Methods}

\subsection{Study area}

The study area is the 07DA watershed north of Fort McMurray in Alberta, Canada (Figure 1a), which drains an area of $9500 \mathrm{~km}^{2}$ into the northern part of the Lower Athabasca Region and is located in the Western Boreal Plain within a sub-humid climate. The watershed encompasses the vast majority of open pit oil sands mine activity in Alberta (Figure 1b). This includes extensive stores of wet tailings (i.e., tailing ponds) covering approximately $89 \mathrm{~km}^{2}$ in 2013 , which act as surface water bodies and whose main water loss is through evaporation (E). These mines and tailings ponds are situated in a mosaic of wetlands, forest, and open-water (Figure 2a).

In our study area, the strata from top to bottom includes soil, surficial and deeper geological layers. Surficial geological layers in the study area are dominated by medium texture lacustrine and glaciolacustrine deposits, with coarse textured moraine and very coarse textured aeolian and fluvial surficial deposits running through the centre of the watershed (Fenton et al., 2013; Figure 2b). Deeper geological layers include very fine shale, shale-limestone and shale-gypsum 
formations (Figure 2c). Because of mainly fine grained deeper geological layers, flow is primarily through shallow (soil and surficial geological) layers. Soils in wetland areas are thinner and separated from the surficial geological layer by impermeable fine-grained layers, but in forestlands the soil is directly connected to surficial geological layers (Devito et al., 2005). Such differences in layering alter the rate and amount of percolation, suggested by variations of hydraulic conductivity (i.e., forestland soil hydraulic conductivities are about $1 \times 10^{-4} \mathrm{~m} / \mathrm{s}$, significantly higher than wetlands with hydraulic conductivities in the range $1 \times 10^{-8}$ to $3 \times 10^{-3} \mathrm{~m} / \mathrm{s}$ ) (Thompson et al., 2015). Water in forestlands typically moves vertically down through the soil towards surficial geological layers, whereas flow in wetlands is predominantly horizontal. Ponds mainly act as the surficial water storage bodies, which may fill and spill during wet/melting periods, temporarily connecting to the surface drainage network.

\subsection{Numerical model}

To assess the effect of climate change and mining disturbance on the soil and surficial geology layer hydrological connectivity we simulate the surface and groundwater flows and their interactions in our study area using GSFLOW (Markstrom et al., 2008).

Surface topography, surficial and geological layer types and thicknesses, surface coverage, and daily climate data are used as inputs to GSFLOW, and organized using a grid ( $2 \mathrm{~km}$ resolution) comprising 2388 cells, whereby each cell acts as an HRU. HRUs are the smallest computational units in the model and are assigned different hydrologic and physical characteristics based on landcover type (wetland, forestland, or open-water). Given the spatial extent of our HRUs, they are significantly larger than the average size of forest patches, wetlands, or pond areas, and thus the dominant land-cover type is assigned to each HRU. 


\subsection{Model setup}

\subsubsection{Sub-waterheds delineation}

AltaLis DEM data (June 2016) were used to delineate watershed and sub-basin boundaries (Figure 1b). Based on available streamflow data (Environment and Natural Resources, February 2016; Regional Aquatics Monitoring Program, August 2016) for the 07DA watershed, the area is divided into 12 sub-basins (Figure 1).

\subsubsection{Physical input data}

According to the Enhanced Wetland Classification data and the general classification by Devito, et al. (2012), the watershed area is divided into wetland HRUs (WHUs; fens, bogs, marshes and swamps), forestland HRUs (FHUs; upland conifer, deciduous and mixedwood), open-water HRUs (and aquatic beds), and other HRUs (Non-natural cover types or anthropogenic areas such as borrow pits) (Figure 2a). However, the mines are not incorporated at this stage of the model development (see Section 2.4.2).

Surficial and deeper geological layers are divided into categories based on their relative hydraulic conductivities (Vogwill, 2005). Soil layers are classified into three main groups of sand, clay and loam (Fenton et al., 2013; Table I; Figure 2b). Surficial geological layers are divided into medium texture lacustrine, coarse grain moraine, and very coarse/sandy textures. Soil and peat layers are similarly classified by texture (Figure 2). Surficial geological layer thickness varies among HRUs (Figure S1-1, Appendix S1), but is generally less than $20 \mathrm{~m}$. Compared with surface topography anomalies (Figure S1-2, Appendix S1), surficial geology layer thicknesses are small 
and therefore the subsurface flow directions through these layers should follow the surface topography.

Eleven deeper geological layers are identified (Hamilton et al., 1999), and to simplify the model and reduce the number of parameters the geological layers are sorted into to two groups, following Vogwill (2005): fine texture and medium texture layers (Figure 2c).

\subsubsection{Parameterization of soil and surficial layers}

Soil and surficial geological layer settings are based on the conceptual model in Devito et al, (2012), which divides the boreal plains into a mosaic of interacting forestlands, wetlands and ponds. In this model hydrologic response areas (HRAs) are delineated as areas possessing the same layer types, and HRUs have both the same surficial layer and soil coverage types. Thus, HRAs may include multiple HRUs if a single surficial geological layer type includes multiple soil cover types. To simplify our model, we made HRAs and HRUs equivalent, by assigning the dominant ( $>50 \%$ area) coverage type to the whole HRA. The preferential and slow flow components in our model occur in soil and surficial geological layer reservoirs, respectively.

Wetland hydrological unit (WHU) cells are assumed covered by peat layers. To limit the vertical flow, soil thickness is set to $3.5 \mathrm{~m}$ in this HRU type, covering both slow and preferential flow reservoirs. In WHUs, the peat layers were hydraulically separated from the underlying surficial geological layers by a thin confining layer. Forest hydrological units (FHU), however, have soil and surficial geological layers that are hydraulically connected. Lateral flow continuity in slow flow reservoirs between WHUs and FHUs is facilitated by setting higher horizontal hydraulic conductivities in the thinner slow flow reservoir in WHUs, proportional to their thicknesses. 
The flow rate between HRUs mainly depends on their slow flow storages rather than their bottom elevations (Markstrom et al., 2008, Eq. 50). The soil and surficial geological layers in FHUs are connected to soil layer in WHUs and considered as shallower subsurface flow (within surficial geological layer reservoir) while the surficial layers in WHUs are connected to deeper geological layers (in WHUs and FHUs) and considered to be the groundwater flow component (within groundwater reservoir). Upward flow from surficial geological layers to soil layers occurs only in FHUs, since the excess water in the gravity reservoir is added to preferential/fast flow (Markstrom et al., 2008, Table 9). In our model, surficial geological layers deeper than $20 \mathrm{~m}$ as well as the medium grain deeper geological layers act as sinks, which can be adjusted by the model.

\subsubsection{Fill-and-spill effect}

Here fill-and-spill is used to reflect the time and water-content dependency of the soil and surficial geological layer hydraulic conductivities and the ability to transfer water in wetlands and ponds. Wetlands and ponds store water and do not spill it to downstream portions of the watershed during low flows, which results in zero hydraulic conductivity. During wet periods, however, ponds are filled and start to spill (Hubbard and Linder, 1986; Tromp van Meerveld and McDonnell, 2006; Pomeroy et al., 2010; Ali et al., 2011; Shaw et al., 2012; Shook et al., 2011, 2015; Hayashi et al., 2016), increasing horizontal hydraulic conductivity. Approximately $15 \%$ of wetland areas are covered by ponds, therefore, we assume $\sim 15 \%$ surface depression storage coverage (ponds) in WHUs. Moreover, $\sim 30 \%$ of the wetland areas drain to ponds, thus a surface depression storage

threshold, above which water can flow out of the ponds, is a model parameter adjusted via calibration. 


\subsubsection{Model parameters}

Surface coverage types are assigned based on the definition of wetlands and forestlands (Devito et al., 2012). Tree canopy coverage is $\sim 62 \%$ and $\sim 32 \%$ in forestlands and wetlands, respectively (Thompson et al., 2015). We use a nonlinear relationship in the calculation of surface-runoffcontributing area and runoff (Markstrom et al., 2008; Eqs. 34a and 34b). Ponds on wetlands are considered open-water storage with $1 \mathrm{~m}$ depth, the surficial zone includes the upper $20 \mathrm{~m}$ of surficial geological and soil layers in FHUs, and 3.5 m (peat) in WHUs.

Soil moisture is divided into wilting point, field-capacity and preferential-flow threshold components. Soil moisture values falling between the wilting point and the field-capacity are included in the capillary reservoir (CPR), whereas soil moisture values falling between fieldcapacity and preferential-flow capacity are included in the gravity reservoir (GVR). Soil moisture exceeding the preferential-flow threshold is in the preferential flow reservoir (PFR), where soil water can flow in larger openings, fractures or conduits as fast flow. Flow coefficients (Markstrom et al., 2008; Eq.s 50, 56, 67a) for PFR (fast flow) and GVR (slow flow) are defined for three surficial geological layer types and two surface coverage types of WHUs and FHUs (Table S2-I, Appendix S2). The groundwater reservoir (GWR) is divided into two geological layer classes of medium and fine texture (Figure 2c).

In GSFLOW, hydraulic conductivity in PFR, GVR and GWR are in the form of empirical coefficients (Markstrom et al., 2008). Thus, to make the hydraulic conductivities more physically meaningful, we developed a relationship between hydraulic conductivity in Darcy's law and the empirical equation used in GSFLOW (Appendix S3). As such, the empirical coefficients in GSFLOW expressed as day ${ }^{-1}$ approximate the K value in Darcy's equation in $\mathrm{m} / \mathrm{s}$. 


\subsection{Model settings and assumptions}

\subsubsection{Determination of hydrological connectivity}

A variety of factors have been employed to characterize $\mathrm{HC}$ within and among land units, such as surface topography (e.g., Buttle, 2006, Lane et al., 2004, 2009), vegetation (Bracken and Croke, 2007), and infiltration and water transfer at the catchment scale (Gomi et al., 2008; Buda et al., 2009). Overland and subsurface flow connections are developed as a function of water volume and rate of transfer (Bracken et al., 2013). In the AOSR, different parts of the watershed are hydrologically connected mainly through the preferential flow paths within the upper peat layers (e.g., Tetzlaff et al., 2007b; Birkel et al., 2010, Gibson et al., 2015, 2016). Thus, surface topography as well as water content and thawing permafrost depth (Gibson et al., 2015) in these layers are the main controls on $\mathrm{HC}$ and surface runoff generation. To investigate and predict structural (potential) HC (Bracken et al., 2013; Golden et al., 2017) in such an environment, we first identify cascading routes based on surface topography using the methodology developed in the Cascade Routing Tool or CRT (Henson et al., 2013). Subsequently, for the HRUs that form a given cascading route, calculated water content (for all HRUs) and the rate of water transfer (between HRUs) are utilized to characterize $\mathrm{HC}$.

We use soil moisture as an indication of potentially active (deep or shallow) subsurface flow paths and their spatial connectivity, as it controls saturated overland flow in the catchment (Tetzlaff, et al., 2009, 2011, Tromp van Meerveld and McDonnell 2005, 2006, James and Roulet, 2007, Ali and Roy, 2010a, Ali et al., 2010b). The appropriate soil moisture threshold likely depends on catchment size, soil texture, the depth to any confining layer, or other factors governing which runoff processes dominate. Specifically, we follow the recommendation of Ali and Roy 
(2010a) that a land unit with soil moisture $\geq 30 \%$ be considered connected to surrounding land units. To ensure that this threshold was appropriate for our study region, we tested the sensitivity of important connectivity metrics (DPCU and APCD, discussed in section 3.2) to variations in the soil moisture threshold. DPCU and APCD were sensitive to soil moisture values between 20-40\%. We chose the midpoint soil moisture, SM (30\%) with highest sensitivity of DPCU and APCD to soil moisture that is also aligned with the conceptual underpinning of Ali and Roy (2010a) that at this value they found that both saturation-excess overland flow and subsurface stormflow can occur at level of $30 \% \mathrm{SM}$. We also found that the temporal and spatial pattern of changes in DPCU and APCD with change in SM threshold within range of 20 to $40 \%$ is almost constant and maximum variations can be seen in 30\% SM (Appendix A).

Given the information provided above, to characterize HC in the AOSR, we consider a chain of cascading routes between a given HRU and the stream network as continuous if the preferential storage along all HRUs comprising the chain exceeds 30\% (Ali and Roy, 2010a). The number of HRUs that are not connected to the stream network are then calculated and used to quantify $\mathrm{HC}$ in the watershed. Therefore, unlike previous studies that used only the topographic indices for defining structural HC (e.g., Beven and Kirkby, 1979; TOPMODEL), both surface topography (i.e., cascading routes between model units) and soil moisture (i.e., $30 \%$ soil moisture threshold, Ali and Roy, 2010a; HU's storage, CEMA, 2014) are utilized in our study for determining $\mathrm{HC}$; that is, $\mathrm{HC}$ is only inferred when two units both have soil moisture above our $30 \%$ threshold and are successive units along a given cascade route.

\subsubsection{Superimposing mining areas}


Oil sands mine leaseholds support different types of activities that exert different levels of disturbance on land cover and hydrologic characteristics (Figure 1a). Mining leaseholds in the model are divided into two parts: 1) wet tailings (i.e. tailings ponds), which are very large surface pits (depressions) where surface water and wastewater from mining activities are stored;2) mining areas, assumed to be covered by a separate surficial (soil and geologic) layer, the hydraulic conductivity of which is a model parameter adjusted via calibration (Figure 1). In the model, there is no outflow from tailings ponds in the form of surface runoff and/or interflow. However, in reality there may be a negligible amount of seepage and evaporation from these ponds.

To implement the spatial changes in the mining areas over time, the exact extent of mining areas was obtained from Alberta Environment and Parks for 1980, 1998, 2007, 2011, 2012 and 2013. Consequently, the calibration period is divided into five intervals, namely, Jan. 1979 to Dec. 1989, Jan. 1990 to Jun. 2002, Jul. 2002 to Dec. 2010, Jan. 2011 to Dec. 2012, and Jan. 2013 to Jul. 2014. The mining footprint, the extent of wet tailings and disturbed area are held constant within each interval, and varied between intervals. When future $\mathrm{HC}$ was predicted (i.e., after Jul. 2014) the extent of the mined area was assumed to be stationary. This is unlikely to be a realistic assumption, as resource development in the region continues. Regardless, this assumption of stationarity is necessary to allow us to isolate the effect of climate change on $\mathrm{HC}$ in the region. The combined effects of mine expansion and climate change were addressed explicitly in the model calibration period (1979 to 2014).

\subsubsection{Climate data and parameters}

Many studies have investigated the effect of climate change on the hydrologic behaviour of watersheds in Alberta (e.g., Boyer et al., 2010; Candela et al., 2012; Farjad et al., 2015, Luo et al., 
2013, Xu et al., 2013). Recently Schneider (2013) used ClimateWNA (Wang et al., 2012) and downscaled data available for 24 Global Circulation Models (GCMs). ClimateAB is a software for generating monthly climate data for Alberta (Mbogga et al., 2010; Alberta Environment, 2005), which uses 20 model-scenarios to generate monthly climate data for a selected location in the region for 2030, 2050 and 2080.

In the scenarios analysis part of this study, the generated climate parameters during the prediction period (Aug 2014 to Dec 2080) are used to simulate changes in streamflow and HC with climate. Daily maximum and minimum temperature, solar radiation and $\mathrm{P}$ in the prediction period are generated in a 3' grid within and around the study area for four scenarios: median, M (Median or MPI-ESM-LR in Schneider, 2013), double temperature change, DT (Hot or HADGEM2-ES in Schneider, 2013), double P change, DP (Dry, GFLD-CM3 in Schneider, 2013) and no P change, NP (Dry, GFLD-CM3 in Schneider, 2013; but with zero change in P) (National Center for Environmental Prediction [NCEP] Climate Forecast System Reanalysis [CFSR]). However, as it has been shown that CFSR P data for Alberta are over-estimated (i.e., Faramarzi et al., 2015), we use monthly P data from ClimateAB to correct CFSR data by multiplying CFSR daily data by the ratio between monthly $\mathrm{P}$ from ClimateAB and CFSR.

Daily climate data are generated using the method presented by Richardson (1981). Moreover, the Hydrologic Evaluation of Landfill Performance (HELP; U.S. Army Waterways Experiment Station) model is modified to generate climate data for longer periods and with some predefined linear trends. This modified code is then used to determine mean monthly $\mathrm{P}$ and temperature as well as the probability of wet days (days with $>0.25 \mathrm{~mm} \mathrm{P}$ ) whose previous day is dry or wet (PWD or PWW, respectively). Gamma Distribution Alpha and Beta parameters are also calculated for use in generating daily P. Mean, minimum and maximum as well as first and third 
quartiles of these quantities for $40 \mathrm{CFSR}$ points and different months revealed that most parameters (except monthly temperature), are spatially variable with large differences between their maximum and minimum values. For the Beta parameter, spatial variabilities change over months, while for PWW and PWD spatial variabilities are almost constant.

In the calculation of climate parameters, we assume the climate data during the calibration period are stationary and a cyclostationary cosine function is fit to the observed daily maximum and minimum temperatures and solar radiation (Richardson, 1981) and coefficient of variations (separately for wet and dry days) in each CFSR point. Mean temperatures in wet and dry days vary by as much as 1.7 to $3.3{ }^{\circ} \mathrm{C}$ and amplitudes change by as much as $1.7{ }^{\circ} \mathrm{C}$, but mean lag times and coefficients of variation do not change significantly between CFSR points. This also applies to the change in mean and amplitude of solar radiation $\left(4.8\right.$ to $\left.9.7 \mathrm{~W} / \mathrm{m}^{2}\right)$ in both dry and wet days.

The generation of $\mathrm{P}$ is done in two steps: 1) generation of wet and dry days using a Markov chain, and 2) generation of $\mathrm{P}$ depths using Gamma distribution coefficients. However, in the generation of wet and dry days in the network of 40 CFSR points we could not simply use Markov chain coefficients (PWW and PWD) as the lateral transition probabilities needed to be considered in the generation of wet and dry days. Thus, to consider the lateral transition probability in wet and dry days in our CFSR points, we developed a Markov Random Space (MRS) method (Appendix S4) to implement both expected spatial and temporal transition probabilities in generated wet and dry days. After generating all wet and dry days, we produce P depths using monthly Gamma distribution coefficients (Alpha and Beta). To produce the expected increasing trend in $\mathrm{P}$ we multiplied the generated P to a linearly increasing trend coefficient.

\subsection{Model Calibration}


Model calibration is conducted using a Parallel-Dynamically Dimensioned Search (DDS) optimization algorithm (Tolson et al., 2007) implemented in the OSTRICH software (Matott, 2016). All model simulations are performed in SHARCNET (Shared Hierarchical Academic Research Computing Network: www.sharcnet.ca) and Compute/Calcul Canada. The calibration period for simulating daily streamflow is from January 1, 1979 to July 31, 2014, considering 5 separate intervals of 1980, 1998, 2007, 2011 and 2013. The prediction period considered for model validation is from August 1, 2014 to December 31, 2080, using snow depth data (1994-2009), 33 parameters (Table S2-I, Appendix S2) relevant to groundwater, soil zone and surface runoff modules and selected according to their sensitivities determined through pre-calibration runs. In addition to the 33 parameters (Table A-1), 3 sets of tied parameters are also defined, which are dependent on one or more calibration parameters and/or other tied parameters.

\subsubsection{Calibration criteria}

Calibration criteria comprise the goodness-of-fit between simulated and observed streamflow time series as well as multiple hydrological signatures calculated using the same time series. For goodness-of-fit, we use Nash-Sutcliffe Efficiency (NSE) measure (Nash and Sutcliffe, 1970) calculated as:

$$
N S E=1-\sigma_{\varepsilon}^{2} / \sigma_{O}^{2}
$$

where $\sigma_{\varepsilon}^{2}$ is the variance of residuals (differences between observed and simulated values), and $\sigma_{O}^{2}$ is the variance of observed values. NSE ranges from minus infinity to 1 (perfect fit).

Hydrologic signatures reflect the functional behavior of a catchment (Black, 1997; Wagener et al., 2007) and can be calculated based on streamflow, snow depth or other available 
hydrologic observations (Carrillo et al., 2011; Clark et al., 2011; Eder et al., 2003; Jothityangkoon et al., 2001; McMillan et al., 2012; Wagener and Montanari, 2011; Shafii and Tolson, 2015). We implement in-model calibration of 15 hydrological signatures (HSs, see definitions and equations in Table 1) in 12 sub-basins (1-11, 13, and 14) as well as snow depth at the Mildred Lake weather station. During calibration, the differences between observed and simulated values for all hydrologic signatures should approach zero, and each calibration criterion needs to be defined such that these deviations are minimized. Based on previous research (Yilmaz et al., 2008; Blazkova and Beven, 2009; Shafii and Tolson, 2015), a deviation scoring factor (D) is calculated and minimized for each signature:

$$
D=\frac{S_{o b s}-S_{s i m}}{S_{o b s}}
$$

where $s_{\text {sim }}$ and $s_{\text {obs }}$ are the simulated and observed values, respectively. Note that the ideal value for $\mathrm{D}$ is zero.

To combine NSE and D for all signatures, we use the following aggregate criterion in model calibration (which is minimized during calibration):

$$
\begin{aligned}
& O b j=\sum_{i=1}^{12} W_{i}\left[1-N S E_{i}\left(Q_{t}\right)\right]^{2}+W_{S}\left[1-N S E\left(S_{t}\right)\right]^{2}+\sum_{i=1}^{12} W_{i} D_{i}\left(F D C_{M S}\right)^{2}+\sum_{i=1}^{12} W_{i} D_{i}\left(F D C_{H V}\right)^{2} \\
& +\sum_{i=1}^{12} W_{i} D_{i}\left(F D C_{L V}\right)^{2}+\sum_{i=1}^{12} W_{i} D_{i}\left(Q_{M}\right)^{2}+\sum_{i=1}^{12} W_{i} D_{i}\left(Q_{V}\right)^{2}+\sum_{i=1}^{12} W_{i} D_{i}\left(Q_{M D}\right)^{2} \\
& +\sum_{i=1}^{12} W_{i} D_{i}\left(Q_{P}\right)^{2}+\sum_{i=1}^{12} W_{i} D_{i}\left(Q_{L A}\right)^{2}+\sum_{i=1}^{12} W_{i} D_{i}\left(Q_{L M}\right)^{2}+\sum_{i=1}^{12} W_{i} D_{i}\left(Q_{L V}\right)^{2} \\
& +\sum_{i=1}^{12} W_{i} D_{i}\left(Q_{M M}\right)^{2}+\sum_{i=1}^{12} W_{i}\left[1-N S E_{i}\left(Q_{M O}\right)\right]^{2}+\sum_{i=1}^{12} W_{i}\left[1-N S E_{i}\left(Q_{A}\right)\right]^{2}
\end{aligned}
$$


This aggregate criterion is the sum of $(1-N S E)^{2}$ and $(D)^{2}$ for each of 12 sub-basins $(i=1, \ldots, 12)$, for all sub-basins as a whole $(i=13)$ and for snow depth. The weights, $W_{i}$ s, for each sub-basin and for all sub-basins are calculated based on the sub-basin area and number of days with streamflow observations (section 4.5.2). The weights $\left(W_{i}\right)$ for sub-basin 1, 2, 3, 4, 5, 6, 7, 8, 10, 11, 13 and 14 are $0.011,0.059,0.040,0.032,0.261,0.180,0.505,0.439,0.004,0.024,0.008$ and 0.013 , respectively, and for all sub-basins jointly $\left(W_{15}\right)$ is 1 . Note that the larger the area and number of observation points, the larger the corresponding weight. Thus, the number of data points and/or the surface area of a given sub-basin is a measure of sub-basin's weights in our objective function (Eq.3).

\subsubsection{Calibration}

The Parallel-Dynamically Dimensioned Search (DDS) was run over 3000 simulations to reduce the calibration criterion from an initial solution of 19.6 to an optimized value of 3.2 (Figure $3 a$ ). In model calibration, we calculated NSE values for daily, monthly, and annual streamflow, as well as the bias in mean streamflow in different sub-basins (Figure 3b). The highest NSE values are in larger sub-basins with longer periods of streamflow data, which have been the focus in model calibration (i.e., more weights are assigned to their corresponding calibration metric). More details about model calibration are presented in Appendix A.

\section{Results}

\subsection{Climate change analysis}

Assuming a linear trend in the values of climate parameters between 2016 and 2080, Table 2 summarises the amount of changes in monthly climate parameters in this time frame for four 
scenarios (M, DT, DP, NP, defined in section 2.4.3). Figure 4 demonstrates the predicted daily hydrologic responses in 2016 and 2080 for the four scenarios, where each curve is the average of 30 simulations based on 30 sets of generated climate data for the underlying scenario. The hydrologic response curves in Figure 4 illustrate that the snow season comes before the $80^{\text {th }}-100^{\text {th }}$ and after the $300^{\text {th }}-330^{\text {th }}$ Julian days (i.e., the responses are stable and mainly at their minimum). Snowmelt happens between the $80^{\text {th }}$ and $110^{\text {th }}$ Julian days, when there is a rise in flow rate, soil moisture and snow melt. Fluctuations in the hydrologic response during days 110 to 300 indicate that this period encompasses the growing season.

Comparing model results in 2016 and 2080 illustrates that there is a longer growing season, earlier snowmelt, a lower maximum snowpack water equivalent, less soil moisture in the DT and NP scenarios, and a higher actual evapotranspiration (ET) in 2080 than under current (2016) conditions.

The first steep ascending part in the flow regime starts approximately 20 days earlier in 2080 than in 2016 (Figure 4), with the DT scenario producing the earliest annual peak and latest recession in total flow. Similarly, the annual peak of snow water equivalent (SWE) occurs later in 2016 than in 2080, and snow accumulation in 2016 starts earlier and peaks higher than in 2080 (Figure 4).

Soil capillary moisture (Figure 4c) is constant during the snow-season in both years; however, soil moisture under the DT and NP scenarios is generally lower in 2080 than in 2016. The pattern of changes in gravity and preferential flow storages in 2016 and 2080 for different scenarios (Figure $4 \mathrm{~d}$ ) is similar to that of total flow rates. The growing-season ( $\sim 110$ to 300 Julian Day) starts with a peak in gravity storage, which happens almost 20 days earlier in 2080 than in 
2016. Further, the last annual recession in gravity storage is around the $300^{\text {th }}$ day in 2016 , and the $330^{\text {th }}$ day in 2080.

Similar to SWE and total flow, snowmelt happens approximately 20 days earlier in 2080 than in 2016 (Figure 4e). The magnitude of actual ET is higher in 2080 than in 2016 almost every

day (Figure 4f). Average daily P amounts under different scenarios are higher in the DP scenario in 2080 compared with 2016 and the differences in P amount are most notable during the growingseason $\left(170^{\text {th }}\right.$ to $220^{\text {th }}$ Julian days) (Figure $4 \mathrm{~g}$ ). The abrupt changes in generated P producing a stepwise pattern across the year is due to the independent generation of $\mathrm{P}$ for each month with a separate set of climate parameters.

The ratios between P and potential ET (Figure 4h) as well as between P and actual ET (Figure 4i) reveal that during the snow-season (Julian Days 80-100 and 300-330), when the surface is snow covered in all scenarios, the ratios are significantly smaller in 2080 than in 2016. During this snow-season, the ratios are also higher than in the growing season. However, we conclude that this is an artifact of the model because the actual and potential ET during the snow-season is minimal, with temperatures largely below zero (average of $-14^{\circ} \mathrm{C}$ in 2016) and the land surface covered in snow. During the growing season, the ratios of P to actual and potential ET in our model are reliable, but very similar in 2016 and 2080 (Figure 4h, i), although for the DT and NP scenarios, the ratios are slightly smaller in 2080 .

\subsection{Hydrological Connectivity}

To show the effect of climate change on hydrological connectivity of surficial layers the daily hydrological connectivity of soil and surficial geology in all HRUs during the prediction period are determined for the four scenarios (M, DP, NP and DT). To more clearly show the temporal 
and spatial changes in HC, the values in 2016 and 2080 are compared. For each scenario, 30 climate simulations are generated and the means and standard deviations corresponding to model results are presented in Figure 5.

Figure 5a demonstrates the daily proportion of connected units, DPCU, in 2016 and 2080 for the different scenarios, which is the number of connected HRUs divided by total number of HRUs on a given day. As mentioned in Section 2.4.1, the connected HRUs are the ones that are connected to at least one HRU that is connected to the stream network. While the curves for 2016 are similar under the different scenarios (only scenario $\mathrm{M}$ is shown for 2016 in Figure 5a), the curves for 2080 vary under different scenarios. The growing-season in 2080 is $\sim 50$ days longer than 2016, starting $\sim 20$ days earlier and ending $\sim 30$ days later (Figure 5a). DPCU standard errors calculated based on 30 simulations for each climate scenario (Figure 5b), shows that although standard deviations are overlapping significantly HC is different in 2080 compared to 2016 . The width of standard deviation strips shows the uncertainty in both model structure and assumption as well as in model inputs (Figure $5 b$ ).

\subsubsection{Temporal changes in HC in wetlands, forestlands and mining areas}

To examine temporal changes in DPCUs in wetlands, forestlands and mining areas, their DPCU curves for the M scenario in 2016 and 2080 are plotted in Figures 6a and b. Overall, the DPCU range in mining areas $(0.32-0.4)$ is significantly lower than the watershed average $(0.25-0.63)$ (Figure 6a). The mining area minimum DPCU in the snow-season $(0.32)$ is higher than the watershed average $(0.25)$, because the mining areas are closer to the main stream network and largely covered by stream network HRUs. In the growing season, however, DPCU in the mining area $(0.35-0.40)$ is significantly less than the watershed average $(0.50-0.60)$. This indicates that in 
the growing season a lower proportion of mining area connects to the stream network despite its proximity to stream network.

Plots of WHU and FHU DPCUs shows that minimum values in forestlands (0.29) are higher than in wetlands $(0.22)$, and the peaks and fluctuations in growing-season are significantly less in FHUs. Moreover, the recession in DPCU, at the end of growing season, occurs $\sim 15$ days later in FHUs, in both 2016 and 2080. The lower range of fluctuations and longer growing season interval in FHUs may be due to the thicker soils and lack of surface depression storage compared with WHUs.

\subsubsection{Spatial changes in hydrological connectivity}

Spatial fluctuations in $\mathrm{HC}$, and the effect of climate change on its distribution are demonstrated by the annual proportion of connected days (APCD) for different HRUs in 2016 and 2080 for the median scenario (Figure 7). APCD is the proportion of days in a year that an HRU is connected, which ranges from 0 to 1 . In both 2016 and 2080, along stream network HRUs, APCD is $\sim 1$ and the ratio decreases by moving farther from streams. Figure 7 a reveals that in $\sim 68 \%$ of the watershed in 2016, including its west and central eastern parts, APCDs are more than $\sim 0.3$, while in the central and southern to south eastern parts, APCD is very low $(\sim 0)$. Here we divided the watershed areas based on their duration of connectivity or APCD values to frequently connected and infrequently connected areas. The frequently connected areas, are connected to the stream network 20 to $50 \%$ of the days during a year (APCD $>20 \%$ ) and infrequently connected areas are connected less than $20 \%(\mathrm{APCD}<20 \%)$. In 2080, the spatial distribution of APCD is almost the same as in 2016 but the values are higher, as much as $\sim 0.1$. To more clearly show the effect of different 
scenarios on the spatial distribution of APCD, APCD is plotted as the differences between 2080 and 2016 for different scenarios (Figure 8), which show higher APCDs in 2080.

To statistically evaluate the change of APCD values over time, a t-test was used on the difference between means in 2016 and 2080 (Figure 8). Colored pixels in Figure 8 demonstrate a statistically significant difference in means. APCD differences are mainly positive and in the range of 0 to 0.25 . However, some negative values can be seen in NP and DT scenarios in 1 to $2 \%$ of area (Figure $8 \mathrm{c}$ and d). The increases are mainly concentrated in the west part of the watershed, where the connected cells were located in 2016, in all scenarios. In the DP scenario increases occurred in the central-eastern portions as well. The areas with positive differences are in 27,43 , 19 and $20 \%$ of the watershed area in M, DP, NP and DT scenarios, respectively. In the DT scenario, the range of negative or positive differences are higher than other scenarios.

\section{Discussion}

We aimed to quantify the influence of changing climate and mining on hydrologic connectivity (HC) in the Alberta Oil Sands Region (AOSR). We used a semi-distributed SW-GW modelling approach with more realistic $\mathrm{P}$ inputs and considered the influence of microtopography. This study region is interesting because of ongoing land cover change associated with the rapid development of oil sands resources. Further, $\mathrm{HC}$ is one of the most important factors in the reclamation of disturbed mining areas, the evaluation of the impact of mining activities and climate change on HC is important for future reclamation projects (Rooney et al. 2015). More broadly, our work addresses an important gap in the application of numerical models to analyze the influence of climate change on HC specifically. Our approach involves two important innovations. First, our model makes use of more realistic P inputs generated by Markov Random Space (MRS) instead 
of mean $\mathrm{P}$ intensity. Second, we use cascade routing to assess the influence of post-glacial landform microtopography on $\mathrm{HC}$.

Overall, we determined that projected climate change will significantly increase the duration of $\mathrm{HC}$, though the spatial extent of $\mathrm{HC}$ is not strongly affected by projected climate change under our different scenarios. The study region is divided in to frequently connected (68\% of the study area) and infrequently connected areas (32\% of the study area) with close to zero annual connected duration. Frequently connected areas are mainly in the western as well as the central-eastern parts of the watershed. In 2080 , in $30-60 \%$ of the frequently connected area, annual connected duration increases by $\sim 10 \%$ on average for all scenarios. The extent of areas with $10 \%$ increase in APCD in 2080 within frequently connected areas in the DP scenario is $1.5-2$ times that of other scenarios. The extent of infrequently connected areas remains almost the same in 2080 and also between scenarios.

The sensitivity of HC to our model parameters indicates that the uncertainties in our simulations should be about two-fold what we present in our plot of DPCU standard deviation envelopes for different scenarios (Figure 5b). The expected excess uncertainty should be due to uncertainties in predicted model parameters.

Mining areas are located mainly in the infrequently connected areas, despite their proximity to the main stream network. Since the mining areas are located within small sub-basins, they receive a limited amount of surface and subsurface water from the upland parts of their own subbasins. On the other hand, the deeper geological layers are mainly clay-rich layers with very low hydraulic conductivity that have no significant effect on the hydrology of surface wetlands. The main subsurface connectivity is instead through shallow groundwater, soil and surficial geological layers (Vallarino, 2009; van der Kamp and Hayashi, 2009). So, the thin surficial geological layers 
(Figure S1-1) and limited upland areas are the main reasons for infrequent connectivity in mining areas in the Alberta Oil Sands Area. Frequently connected areas are in more elevated areas with thicker surficial geological layers and mainly in wetlands. As it was stated by Amon et al. (2005), wetlands with a groundwater connection tend to show moderated water-level changes during wetdry climate cycles, and in our simulations thicker surficial layers means higher shallow groundwater connection. While infrequently connected areas primarily have thinner surficial layers, located in lower elevations and mainly in forestlands. In previous studies also it was mentioned that the forestlands supply water to the wetlands (Devito et al., 2012).

Because of the thicker surficial geological layer, lack of surface depression storage and connection between surface soil and surficial geological layers typical of forestlands, their connectivity is temporally more stable with smaller fluctuations and with longer annual duration ( $\sim 15$ days), compared with wetlands. Devito et al., (2012) also stated that the wetland HUs respond more rapidly to short-term changes in climate cycles and have shorter "water memory" than the forestland HUs. Water follows deeper flow pathways in forestlands compared to wetlands and therefore takes longer to move through the system. For the boreal watersheds with the same geological setting, $\mathrm{HC}$ in areas with thinner surficial geological layers are more vulnerable to mining activities and climate change.

Other hydrologic effects of climate change included extending the growing season and the snowmelt period. Generally, ET increases and snowpack depth decreases, leading to lower capillary soil moisture during the growing season. However, increases in P offset this, resulting in the ratios between $\mathrm{P}$ and actual or potential ET remaining relatively unchanged. The specifics of the scenario influence the exact start and end dates of the growing season, revealing that an 
increase in temperature is more influential than a change in P. However, the DP scenario was the only example that maintained snow depth at 2016 levels.

\section{Conclusion}

We developed a semi-distributed surface-groundwater modelling approach and generated four climate scenarios to evaluate the effects of climate change and mining activities in the AOSR. We determined that climate change has a greater influence on the duration of HC than on its spatial distribution. Our results also revealed that the spatial and temporal distribution of HC (DPCU and APCD) are not significantly sensitive to changes in the soil moisture threshold. We interpret this to means that $\mathrm{HC}$ at the watershed scale is controlled by other parameters (e.g., hydraulic conductivity of the soil and surficial geology layers or watershed size). However, the similarity between our soil moisture threshold and that adopted by Ali and Roy (2010a) does not suggest that the dominant runoff processes are the same.

Our results are in agreement with other Canadian models that considered the extremes in temperature and precipitation in their predictions (Tebaldi et al., 2006; Kharin et al., 2007; Pike et

al., 2008); however, our scenario generations are based on mean changes in precipitation and temperature. Our predictions of an earlier snowmelt season, and increase in stream flow in the early growing season (March and April), and increase in the length of the growing season (increase in length of frost free period and number of growing degree days), a decrease in the depth of the snow pack, and a decrease in length of the snow season are in general agreement with previous studies conducted elsewhere in Canada (Leith and Whitfield, 1998; Zhang et al., 2001; Pike et al., 2008). Yet, given the comparably smaller size of our study area and spatial variability of climate 
parameters, our results are not in complete agreement with some specific results such as the predicted decrease in streamflow rate in summer and fall predicted by some other Canadian models (Leith and Whitfield, 1998; Zhang et al., 2001; Pike et al., 2008).

Lastly, we conclude that in areas where more permeable surficial geological layers are limited by fine-grained and impermeable deeper geological layers, areas with thicker surficial geological layers will exhibit greater HC. Also, in forestlands with thicker surficial geological layers, $\mathrm{HC}$ is more stable and lasted for longer annual durations than in wetlands where surficial geological layers were typically thinner. Although the mining areas are located in downstream parts of the watershed and expected to be supplied by upstream areas, their thinner surficial geological layer made them infrequently connected and more vulnerable to the impacts of mining activities. Our results about the effect of surficial geological layer thickness on HC can provide decision makers information to understand and manage the potential response of watershed $\mathrm{HC}$ to climate change and mining activities. To more accurately assess the effect of mining activities on the surficial geological layer's HC in future studies, we recommend collection of more detailed hydrological observations from the impacted mining areas. Additionally, we recommend studying the sensitivity of soil and surficial geological layer $\mathrm{HC}$ to the layers' hydraulic conductivities, watershed size and other watershed parameters.

\section{Acknowledgements}

We acknowledge Torey McLeish, Jemmy Hu (SHARCNET), Robert Regan (USGS), Monireh Faramarzi (University of Calgary), Caroline Bampfylde (Government of Alberta), and Danielle Cobbaert (Government of Alberta) for their help and support. Computations were done using the facilities at SHARCNET (Shared Hierarchical Academic Research Computing Network: 
www.sharcnet.ca) and Compute/Calcul Canada. Funding provided by Husky Energy (Rooney, Petrone, Robinson) and NSERC CRD (HEAD3) (Petrone). The authors also appreciate the constructive and very useful comments from reviewers.

\section{Supporting information}

Supporting information are divided to four appendixes: S1 to S4. Appendix S1 presents surficial layer and surface topography maps. In Appendix S2 the model parameters are illustrated in two tables. The methodology for derivation of equivalent $\mathrm{K}$ is discussed in Appendix S3 and finally in Appendix S4 there are details about derivation of Markov Random Space equations. 


\section{References:}

Alberta Environment (2005). Alberta Climate Model (ACM) to provide climate estimates (19611990) for any location in Alberta from it geographic coordinates. Alberta Environment Publ. No. T/749. ISBN No. 0-7785-3939-3 (Printed Edition), ISBN. 0-7785-3941-5 (Online Edition)

Alberta Environment and Park (2016) Oil Sands Industrial Feature Digital Data.

Ali, G. A., \& Roy, A. G. (2009). Revisiting hydrologic sampling strategies for an accurate assessment of hydrologic connectivity in humid temperate systems. Geography Compass, $3,350-374$.

Ali, G. A., \& Roy, A. G. (2010a). Shopping for hydrologically representative connectivity metrics in a humid temperate forested catchment. Water Resources Research, 46, W12544.

Ali, G. A., Roy, A. G., Turmel, M. C., \& Courchesne, F. (2010b). Source-to-stream connectivity assessment through end-member mixing analysis. Journal of Hydrology, 392 (3-4), 119135.

Ali, G. A., L'Heureux, C., Roy, A. G., Turmel, M. C., \& Courchesne, F. (2011). Linking spatial patterns of perched groundwater storage and streamflow generation processes in a headwater forested catchment. Hydrological Processes, 25(25), 3843-3857. http://dx.doi.org/10.1002/hyp.8238.

AltaLis DEM data (n.d.). Retrieved (June 2016), from http://www.altalis.com

Amon, J.P., Jacobson, C.S., \& Shelley, M.L. (2005). Construction of fens with and without hydric soils. Ecological Engineering, 24, 341-357. 
Antoine, M., Javaux, M., \& Bielders, C. (2009). What indicators can capture runoff relevant connectivity properties of the micro-topography at the plot scale? Advances in Water Resources, 32, 1297-1310.

Bennett, K.E., Gibson, J.J., \& McEachern, P.M. (2008). Water-yield estimates for critical loadings assessment: comparisons of gauging methods versus an isotopic approach. Canadian Journal of Fisheries and Aquatic Science, 65, 83-99.

Beven, K. J., \& Kirkby, M. J. (1979). A physically-based, variable contributing area model of basin hydrology. Hydrological Science Bulletin, 24, 43-69.

Birkel, C., Tetzlaff, D., Dunn, S. M., \& Soulsby, C. (2010). Towards simple dynamic process conceptualization in rainfall runoff model using multi-criteria calibration and tracers in temperate, upland catchments. Hydrological Processes, 24, 260-275.

Birks, J., Jones, J.P., \& Gibson, J. (2012). Surface water-groundwater interactions in the Lower Athabasca Region, Submitted to: CEMA, Alberta Innovates-Technology Futures.

Black, P. E. (1997). Watershed functions, Journal of the American Water Resources Association, 33(1), 1-11.

Blackwell, M. S. A., Hogan, D. V., \& Maltby, E. (1999). The use of conventionally and alternatively located buffer zones for the removal of nitrate from diffuse agricultural runoff. Water Science and Technology, 39, 157-164.

Blazkova, S., \& Beven, K. (2009). A limits of acceptability approach to model evaluation and uncertainty estimation in flood frequency estimation by continuous simulation: Skalka catchment, Czech Republic. Water Resources Research, 45, W00B16, doi:10.1029/2007WR006726. 
Boyer, C., Chaumont, D., Chartier, I., \& Roy, A. G. (2010). Impact of Climate change on the hydrology of St. Lawrence tributaries. Journal of Hydrology, 384(1-2), 65-83.

Bracken, L. J., \& Croke, J. (2007). The concept of hydrological connectivity and its contribution to understanding runoff dominated geomorphic systems. Hydrological Processes, 21, 1749-1763.

Bracken, L. J., Wainwright, J., Ali, G. A., Tetzlaff, D., Smith, M. W., Reany, S. M., \& Roy, A. G. (2013). Concepts of hydrological connectivity: Research approaches. Pathways and future agendas. Earth-Science Reviews, 119, 17-34.

Bridge, S., \& Johnson, E. (2000). Geomorphic principles of terrain organization and vegetation gradients. Journal of Vegetation Science, 11, 57-70. https://doi.org/10.2307/3236776.

Buda, A. R., Kleinman, P. J. A., Srinivasan, M. S., Bryant, R. B., \& Feyereisen, G. W. (2009). Factors influencing surface runoff generation from two agricultural hillslopes in central Pensylvania. Hydrological Processes, 23, 1295-1312.

Buttle, J. M. (2006). Mapping first order controls on streamflow from drainage basins: the $\mathrm{T}^{3}$ template. Hydrological Processes, 20, 3415-3422.

Callow J. N., \& Smettem, K. R. J. (2009). The effect of farm dams and constructed banks on hydrologic connectivity and runoff estimation in agricultural landscapes. Environmental Modelling \& Software, 24, 959-968.

Candela, I., Tamoh, K., Olivares, G., \& Gomez, M. (2012). Modelling impacts of climate change on water resources in ungauged and data-scarce watersheds, Application to the Siurana catchment (NE Spain). Sci Total Environ, 440, 253-60. 
Carrillo, G., Troch, P. A., Sivapalan, M., Wagener, T., Harman, C., \& Sawicz, K. (2011). Catchment classification: Hydrological analysis of catchment behaviour through processbased modeling along a climate gradient. Hydrol, Earth Syst. Sci., 15(11), 3411-3430.

CEMA, Cumulative Environmental Management Association, (2014). Guidelines for wetlands establishment on reclaimed oil sands leases. Third edition.

Clark, M. P., Kavetski, D., \& Fenicia, F. (2011). Pursuing the method of multiple working hypotheses for hydrological modeling, Water Resources Research., 47, W09301, doi:10.1029/2010WR009827.

De Roo, A. P. J., \& Jetten, V. G. (1999). Calibrating and validating the LISEM model for two data sets from the Netherlands and South Africa. Catena, 37, 477-493.

Devito, K., Creek, I., Gan, T., Mendoza, C., Petrone, R., Silins, U., \& Smerdon, B. (2005). A framework for broad-scale classification of hydrologic response units on the Boreal Plain: is topography the last thing to consider? Hydrological Processes, 19, 1705-1714.

Devito, K., Mendoza, C., \& Qualizza, C. (2012). Conceptualizing water movement in the boreal plains. Implication for watershed construction, Synthesis Report Prepared for the Canadian Oil Sands Network for Research and Development. Environmental and Reclamation Research Group. 164 pp.

Devito, K. J., Hokanson, K. J., Moore, P. A., Kettridge, N., Anderson, A. E., Chasmer, L., Hopkinson, C., Luckenbach, M. C., Mendoza, C. A., Morissette, J., Peters, D. L., Petrone, R. M., Silins, U., Smerdon, B., Waddington, J. M. (2017). Landscape controls on longterm runoff in subhumid heterogeneous Boreal Plains catchments. Hydrological Processes, 31(15), 2737-2751. doi: 10.1002/hyp.11213

DHI, (2009). MIKE SHE Volume 1: User Guide. (2009 Edition). 230 p. 
Eder, G., Sivapalan, M., \& Nachtnebel, H. P. (2003) Modelling water balances in an Alpine catchment through exploitation of emergent properties over changing time scales. Hydrological Processes, 17(11), 2125-2149.

Environment and Natural Resources, Government of Canada (n.d.) Retrieved February 2016, from http://wateroffice.ec.gc.ca/search/searchResult_e.html

Faramarzi, M., Srinivasan, R., Iravani, M., Bladon, K. D., Abbaspour, K. C., Zehnder, A. J. B., \& Goss, G. G. (2015). Setting up a hydrological model of Alberta: Data discrimination analysis prior to calibration. Environmental Modelling \& Software, 74, 48-65. http://dx.doi.org/10.1016/j.envsoft.2015.09.006

Farjad, B., Gupta, A., \& Marceau, D. J. (2015). Hydrological Regime responses to Climate Change for the 2020s Periods in the Elbow River Watershed in Southern Alberta, Canada. Environmental Management of River Basin Ecosystems, Springer Earth System Sciences, DOI 10,1007/978-3-319-13425-3_4

Fenton, M. M., Waters, E. J., Pawley, S. M., Atkinson, N., Utting, D. J. \& Mckay, K. (2013). Surficial Geology of Alberta; Alberta Energy Regulator, AER/AGS Map 601, scale 1:1000 000.

Ferguson, G.P., Rudolph, D.L. \& Barker, J.F. (2009). Hydrodynamics of a large oil sand tailing impoundment and related environmental implications. Canadian Geotechnical Journal, $46,1446-1460$.

Freeman, M. C., Pringle, C. M., \& Jackson, R. C. (2007). Hydraulic connectivity and the contribution of stream headwaters to ecological integrity at regional scale. Journal of American Water Resources Association, 43 (1), 5-14. 
Gibson, J.J., Birks, S.J., Tattrie, K., Richardson, K., Kumar, S., Moncur, M., Yi, Y., Szabova, M., Jasechko, S., \& Eby, P. (2009). Isotope tracing of water yield and chemical loading in the Alberta Oil Sands region for evaluating sensitivity to acid deposition. Technical report prepared for Cumulative Environmental Management Association, 23 Dec 2009, 39p.

Gibson, J.J., Birks, S.J., Yi, Y., \& Vitt, D.H. (2015). Runoff to boreal lakes linked to land cover, watershed morphology and permafrost thaw: a 9-year isotope mass balance assessment. Hydrological Processes, 29, 3848-3861.

Gibson, J.J., Yi, Y., \& Birks, S.J. (2016) Isotope-based partitioning of streamflow in the oil sands region, northern Alberta: Towards a monitoring strategy for assessing flow sources and water quality controls. Journal of Hydrology: Regional Studies, 5, 131-148.

Golden, H.E., Lane, C.R., Amatya, D.M., Bandilla, K.W., Kiperwas, H.R., Knightes, C.D., \& Ssegane, H. (2014). Hydrologic connectivity between geographically isolated wetlands and surface water systems: A review of selected modeling methods. Environmental Modeling \& software, 53, 190-206.

Golden, H.E., Creed, I.F., Ali, G., Basu, N.B., Neff, B.P., Rains, M.C., McLaughlin, D.L., Alexander, L.C., Ameli, A.A., Christensen, J.R., Evenson, G.R., Jones, C.N., Lane, C.R., \& Lang, M. (2017). Integrating geographically isolated wetlands into land management decisions. Frontiers in Ecology and the Environment, 15(6), 319-327. doi:10.1002/fee. 1504 .

Gomi, T., Sidle, R. C., Miyata, S., Kosugi, K., \& Onda, Y. (2008). Dynamic runoff connectivity of overland flow on steep forested hillslopes: scale effects and runoff transfer. Water Resources Research, 44, W08411. 
Hamilton, W. N., Price, M. C., \& Langenberg, C. W. (1999). Geological Map of Alberta, Alberta Geological Survey, Alberta Energy and Utilities Board, Map No. 236, scale 1:1,000,000

Harbaugh, A. W. (2005). MODFLOW-2005, the U.S. Geological Survey modular ground-water model- the Ground-Water Flow Process: U.S. Geological Survey Techniques and Methods 6-A16, variously paginated.

Hayashi, M., van der Kamp, G., \& Rosenberry, D.O. (2016). Hydrology of Prairie wetlands: Understanding the integrated surface-water and groundwater processes. Wetlands, 36, S237-S254. doi:10.1007/s13157-016-0797-9.

Henson, W. R., Medina, R. L., Mayers, C. J., Niswonger, R. G., \& Regan, R. S. (2013). CRTCascade Routing Tool to define and visualize flow paths for grid-based watershed models: U.S. Geological Survey Techniques and Methods 6-D2, 28 p.

Hill, M.C. (1992). A computer program (MODFLOWP) for estimating parameters of a transient, three-dimensional, ground-water flow model using nonlinear regression: U.S. Geological Survey Open-File Report 91-484, 358 p.

Hubbard, D.E., \& Linder, R.L. (1986). Spring runoff retention in Prairie Pothole wetlands. Journal of Soil and Water Conservation, 41(2), 122-125.

James, A. L., \& Roulet, N. T. (2007). Investigating hydrologic connectivity and its association with threshold change in runoff response in a temperate forested watershed. Hydrological Processes, 21, 3391-3408.

Jothityangkoon, C., Sivapalan, M., \& Farmer, D. L. (2001). Process controls of water balance variability in a large semi-arid catchment: Downward approach to hydrological model development. Journal of Hydrology, 254 (1-4), 174-198. 
Kharin, V.V., Zwiers, F.W., Zhang, X., \& Hagerl, G.C. (2007). Changes in temperature and precipitation extremes in the IPCC ensemble of global coupled model simulations. Journal of Climate, 20, 1419-1444.

Lane, S. N., Brookes, C. J., Kirkby, M. J., \& Holden, J. (2004) A network-index based version of TOPMODEL for use with high-resolution digital topographic data. Hydrological Processes, 18, 191-201.

Lane, S. N., Reaney, S. M., \& Heathwaite, A. L. (2009). Representation of landscape hydrological connectivity using a topographically driven surface flow index. Water Resources Research, 45, W08423, doi:10.1029/2008WR007336

Leavesley, G. H., Lichty, R. W., Troutman, B. M., \& Saindon, L. G. (1983). Precipitation-runoff modeling system-User's manual: U.S. Geological Survey Water-Resources Investigations Report 83-4238, 207p.

Leavesley, G. H., Markstrom, S. L., Viger, R. J., \& Hay, L. E. (2005) USGS Modular Modeling System (MMS)-Precipitation-Runoff Modeling System (PRMS) MMS-PRMS, in Singh, V., and Frevert D., eds., Watershed Models: Boca Raton, Fla., CRC Press, p. 159-177.

Leith, R.M., \& Whitfield, P. (1998). Evidence of climate change effects on the hydrology of streams in south-central B.C. Canadian Water Resources Journal, 23(3), 219-230.

Li, W., \& Zhang, C. (2008). A single-chain-based multidimensional Markov chain model for subsurface characterization. Environ. Ecol. Stat., 15, 157-174. DOI 10.1007/s10651-0070045-9.

Luo, Y., Ficklin, D. L., Liu, X., \& Zhang, M. (2013). Assessment of Climate change impacts on hydrology and water quality with a watershed modeling approach. Science of the Total Environment. 450-451, 72-82. http://dx.doi.org/10.1016/j.scitotenv.2013.02.004 
Markstrom, S. L., Niswonger, R. G., Regan, R. S., Prudic, D. E., \& Barlow, P. M. (2008). GSFLOW-Coupled groundwater and surface-water flow model based on the integration of the Precipitation-Runoff Modeling System (PRMS) and the Modular Ground-Water Flow Model (MODFLOW-2005): U.S. Geological Survey Techniques and Methods 6-D1, 240 p.

Matott, L. S. (2016). Ostrich-An Optimization Software Toolkit for Research Involving Computational Heuristics, Documentation and User's Guide. State University of New York at Buffalo, Center for Computational Research.

Maxwell, R.M., Kollet, S.J., Smith, S.G., Woodward, C.S., Falgout, R.D., Baldwin, C., Bosl, W.J., Hornung, R., \& Ashby, S. (2009). PARFLOW User's Manual, v 1.3. GNU Licensed by the Free Software Foundation, Inc. 127p.

Mbogga, M. S., Hansen, C., Wang, T., \& Hamann, A. (2010). A comprehensive set of interpolated climate data for Alberta. Government of Alberta, Publication number: Ref. T/235. ISBN: 978-0-7785-9184-9 (on-line- edition), 978-0-7785-9183-2 (print edition).

McGuire, K. J, \& McDonnell, J. J. (2010). Hydrological connectivity of hillslopes and streams: characteristics time scales and nonlinearities. Water Resources Researches, 46, W10543, doi:10.1029/2010WR009341.

McMillan, H., Krueger, T., \& Freer, J. (2012) Benchmarking observational uncertainties for hydrology: Rainfall, river discharge and water quality. Hydrological Processes, 26(26), 4078-4111.

Meerkerk, A. L., van Wesemael, B., \& Bellin, N. (2009). Application of connectivity theory to model the impact of terrace failure on runoff in semi-arid catchments. Hydrological Processes, 23,2792-2803. 
Nash, J. E., \& Sutcliffe, J. V. (1970). River flow forecasting through conceptual models: Part 1- A discussion of principles. J. Hydrol., 10(3), 282-290.

Petrone, R. M., Silins, U., \& Devito, K. J. (2007). Dynamics of evapotranspiration from a riparian pond complex in the Western Boreal Forest Alberta, Canada. Hydrological Processes, 21, 1391-1401. http://doi.org/10.1002/hyp.6298

Petrone, R. M., Devito, K. J., Silins, U., Mendoza, C., Brown, S. C., Kaufman, S. C., \& Price, J.S. (2008). Transient peat properties in two pond-peatland complexes in the sub-humid Western Boreal Plain, Canada. Mires Peat., 3, 1-13.

Pike, R.G., Spittlehouse, D.L., Bennett, K.E., Egginton, V.N., Tschaplinski, P.J., Murdock, T.Q., \& Werner A.T. (2008). Climate change and watershed hydrology: Part I - Recent and Projected changes in British Columbia. Watershed Management Bulletin, 11(2), 1-7.

Pomeroy, J., Fang, X., Westbrook, C., Minke, A., Guo, X., \& Brown, T. (2010). Prairie hydrological model study progress report. Centre for Hydrology Report \#7.

Reaney, S. M., Bracken, L. J., \& Kirkby, M. J. (2007). Use of the connectivity of Runoff Model (CRUM) to investigate the influence of storm characteristics on runoff generation and connectivity in semi-arid areas. Hydrological Processes, 21 (7), 894-906.

Regional Aquatics Monitoring Program (RAMP) (n.d.) Home page. Retrieved August 2016, from http://www.ramp-alberta.org/data/map/default.aspx?c=Hydrology

Richardson, C.W. (1981). Stochastic simulation of daily precipitation, temperature and solar radiation. Water Resources Research, 17(1), 182-190.

Rizzo, B., \& Wiken, E. (1989). Assessing the sensitivity of Canada's ecosystems to climatic change, in Koster, E.A., and M.M. Boer, compilers, Landscape Ecological Impacts of 
Climate Change on Boreal/(Sub)Arctic Regions with emphasis on Fennoscandia, LilC Project, pages 94-111.

Rooney, R., Robinson, D. T., \& Petrone, R. (2015). Megaproject reclamation and climate change. Nature Climate Change, 5, 963-966. doi:10.1038/nclimate2719

Royal Society of Canada (2010). The Royal Society of Canada Expert Panel: Environmental and Health Impacts of Canada's Oil Sands Industry, 414p.

Schneider, R. R. (2013). Alberta's Natural Subregions Under a Changing Climate: Past, Present and Future, Prepared for Biodiversity Management and Climate Change Adaptation Project.

Shafii, M., \& Tolson, B. A. (2015). Optimizing hydrological consistency by incorporating hydrological signatures into model calibration objectives. Water Resources Research, 10.1002/2014WR016520.

Shaw, D.A., Vanderkamp, G., Conly, F.M., Al, P., \& Martz, L. (2012). The fill-spill hydrology of Prairie wetland complexes during drought and deluge. Hydrological Processes, 26(20), 3147-3156. Doi:10.1002/hyp.8390.

Shook, K.R. \& Pomeroy, J.W. (2011). Memory effects of depressional storage in Northern Prairie hydrology. Hydrological Processes, 25(25), 3890-3898. Doi:10.1002/hyp.8381.

Shook, K., Pomeroy, J., \& van der Kamp, G. (2015). The transformation of frequency distributions of winter precipitation to spring streamflow probabilities in cold regions; case studies from the Canadian Prairies. Journal of Hydrology, 521, 395-409. Doi:10.1016/j.jhydrol.2014.12.014. 
Tebaldi, C., Hayhoe, J.M., Arblaster, J.M., \& Meehl, G.A. (2006). Going to the extremes: An intercomparison of model-simulated historical and future changes in extreme events. Climate Change, 79, 185-211.

Tetzlaff, D., Soulsby, C., Bacon, P. J., Youngson, A. F., Gibbins, C., \& Malcolm, I. A. (2007a). Connectivity between landscapes and riverscapes - a unifying theme in integrating hydrology and ecology in catchment science? Hydrological Processes, 21, 1385-1389.

Tetzlaff, D., Soulsby, C., Waldron, S., Malcolm, I. A., Bacon, P. J., Dunn, S. M., \& Lilly, A. (2007b). Conceptualization of runoff processes using GIS and tracers in a nested mesoscale catchment. Hydrological Processes, 21, 1289-1307.

Tetzlaff, D., Seibert, J., McGuire, K. J., Laudon, H., Burn, D. A., Dunn, S. M., \& Soulsby, C. (2009). How does landscape structure influence catchment transit time across different geomorphic provinces? Hydrological Processes, 23, 945-953.

Tetzlaff, D., McNamara, J. P., \& Carey, S. K. (2011). Measurements and modelling of storage dynamics across scales. Hydrological Processes, 25, 3831-3835.

Therrien, R., McLaren, R.G., Sudicky, E.A., \& Panday, S.M. (2010). HydroGeoSphere: A threedimensional numerical model describing fully-integrated subsurface and surface flow and solute transport. Groundwater Simulations Group, Waterloo, Ontario, 469p.

Thompson, C., Mendoza, C. A., Devito, K. J., \& Petrone, R. M. (2015). Climate controls on groundwater-surface water interactions within the Boreal Plains of Alberta: Field observations and numerical simulations. Journal of Hydrology, 527, 734, 746.

Tolson, B. A., Sharma, V., \& Swayne, D. A. (2007). A parallel implementations of the Dynamically Dimensioned Search (DDS) Algorithm. International symposium on 
Environmental Software Systems (ISESS) 2007, Prague, Czech Republic. May 22-25, 2007.

Tromp van Meerveld, I., \& McDonnell, J. J. (2005). Comment to 'Spatial correlation of soil moisture in small catchments and its relationship to dominant spatial hydrological processes. Journal of Hydrology, 303, 307-312.

Tromp van Meerveld, I., \& McDonnell, J. J. (2006). Threshold relations in subsurface stormflow: 2. The fill and spill hypothesis. Water Resources Research, 42 (2), W02411.

Vallarino, A. (2009). Implications of shallow groundwater and surface water connections for nitrogen movement in typical Boreal Plain landscapes. Master of Sciences Thesis, Department of Geography, University of Victoria.

Van der Kamp, G., Hayashi, M. (2009). Groundwater-wetland ecosystem interaction in the semiarid glaciated plains of North America. Hydrogeology Journal, 17, 203-214. Doi:10.1007/s10040-008-0367-1.

Viger, R.J., Hay, L.E., Jones, J.W., \& Buell, G.R. (2010). Accounting for large numbers of small water bodies in the application of the precipitation-runoff modeling system in the Flint River basin, Georgia. U.S. Geological Survey Open-File Report 2010-5062, p. 37.

Vining, K.C. (2002). Simulation of streamflow and wetland storage, Starkweather Coulee Subbasin, North Dakota, water years 1981-98. U.S. Geological Survey Water-Resources Investigations Report 02-4113, p. 28.

Vogwill, R. I. J. (2005). Hydrogeological Map of Lesser Slave Lake Area, Alberta, NTS 830.

Wagener, T., Sivapalan, M., Troch, P., \& Woods, R. (2007) Catchment classification and hydrologic similarity. Geogr. Compass, 1(4), 901-931. 
Wagener, T., \& Montanari, A. (2011). Convergence of approaches toward reducing uncertainty in predictions in ungauged basins. Water Resources Research, 47, W06301, doi:10.1029/2010WR009469.

Wainwright, J., \& Parsons, A. J. (2002). The effect of temporal variations in rainfall on scale dependency in runoff coefficients. Water Resources Research, 38 (12), 1271-1282. Doi:10.1029/2000WR000188,2002

Wang, T., Hamann, A., Spittlehouse, D., \& Murdock, T. (2012). ClimateWNA: high-resolution spatial climate data for western North America. Journal of Applied Meteorology and Climatology, 51, 16-29.

Winter, T. (2001). The concept of hydrologic landscapes. Journal of the American Water Resources Association, 37, 335-349. https://doi.org/10.1111/j.1752-1688.2001.tb00973.x

Worley Parsons Canada Ltd. (2010) Groundwater flow model for the Athabasca Oils Sands (in situ) area south of Fort McMurray: Report prepared for Alberta Environment, Phase 2, 161 p.

Xu, Y. P., Zhang, X., Ran, Q., \& Tian, Y. (2013). Impact of climate change on hydrology of upper reaches of Qiantang River Basin, East China. Journal of Hydrology, 483, 51-60.

Yasuda, N., Thomson, N.R., \& Barker, J.F. (2010). Performance evaluation of a tailing pond seepage collection system. Canadian Geotechnical Journal, 47, 1305-1315. http://dx.doi.org/10.1139/T10-029.

Yilmaz, K. K., Gupta, H.V., \& Wagener, T. (2008). A process-based diagnostic approach to model evaluation: Application to the NWS distributed hydrologic model. Water Resources Research, 44, W09417, doi:10.1029/2007WR006716. 


\section{Zhang, X., Harvey, K.D., Hogg, W.D., \& Yuzyk, T.R. (2001). Trends in Canadian streamflow. Water Resources Research, 37(4), 987-998.}

\section{Figure Captions(Legends):}

Figure 1 a) Extent of open pit oil sands mine activity in 2013. b) Watershed 07DA is subdivided into sub-basins 1 to 14 , and all but 9 (along the Athabasca River) were used in this study. Streamflow data from 9 were not available.

Figure 2 a) Distribution of the four main coverage types based on Devito et al. (2012) and Enhanced Wetlands Classification maps, and b) distribution of three surficial layer classes on our model HRUs. c) Distribution of two simplified classes of bedrock or deeper geological layers.

Figure 3 a) Normalized objective function value during 3000 calibration iterations. b) NSE values for the daily (I), monthly (II), annual (III) and mean streamflow (IV) in different sub-basins.

Figure 4 Simulated daily hydrologic responses for 2016 (solid lines) and 2080 (dashed lines) based on four climate change scenarios: Median (M), Double Temperature (DT), Double Precipitation (DP) and no precipitation change (NP).

Figure 5 a) Mean daily proportion of connected units for median (M), double precipitation (DP), no change in precipitation (NP) and double temperature (DT) scenarios in 2016 and 2080 for the entire watershed. Snow-season, growing-season and snowmeltperiod for 2080 are illustrated. b) Standard deviation area of daily proportion of connected units for median (M), double precipitation (DP), no change in precipitation (NP) and double temperature (DT) scenarios in 2080 for the entire watershed.

Figure 6 Daily proportion of connected units for median (M) scenario in 2016 and 2080 for the entire watershed and the mining areas (Mine) (a) as well as for the entire watershed, wetland and forestland areas (b).

Figure 7 Annual proportion of connected days in different HRUs in 2016 and 2080 for the median (M) change scenario.

Figure 8 Increase in annual proportion of connected days in different HRUs in 2080 compared with 2016 for median (M), double precipitation (DP), no change in precipitation (NP) and double temperature (DT) scenarios. 


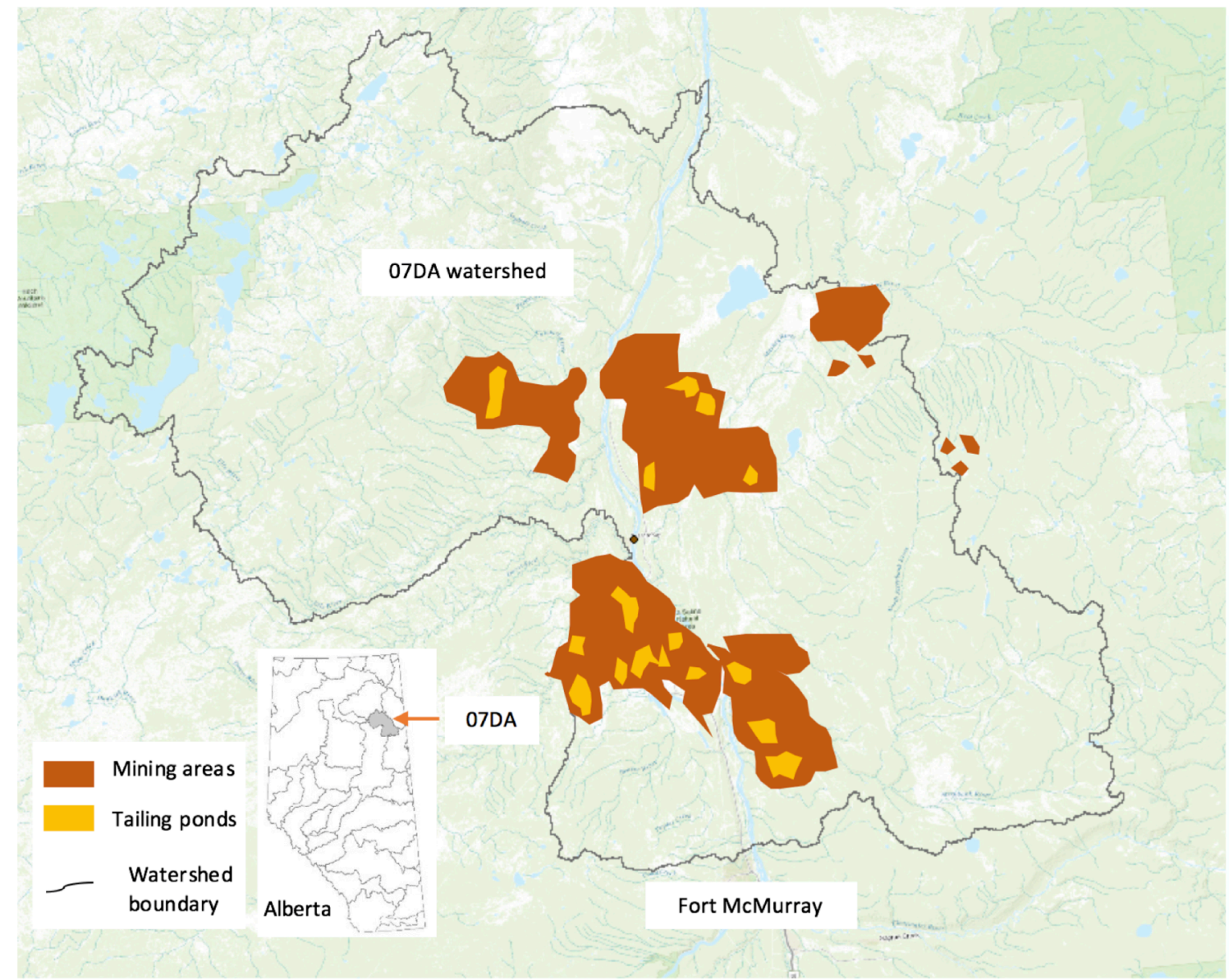

a)

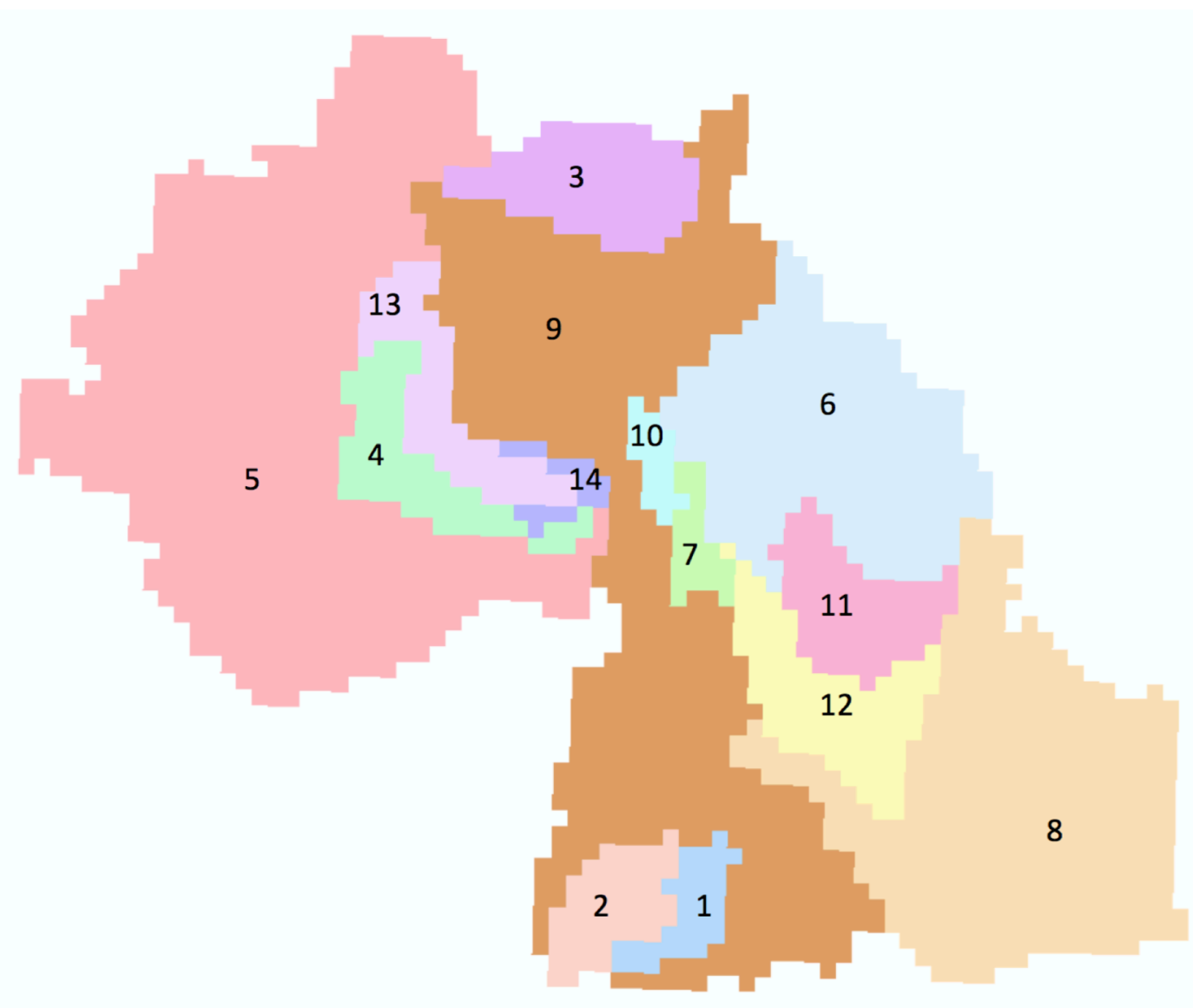

b)

Figure 1 a) Extent of open pit oil sands mine activity in 2013. b) Watershed 07DA is subdivided into sub-basins 1 to 14, and all but 9 (along the Athabasca River) were used in this study. Streamflow data from 9 were not available. 


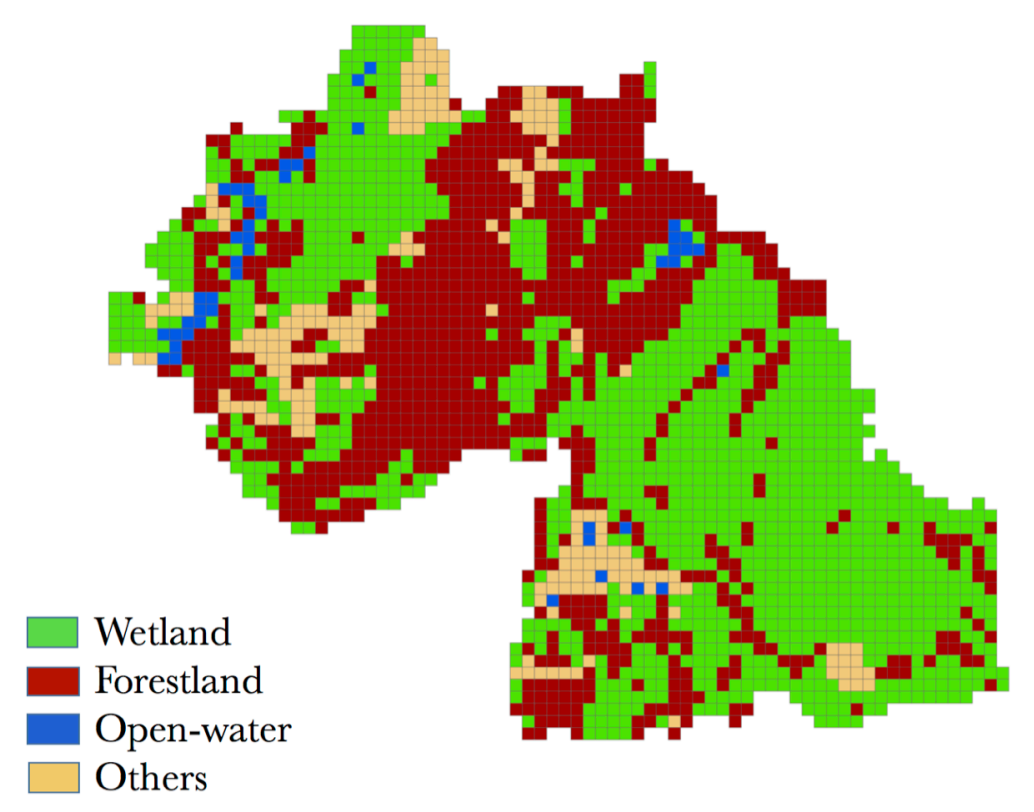

a)

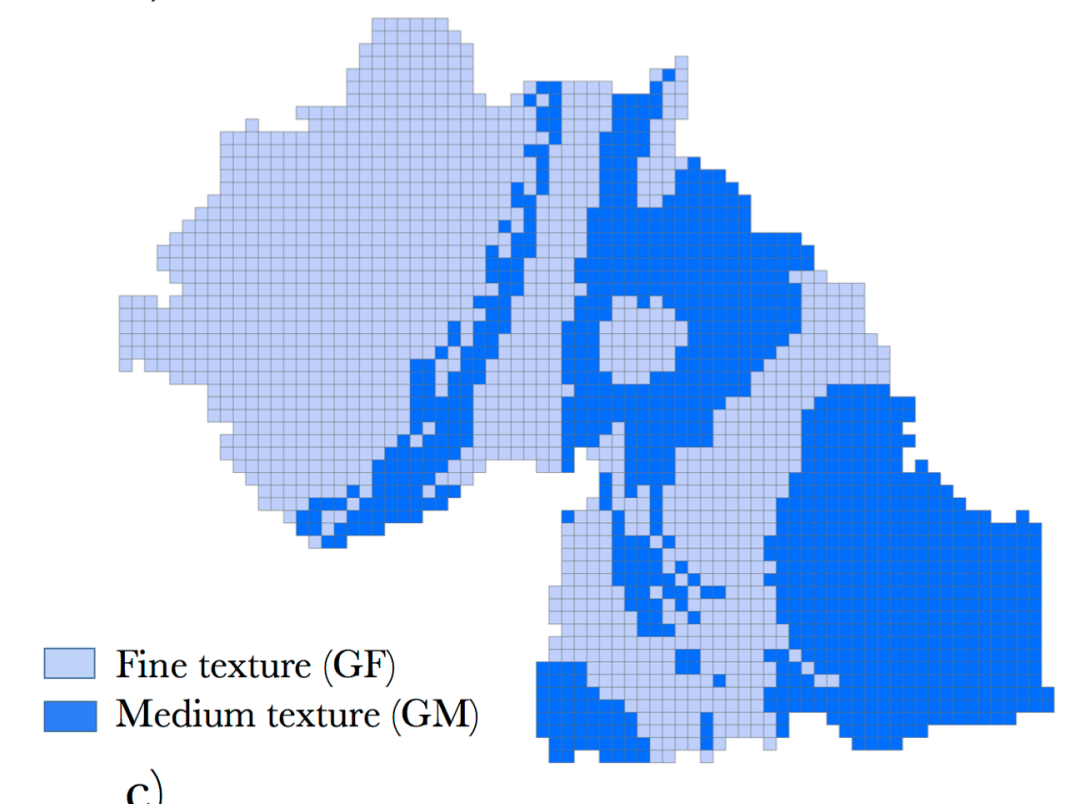

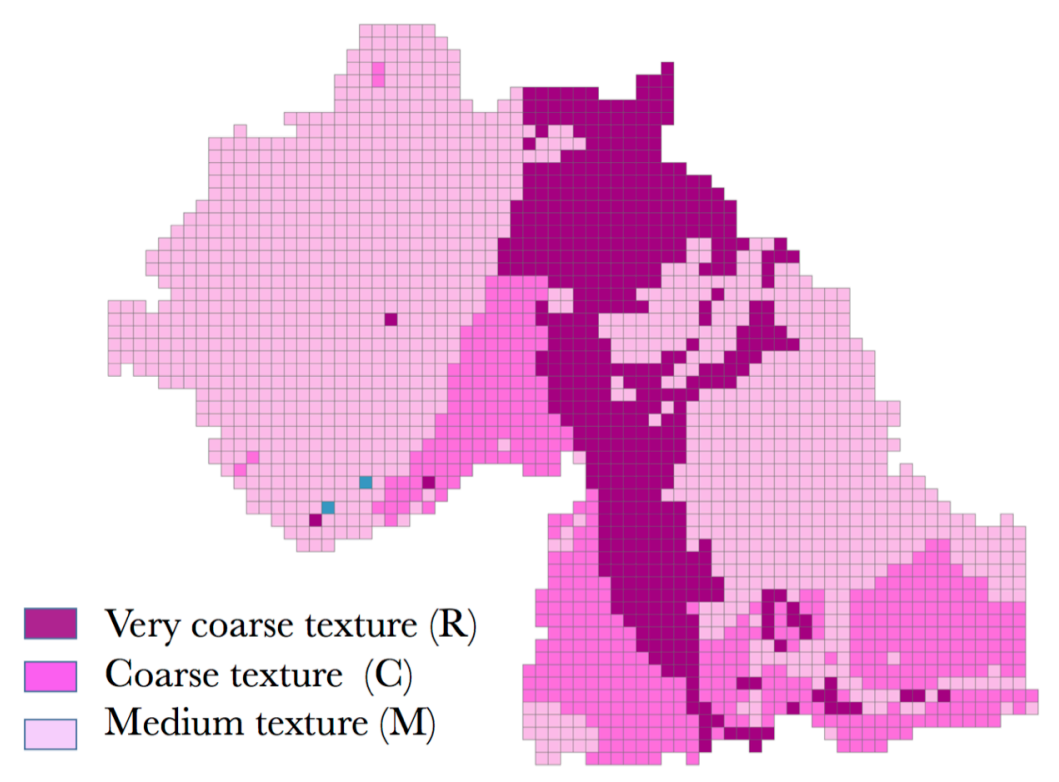

b)

Figure 2 a) Distribution of the four main coverage types based on Devito et al. (2012) and Enhanced Wetlands Classification maps, and b) distribution of three surficial layer classes on our model HRUs. c) Distribution of two simplified classes of bedrock or deeper geological layers. 


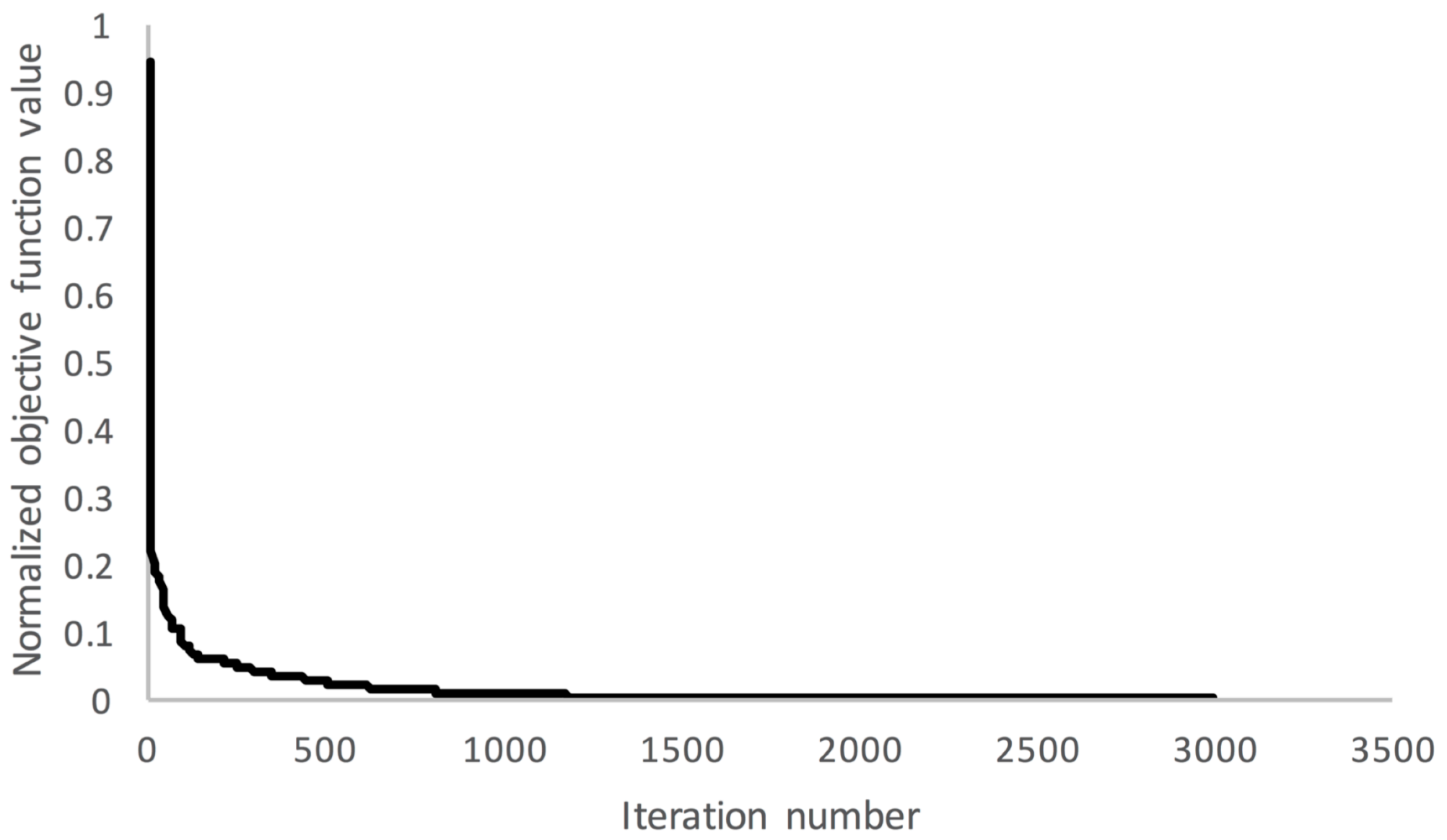

Figure 3 a) Normalized objective function value during 3000 calibration iterations. 


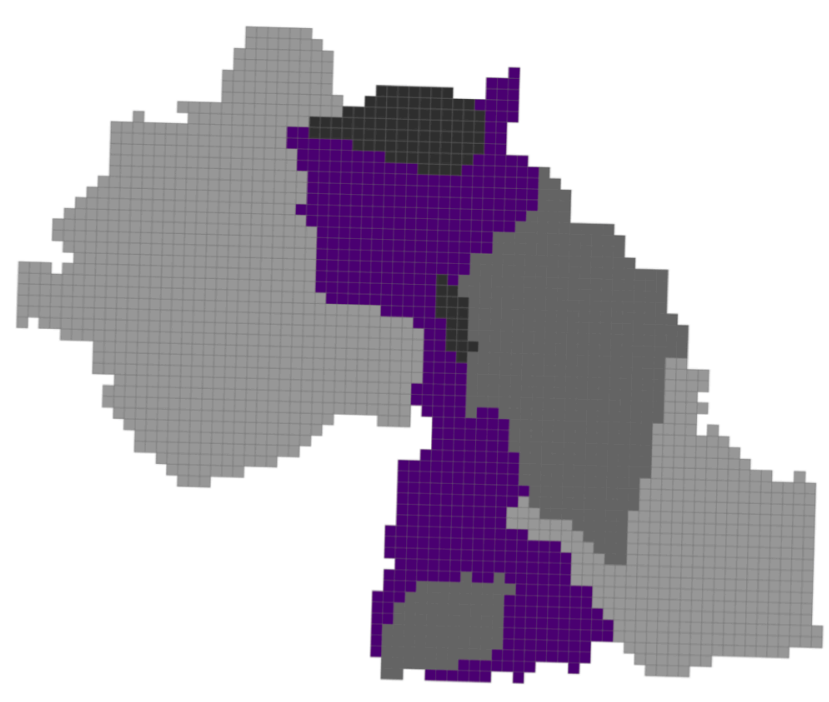

I) NSE for daily streamflow
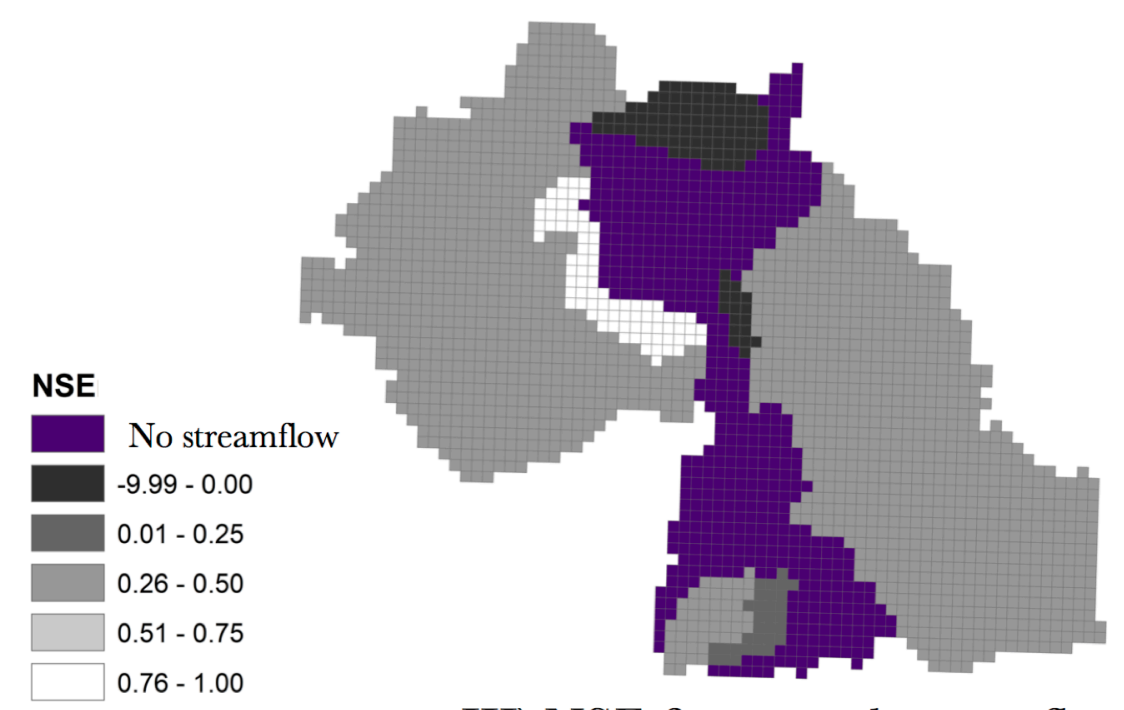

III) NSE for annual streamflow

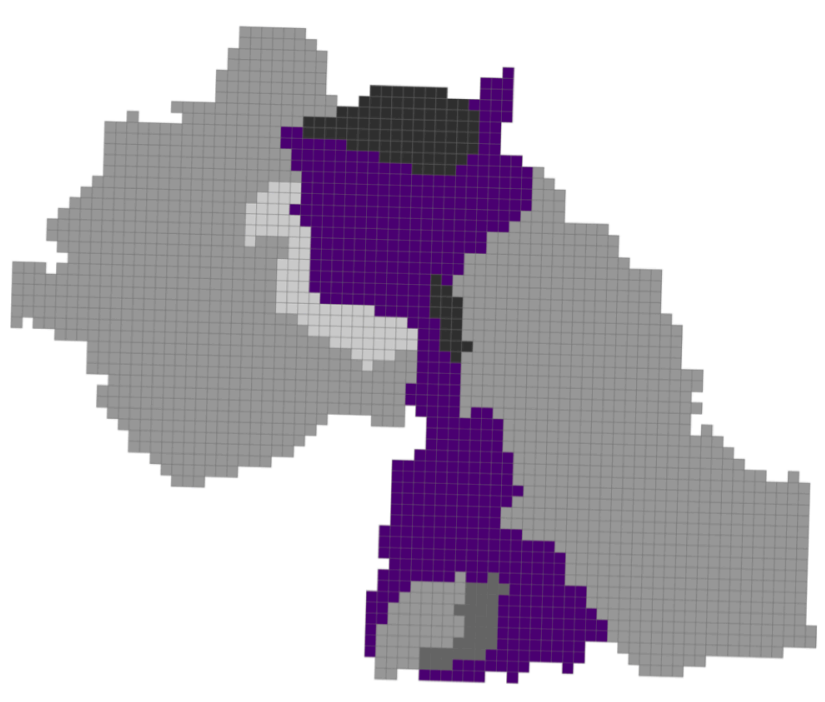

II) NSE for monthly streamflow

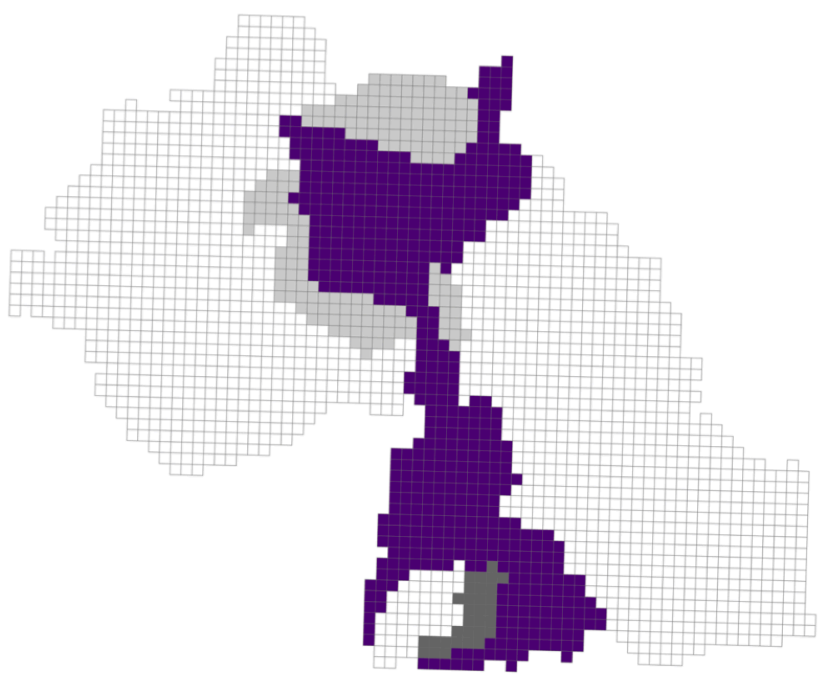

IV) NSE for mean streamflow

Figure $3 \mathrm{~b} N S E$ values for the daily (I), monthly (II), annual (III) and mean streamflow (IV) in different sub-basins. 


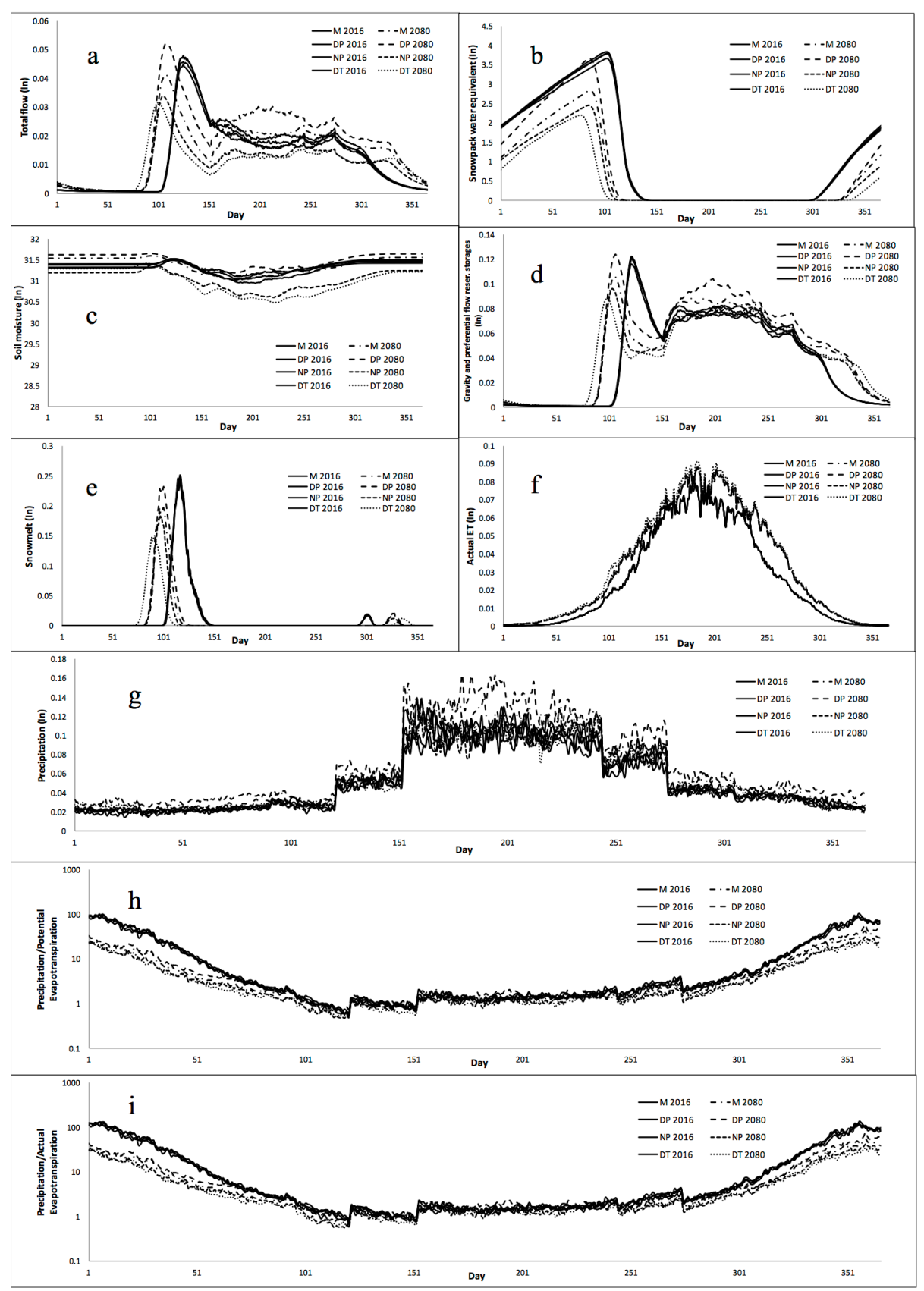

Figure 4 Simulated daily hydrologic responses for 2016 (solid lines) and 2080 (dashed lines) based on four climate change scenarios: Median (M), Double Temperature (DT), Double Precipitation (DP) and no precipitation change (NP). 

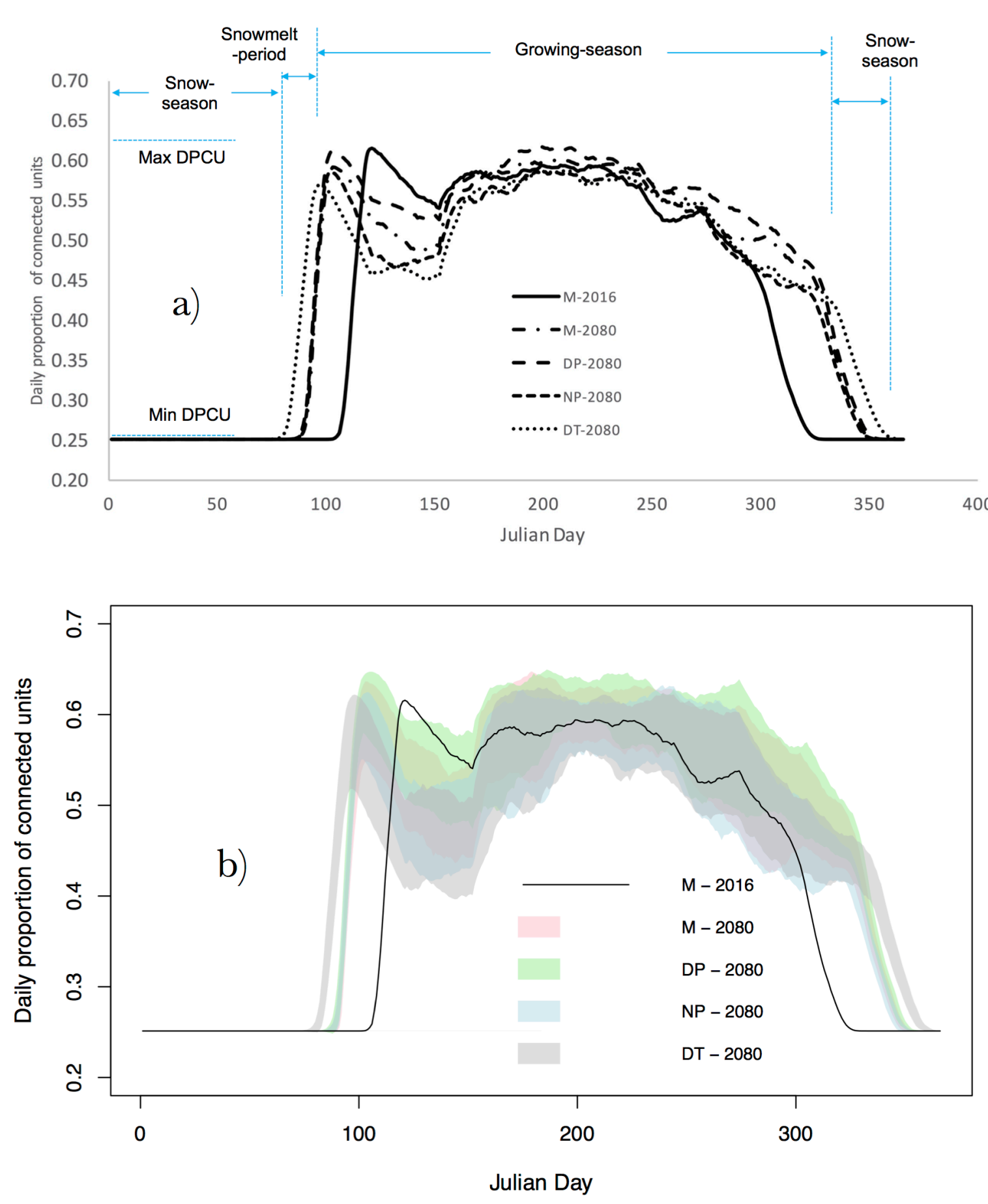

Figure 5 a) Mean daily proportion of connected units for median (M), double precipitation (DP), no change in precipitation (NP) and double temperature (DT) scenarios in 2016 and 2080 for the entire watershed. Snow-season, growing-season and snowmelt-period for 2080 are illustrated. b) Standard deviation area of daily proportion of connected units for median $(\mathrm{M})$, double precipitation (DP), no change in precipitation (NP) and double temperature (DT) scenarios in 2080 for the entire watershed. 


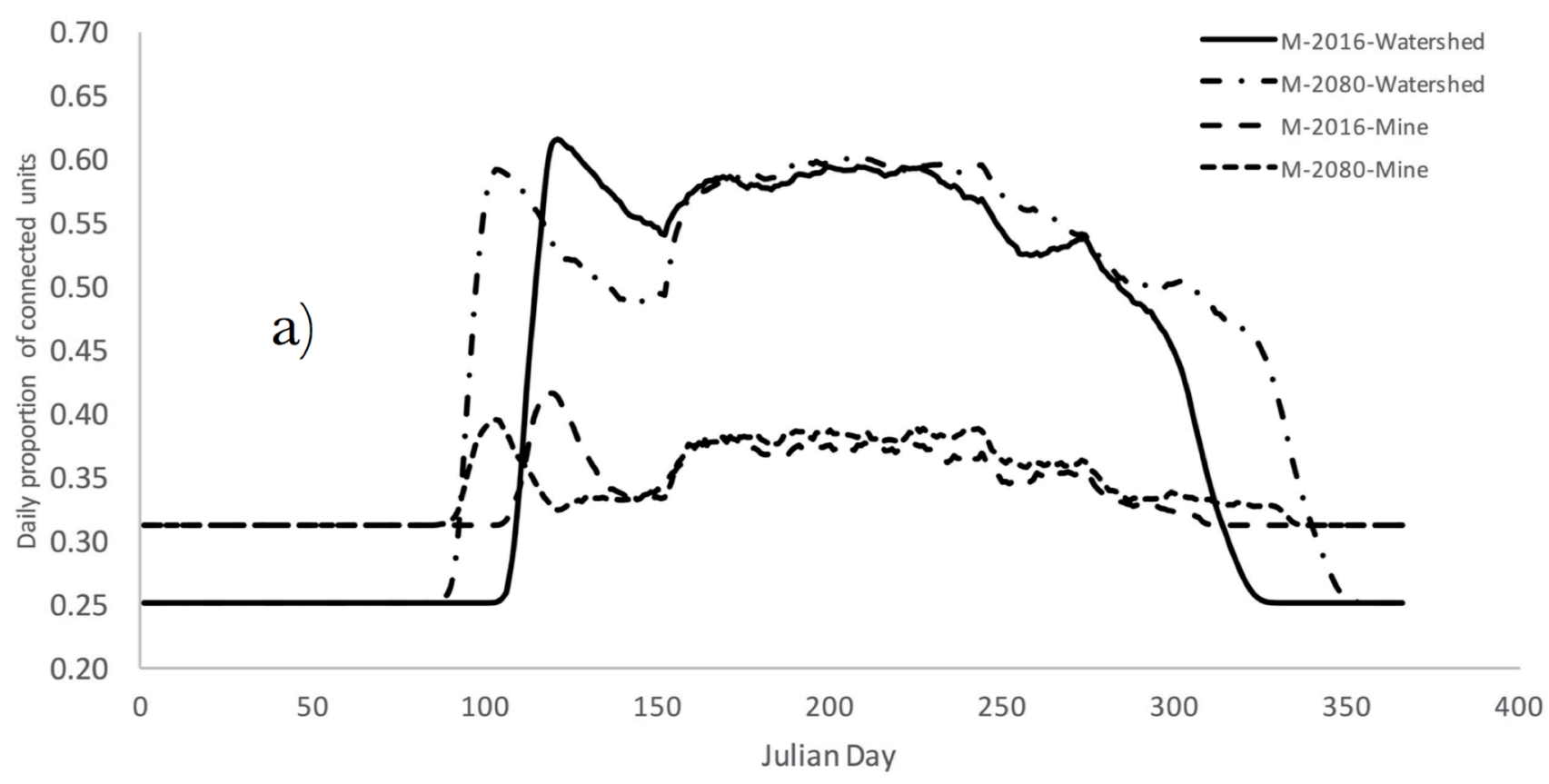

Figure 6 Daily proportion of connected units for median (M) scenario in 2016 and 2080 for the entire watershed and the mining areas (Mine) (a) as well as for the entire watershed, wetland and forestland areas (b).

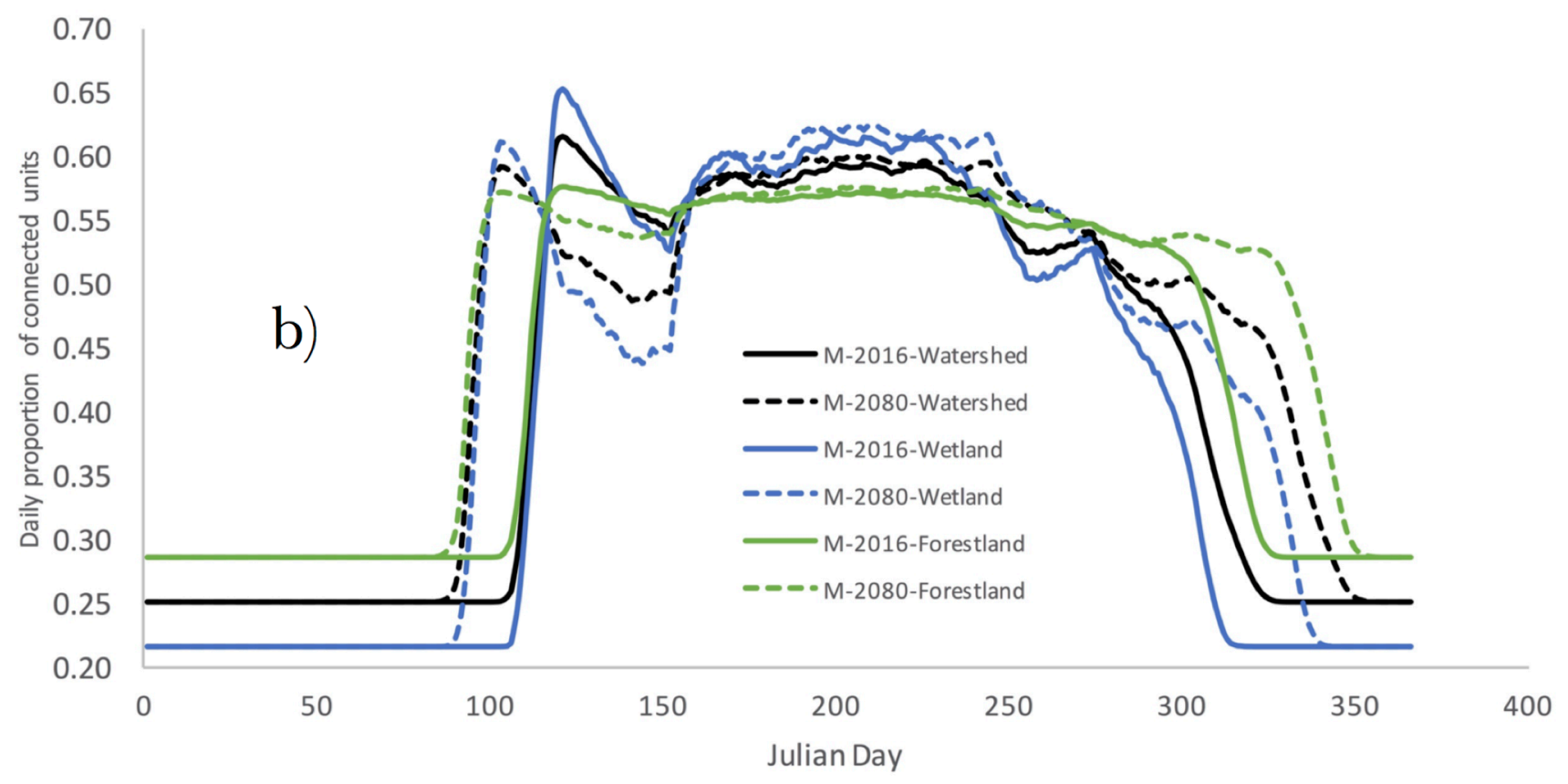




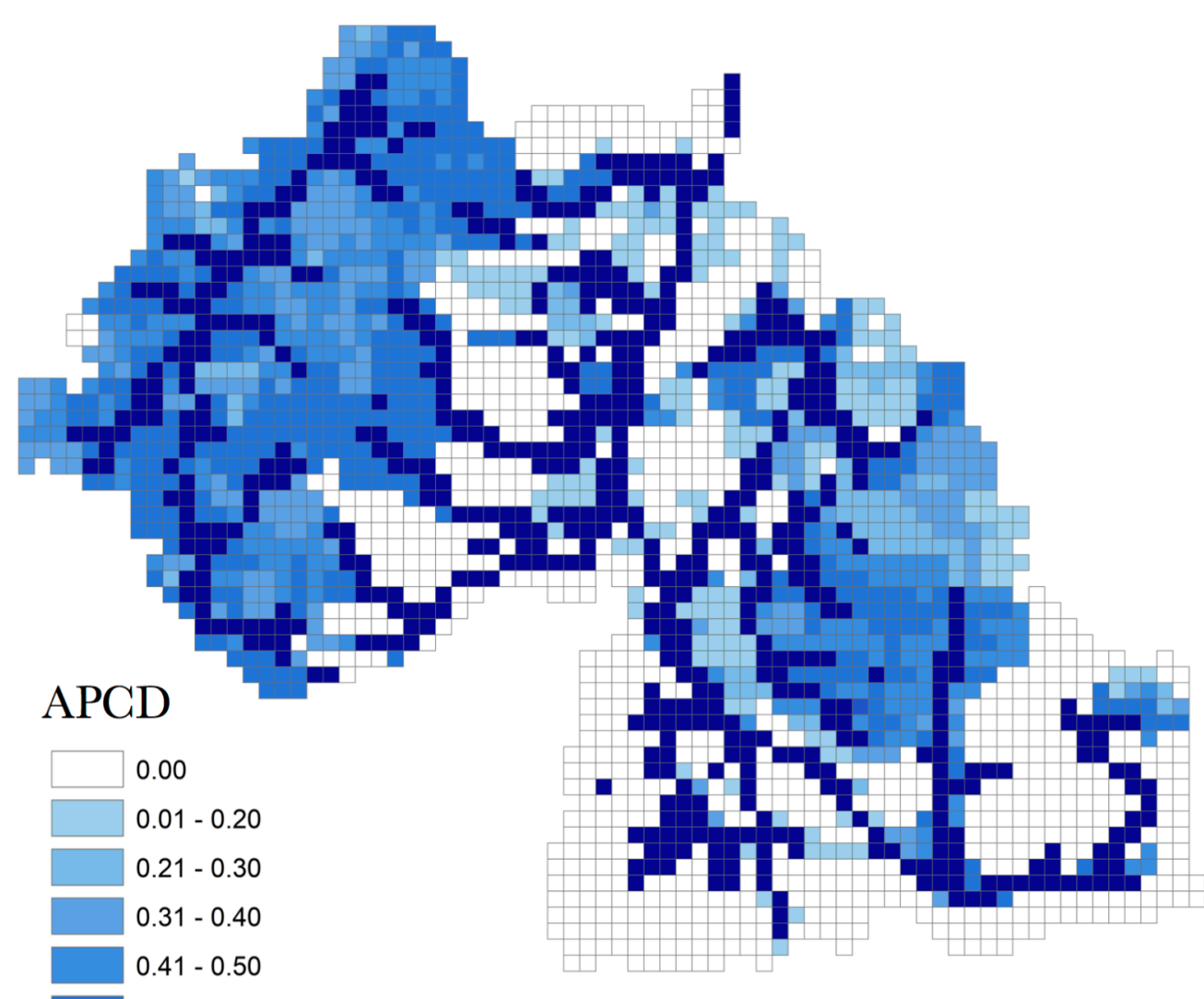

a) 2016

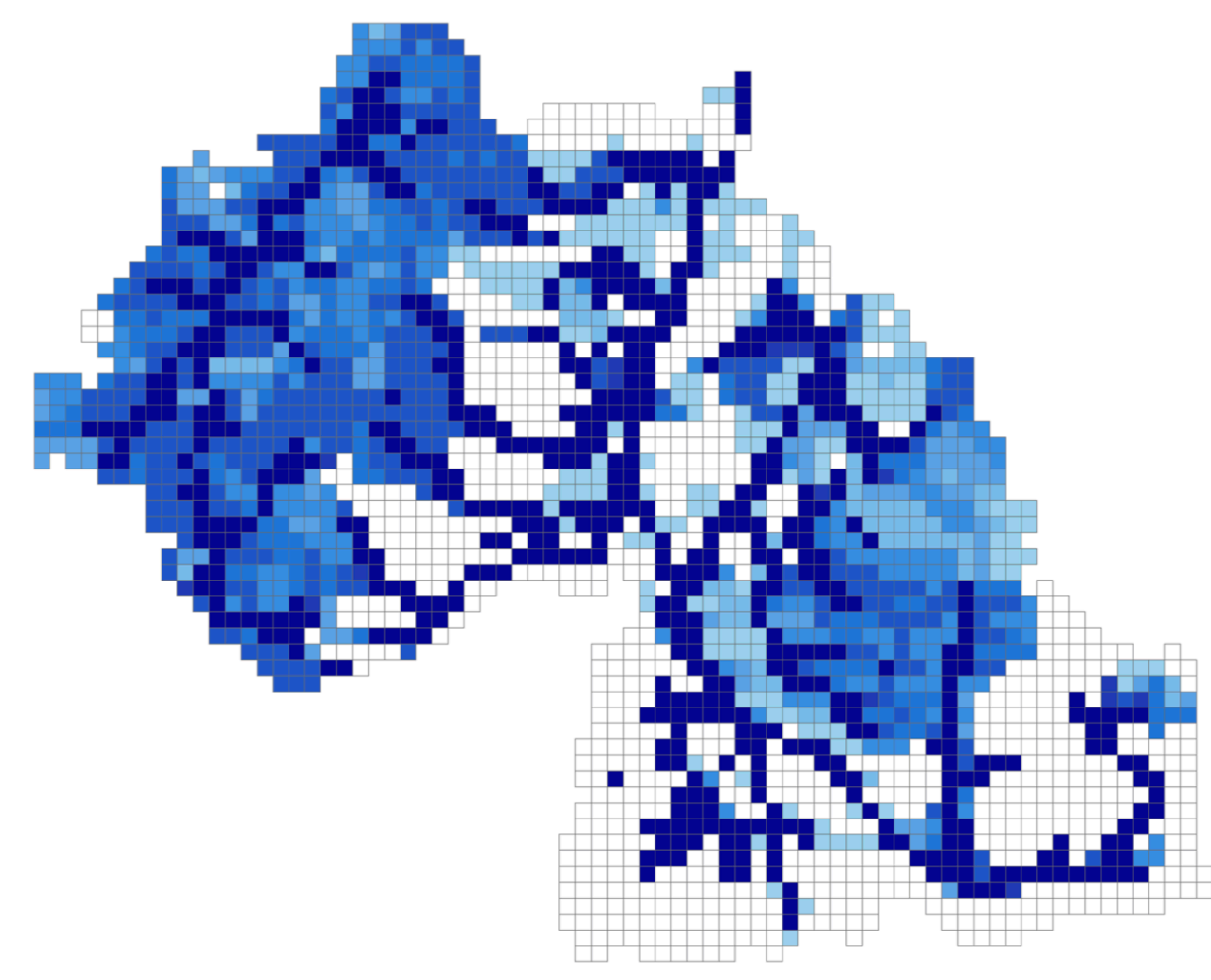

b) 2080

Figure 7 Annual proportion of connected days in different HRUs in 2016 and 2080 for the median (M) change scenario. 


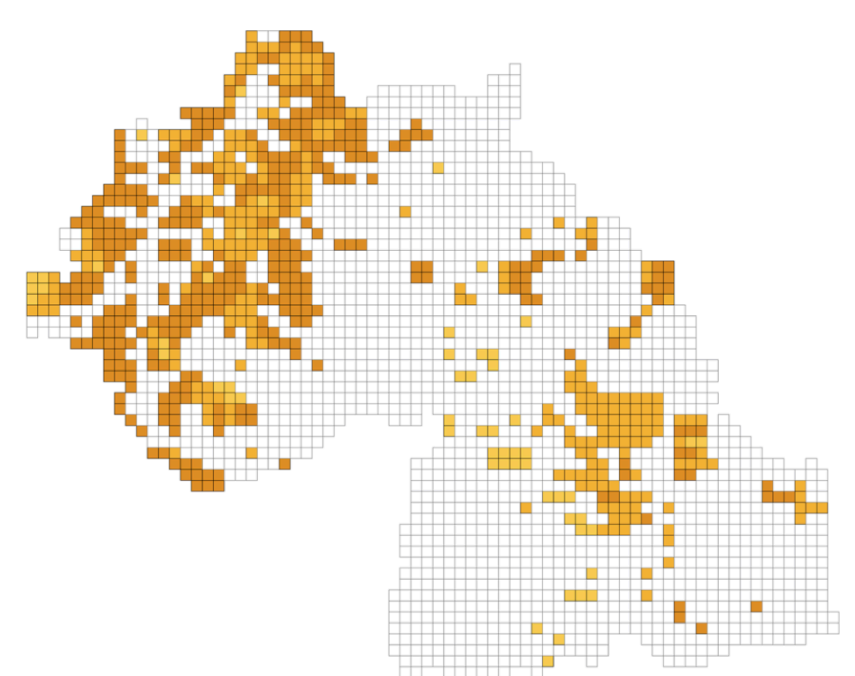

a) Median (M)
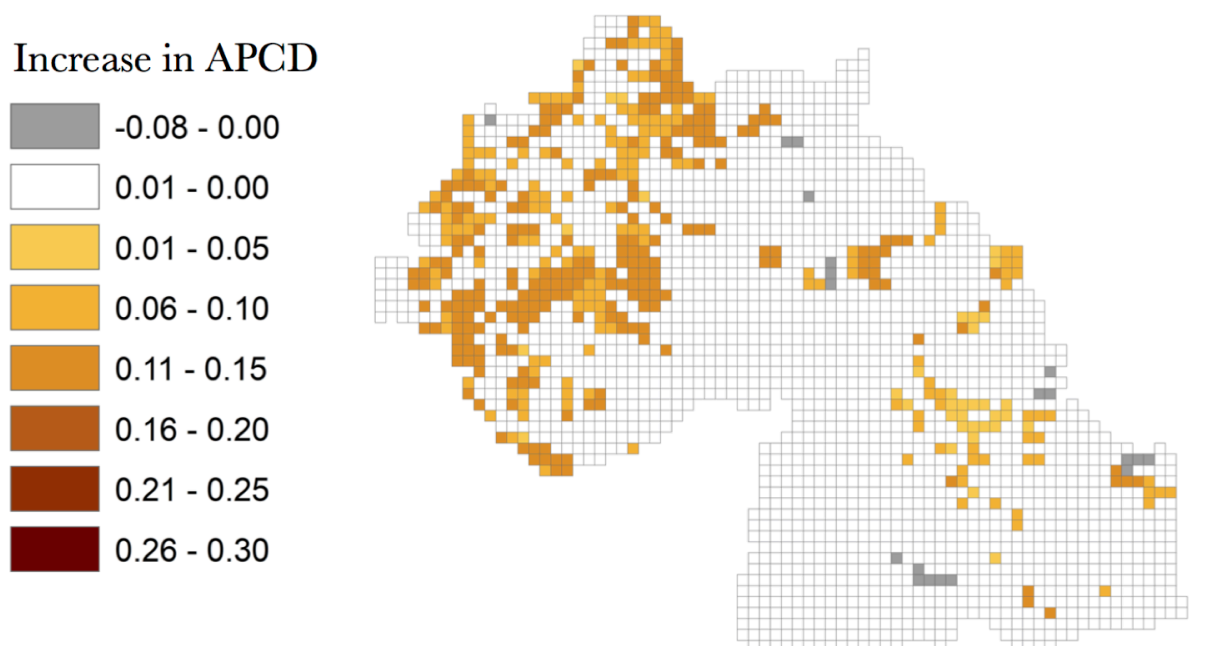

c) No change in precipitation (NP)

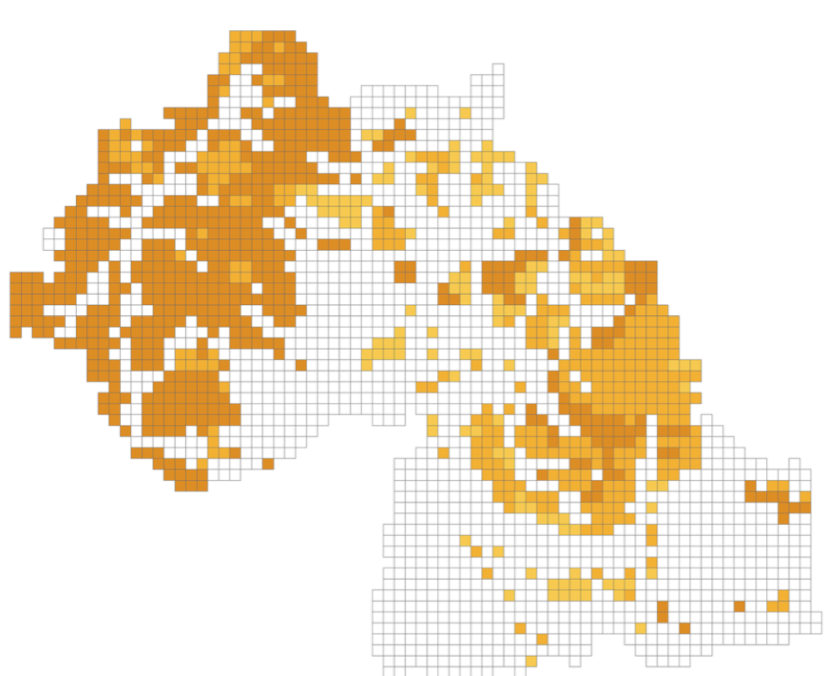

b) Double precipitation (DP)

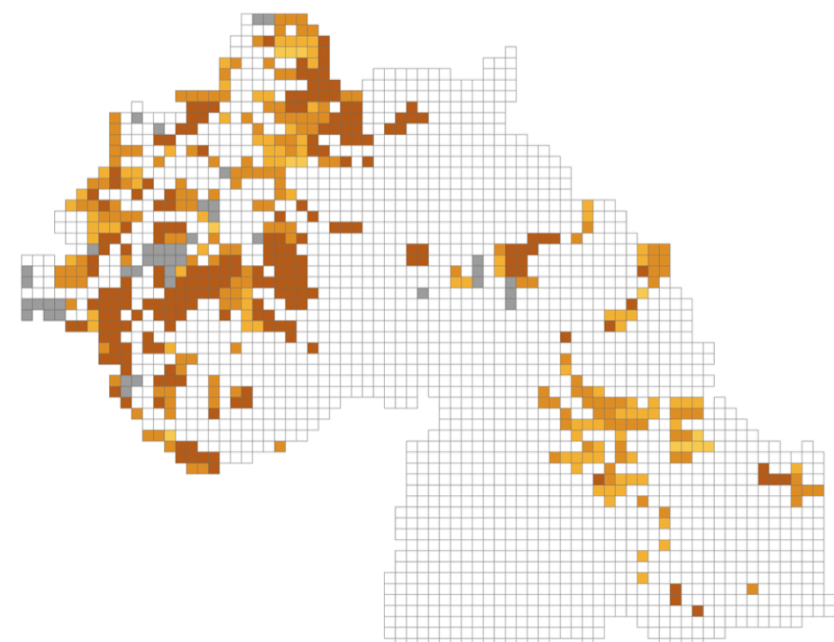

d) Double temperature (DT)

Figure 8 Increase in annual proportion of connected days in different HRUs in 2080 compared with 2016 for median (M), double precipitation (DP), no change in precipitation (NP) and double temperature (DT) scenarios. 
Table 1 Hydrological signatures used in our model calibration.

\begin{tabular}{|c|c|c|}
\hline Hydrological signature name & Symbol & Equation/Definition \\
\hline Streamflow & $Q_{t}$ & Daily streamflow rates in $\mathrm{m}^{3} / \mathrm{s}$ \\
\hline Snow depth & $S_{t}$ & Daily snow depth in inches \\
\hline $\begin{array}{l}\text { Flow duration curve mid-segment } \\
\text { slope }^{*}\end{array}$ & $F D C_{M S}$ & $\begin{array}{l}\log \left(Q_{m 1}\right)-\log \left(Q_{m 2}\right) ; m 1 \text { and } m 2 \text { are the lowest and highest } \\
\text { flow exceedance probabilities within the midsegment of FDC }(0.2 \\
\text { and } 0.7 \text { in this research) }\end{array}$ \\
\hline $\begin{array}{l}\text { Flow duration curve high-segment } \\
\text { volume }^{*}\end{array}$ & $F D C_{H V}$ & $\begin{array}{l}\sum_{h=1}^{H} Q_{h} ; h=1,2,3, \ldots, H \text { are flow indices located within the high } \\
\text { flow segment (exceedance probabilities lower than } 0.02 \text { ); } H \text { is index } \\
\text { of the maximum flow }\end{array}$ \\
\hline $\begin{array}{l}\text { Flow duration curve low-segment } \\
\text { volume }^{*}\end{array}$ & $F D C_{L V}$ & $\begin{array}{l}-1 . \sum_{l=1}^{L}\left[\log \left(Q_{l}\right)-\log \left(Q_{L}\right)\right] \quad ; \quad l=1,2,3, \ldots, L \text { are flow indices } \\
\text { located within the low-flow segment }(0.7-1.0 \text { flow exceedance } \\
\text { probabilities }) ; L \text { is the index of the minimum flow }\end{array}$ \\
\hline Mean streamflow* & $Q_{M}$ & $\sum_{t=1}^{N} Q_{t} / N$ \\
\hline Streamflow variance ${ }^{*}$ & $Q_{V}$ & $\sum_{t=1}^{N}\left(Q_{t}-\bar{Q}\right)^{2} /(N-1) ; \bar{Q}$ is the average of the entire flow data \\
\hline Median streamflow ${ }^{*}$ & $Q_{M D}$ & Median of the entire flow data \\
\hline Peak streamflow ${ }^{*}$ & $Q_{P}$ & Peak of the entire flow data \\
\hline Lag-1 autocorrelation coefficient ${ }^{*}$ & $Q_{L A}$ & $\sum_{t=1}^{N}\left(Q_{t}-\bar{Q}\right)\left(Q_{t+1}-\bar{Q}\right) / \sum_{t=1}^{N}\left(Q_{t}-\bar{Q}\right)^{2}$ \\
\hline Mean log-transformed streamflow ${ }^{*}$ & $Q_{L M}$ & $\sum_{t=1}^{N} \ln \left(Q_{t}\right) / N$ \\
\hline $\begin{array}{l}\text { Variance of log-transformed } \\
\text { streamflow }^{*}\end{array}$ & $Q_{L V}$ & $\sum_{t=1}^{N}\left(\ln \left(Q_{t}\right)-\bar{q}\right)^{2} /(N-1) \quad ; \bar{q}$ is the average of $\ln (Q)$ \\
\hline Maximum of monthly streamflow* & $Q_{M M}$ & $\operatorname{Max}\{F(i)\}, i=1,2, \ldots, 12$, where $F(i)$ is the average flow in month $i$ \\
\hline Monthly streamflow & $Q_{M O}$ & Monthly streamflow in $\mathrm{m}^{3}$ \\
\hline Annual streamflow & $Q_{A}$ & Annual streamflow in $\mathrm{m}^{3}$ \\
\hline
\end{tabular}




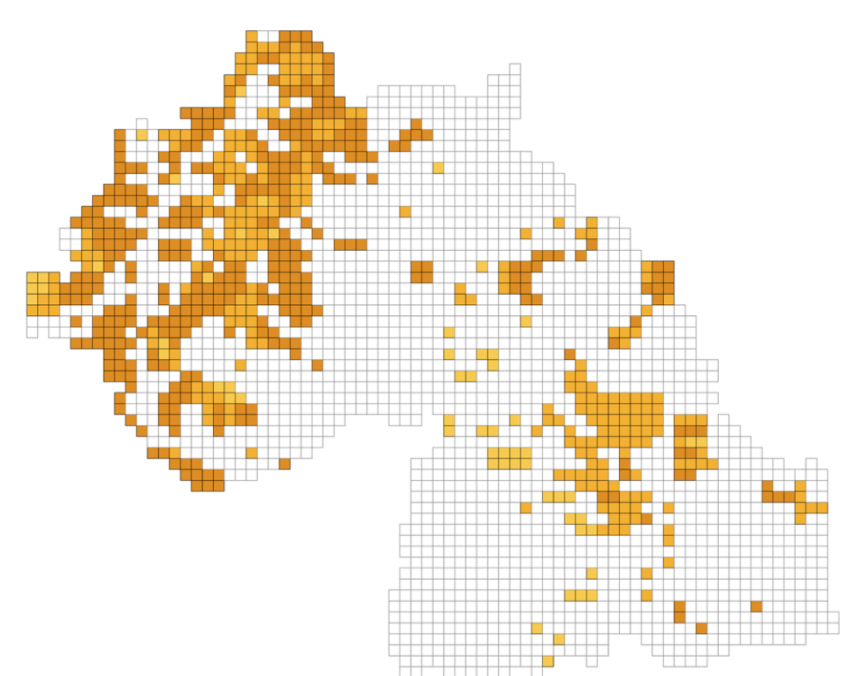

a) Median (M)
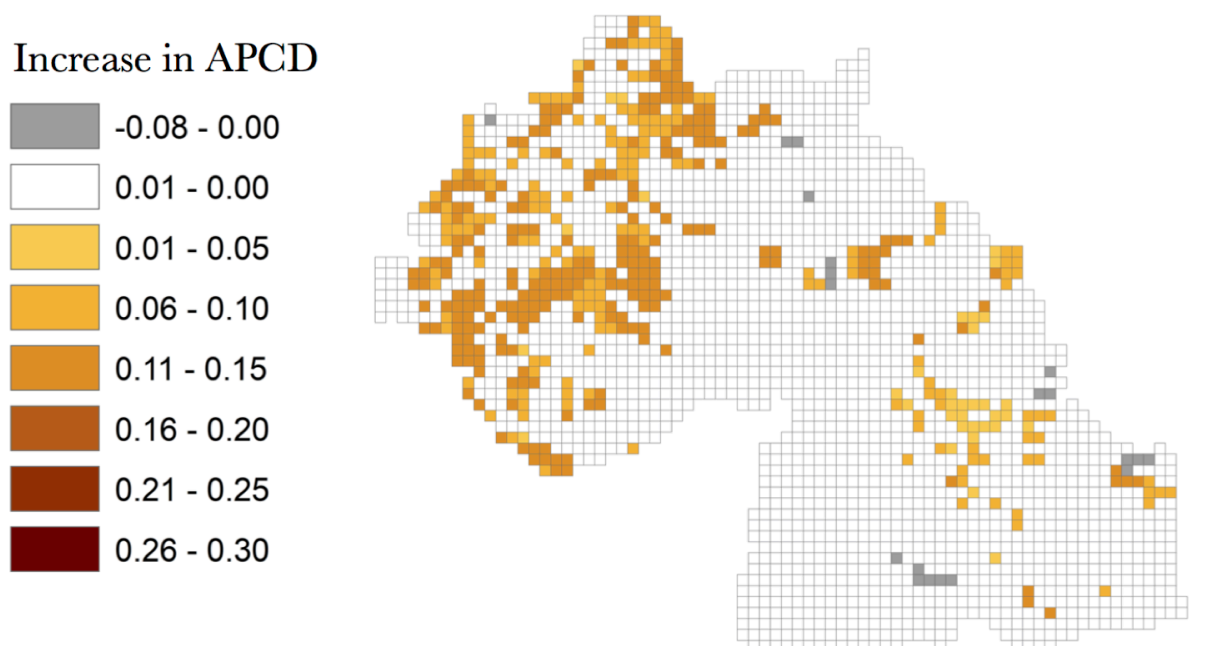

c) No change in precipitation (NP)

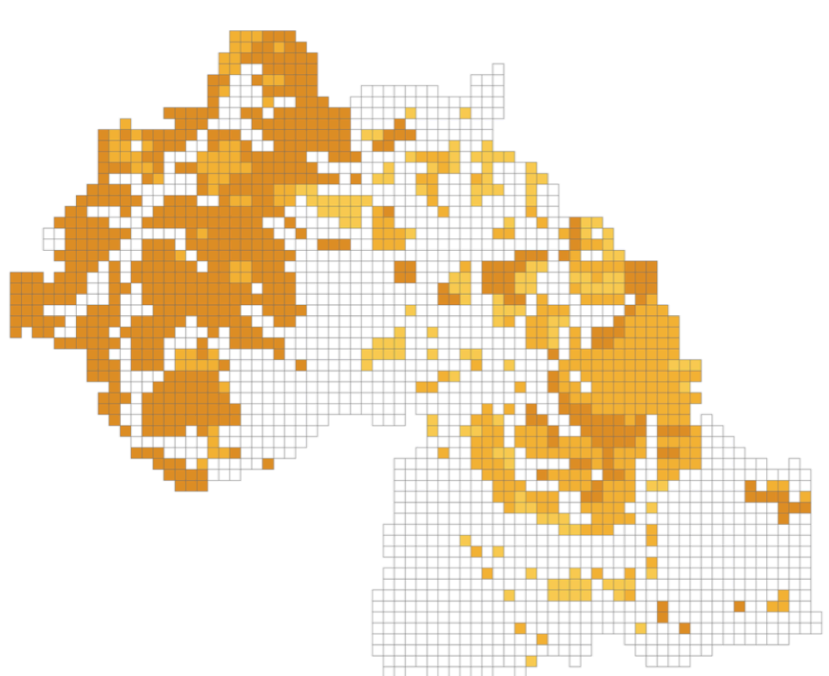

b) Double precipitation (DP)

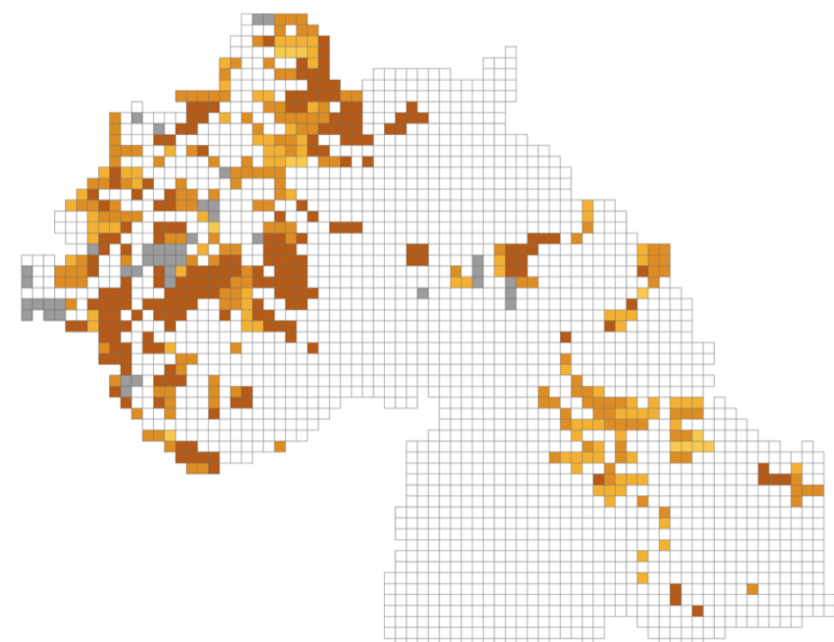

d) Double temperature (DT)

Figure 8 Increase in annual proportion of connected days in different HRUs in 2080 compared with 2016 for median (M), double precipitation (DP), no change in precipitation (NP) and double temperature (DT) scenarios. 
Table 2 Increase in Precipitation, maximum and minimum temperature in 2080 compared with 2014 for median (M), double temperature change (DT), double precipitation change (DP) and no precipitation change (NP) scenarios.

Median (M) Scenario

\begin{tabular}{llll} 
& $\begin{array}{l}\text { Precipitation } \\
(\mathrm{mm})\end{array}$ & $\begin{array}{l}\text { Max Temp. } \\
\left({ }^{\circ} \mathrm{C}\right)\end{array}$ & $\begin{array}{l}\text { Min Temp. } \\
\left({ }^{\circ} \mathrm{C}\right)\end{array}$ \\
\hline Min & 5.08 & 5.02 & 6.55 \\
Max & 8.17 & 5.63 & 8.70 \\
Mean & 6.28 & 5.53 & 6.76
\end{tabular}

Double temperature change (DT) Scenario

\begin{tabular}{llll} 
& $\begin{array}{l}\text { Precipitation } \\
(\mathrm{mm})\end{array}$ & $\begin{array}{l}\text { Max Temp. } \\
\left({ }^{\circ} \mathrm{C}\right)\end{array}$ & $\begin{array}{l}\text { Min Temp. } \\
\left({ }^{\circ} \mathrm{C}\right)\end{array}$ \\
\hline Min & -2.50 & 7.63 & 8.05 \\
Max & 3.08 & 8.35 & 8.36 \\
Mean & 1.63 & 7.98 & 8.23
\end{tabular}

Double precipitation change $(\mathbf{D P})$ Scenario

\begin{tabular}{llll} 
& $\begin{array}{l}\text { Precipitation } \\
(\mathrm{mm})\end{array}$ & $\begin{array}{l}\text { Max Temp. } \\
\left({ }^{\circ} \mathrm{C}\right)\end{array}$ & $\begin{array}{l}\text { Min Temp. } \\
\left({ }^{\circ} \mathrm{C}\right)\end{array}$ \\
\hline Min & 11.83 & 5.61 & 6.88 \\
Max & 17.50 & 6.75 & 7.47 \\
Mean & 13.93 & 5.78 & 7.15
\end{tabular}

\begin{tabular}{llll} 
No precipitation change (NP) & $\begin{array}{l}\text { Scenario } \\
\text { Precipitation } \\
(\mathrm{mm})\end{array}$ & $\begin{array}{l}\text { Max Temp. } \\
\left({ }^{\circ} \mathrm{C}\right)\end{array}$ & $\begin{array}{l}\text { Min Temp. } \\
\left({ }^{\circ} \mathrm{C}\right)\end{array}$ \\
\hline Min & 0.00 & 5.61 & 6.88 \\
Max & 0.00 & 6.75 & 7.47 \\
Mean & 0.00 & 5.78 & 7.15
\end{tabular}




\section{Appendix A}

\section{A.1 Model Calibration}

In model calibration and in terms of best output results, we chose the same upper and lower limits for different HRA material calibration parameters (rmC, rmPM, rmPC and rmPR) regardless of their material type, to examine how results reflect the material types (Table A-1). Calibrated values show that groundwater conductivities (gwflow_coef) vary in the range 0.1 to 0.12 day $^{-1}$ (empirical coefficients for slow flow, fast flow and groundwater conductivities in day ${ }^{-1}$ are equivalent to $\mathrm{K}$ in $\mathrm{m} / \mathrm{s}$ [Appendix S3]). These values were similar for the two types of groundwater reservoirs. Hydraulic conductivities for fast flow and slow flow range from 0.07 to $0.5 \mathrm{day}^{-1}$, and from $4.0 \times 10^{-}$

${ }^{3}$ to $2.0 \times 10^{1}$ day $^{-1}$, respectively. The comparably higher range of hydraulic conductivities in the slow flow reservoir should be due to thinner slow flow parts in WHUs (as we discussed in section 2.3.3). We assigned proportionally higher horizontal hydraulic conductivity in them to compensate for their thickness. Also unexpected, hydraulic conductivities in fast flow reservoir in mining areas (fsNIN and flMIN) are almost the same as in other parts. Both surficial (preferential and slow flow) and deeper layers show high efficacy in transferring water, as evidenced by the high hydraulic conductivities in all model layers.

The parameter soil_rechr_max, which is responsible for storage in the upper part of capillary storage and the creation of runoff, has a proportionally wide range of $7.6 \times 10^{-3}$ to $0.24 \mathrm{~m}$ (rmC and rmPC). Maximum daily flow of soil capillary water and from gravity reservoirs (CPR and GVR) to groundwater(GWR) (soil2gw_max) is about 0.15 to $0.33 \mathrm{~m}$ for both fine and medium texture deep layers. Drainage from gravity reservoirs to groundwater (ssr2gw_rate), for WHUs and FHUs were $\sim 0.51$ and $\sim 22.9 \mathrm{~mm} /$ day, respectively. There is a high capacity for water 
percolation from surficial layers water to groundwater reservoirs, primarily through FHUs. The daily fraction of outflow from groundwater reservoirs to deeper parts (gwsink_coef of 0.99, 0.0, 0.03 and 0.99 in medium geological layer, medium, coarse and very coarse surficial layers, respectively) proves the capacity of the groundwater reservoir to transfer water to deeper parts.

Capillary and gravity porosities are determined as 0.27 and 0.13 , respectively. The total porosity, of about 0.4 , is in good agreement with what is reported by Thompson et al. (2015) for HRA layers, but is much lower than the reported peat value (0.4 to 0.9 , Thompson et al., 2015). Expectedly, there is a higher outflow rate in coarser surficial and deeper geological layers. An average optimal maximum soil moisture (soil_moist_max) of $0.79 \mathrm{~m}$ was determined by assuming a $3 \mathrm{~m}$ soil thickness (root depth) and a calibrated value of 0.27 for capillary porosity. The optimal average value of $1.1 \mathrm{~m}$ for soil gravity storage (pref_flow_thrsh) was determined based on the average soil thickness of $8.9 \mathrm{~m}$ (for both WHUs and FHUs), calibrated gravity porosity of 0.13 and maximum fast $/$ preferential reservoir (pref_flow_max) of $0.25 \mathrm{~m}$. There is a good agreement between calculated and reported porosity values and assigned layer thicknesses for preferential and slow flow layers and the reported values for soil thickness and existing maps for the surficial geological layer thicknesses.

The standard errors of calibration for 14 parameters (out of 33), calculated by DDS, are within an acceptable range (bold numbers in Table A-1). For slow flow coefficients as well as maximum daily flow of water from the capillary and soil gravity reservoirs (CPR and GVR) to groundwater (soil2gw_max), the standard errors are very large and are reported as "not_reported" when $>1 \mathrm{E}+05$. These high standard error values are due to the lack of water level or soil moisture observations in these layers. 


\section{A.2 Sensitivity analysis}

To show the most influential parameters, the average absolute scaled sensitivity (AASS) values for the calibration parameters are calculated. The AASS is the average of the scaled sensitivity of each parameter to different hydrological signatures (Hill, 1992). The most sensitive parameters are the ratio of infiltrated water to preferential reservoir to infiltrated water to capillary reservoir (pdC, pref_flow_den), preferential flow reservoir conductivity (flc, fastcoef_lin), groundwater conductivity (gfGF and gfGM, gwflow_coef), open surface depression storage threshold (oft, op_flow_thres) and capillary porosity (cpor). The second most sensitive parameters are preferential flow reservoir conductivity (fsC, fastcoef_sq), groundwater outflow to deeper parts (siC, gwsink_coef) and ratio of infiltrated water to preferential to capillary flow reservoirs in peat layer (pdPC, pref_flow_den). As expected, the most influential parameters are more relevant to surficial layers, preferential flow and surface depression storage.

We evaluated the hydrologic signatures in the model calibration and assessment of hydrological connectivity (HC). The evaluation was conducted by comparing the AASS of the calibration parameters to their absolute scaled sensitivities (ASS) to hydrological connectivity (HC-Wat) and to their ASS to hydrologic connectivity in mining areas (HC-Mine). Some parameters are significantly more sensitive to HC-Wat and HC-Mine than hydrologic signatures (Table 1). Both HC-Wat and HC-Mine are sensitive to preferential flow conductivity (flC and fsC) while just HC-Wat is sensitive to the ratio of infiltration to preferential and capillary flow reservoirs (pdC, pdPC) as well as preferential flow conductivity (flPC and fsPC). That may be related to the larger extent of watershed than mining area and having larger number of parameters involved. It shows that HCs are more related to preferential/fast flow and, soil and surficial 
geological layer hydraulic characteristics, and in mining areas unexpectedly the HCs are more related to surficial layers in upstream FHUs rather than the surficial layers in nearby WHUs.

We analyzed the sensitivity of DPCU and APCD to the soil moisture threshold selected to define when units are considered hydrologically connected by trying different values for the threshold, from 15 to $40 \%$. With higher soil moisture thresholds, DPCU curves were shifted down and almost without any change in their general pattern. But increase in soil moisture threshold caused reduction in the extent of connected areas in APCD maps as much as $<\sim 20 \%$, both in 2016 and 2080. Although the pattern of connected cells in APCD maps and their extents in 2016 and 2080 did not change significantly by changing the soil moisture threshold, we observed the largest differences between APCD maps in 2016 and 2080 using a soil moisture threshold of $\sim 30 \%$. We consequently retained this threshold value for connectivity.

Sensitivity analysis shows that $\mathrm{HC}$ in the entire watershed and in mining areas is highly sensitive to the preferential flow surficial layer parameters; their sensitivities are significantly higher than the sensitivity of hydrologic signatures to surficial layer parameters. This suggests that some observations related to water level, soil moisture or flow rates in surficial layers could significantly change our results and our model reliability. Our results show that the hydraulic conductivities in surficial layers in mining areas are the same as in other parts of the watershed. It seems that more observations are needed to prove our ability to detect and predict impact of mining activities on the hydraulic conductivity of the surficial layers in mining areas. 


\section{Appendix S1: Maps}

The distributions of surficial layer thickness and surface topography are shown in Figures S1-1 and $\mathrm{S} 1-2$.

\section{Appendix S2: Model parameters}

Model parameters are presented in Tables S2-I and S2-II.

\section{Appendix S3: Equivalent $\mathrm{K}$ in GSFLOW}

The relationship between the empirical fast-flow/preferential flow coefficients in GSFLOW (Eq.S3-1) (Markstrom et al., 2008) and hydraulic conductivity in Darcy's equation was determined by comparing two equations.

$V_{v}=F_{l} \times h_{0}+F_{s} \times h_{0}^{2}$

In empirical equation $F_{l}$ and $F_{S}$ are linear and square fast flow coefficients and $h_{0}$ is the volume per unit area of water in gravity reservoir and $V_{v}$ is volumetric flow rate per unit area to gravity reservoir. The surface area that used for calculation of $V_{v}$ is the horizontal surface area of the cell and to convert it to the lateral flow velocity $\left(V_{h}\right)$ it should be divided by the ratio between the cell with to $h_{0}$ :

$V_{h}=\left(F_{l} \times h_{0}+F_{s} \times h_{0}^{2}\right) D / h_{0}$

In that $D$ is the width of the model cells. Also, Darcy's equation for the flow in a typical rectangular cell in GSFLOW was written as below:

$V_{h}=\frac{K \Delta h}{D}=\frac{K \Delta h}{h_{0} D} h_{0}$

in which $K$ is the hydraulic conductivity and $\Delta h$ is the head difference between the cells. 
Flow in a mode cell can completely horizontal or completely vertical when the flow is passing through the cell or when the cell is recharging from the surface, respectively, or something between these two cases. For the simple horizontal flow in that the water inflow from one lateral side and flow out form other lateral side, by comparing Eq.s S3-2 and S3-3 Kcan be determined as follow:

$K=\left(F_{l}+F_{S} \times h_{0}\right) \frac{D^{2}}{\Delta h}$

For the second case, the inflow is from the surface of the cell, as the surface recharge, that is vertically downward and then horizontal to the lateral side/sides of the cell (Figure S3-1). This case is more likely in surficial layers in wetlands, where the majority of inflow is through recharge from the surface and the outflow is mainly through the lateral sides. So, the flow lines are vertically downward close the top surface and gradually turn to horizontal through percolating down toward lateral faces (Figure S3-1). To simplify the flow, it can be assumed that the water flows through separate conduits (Figure S3-1). To derive an equivalent $K$, Darcy's equation can be written for each conduit separately, and by considering the change in flow cross section along each conduit. Along each conduit $(i)$ the total drawdown $(\Delta h)$ is the sum of drawdowns in each part along the conduit (Figure S3-1).

$\Delta h=\sum_{i=1}^{n} \Delta h_{i}$

For the flow section width of $D$ the equation can be written as:

$\Delta h=\sum_{i=1}^{n} \frac{Q L_{i}}{K D w_{i}}$

In which $L_{i}$ and $w_{i}$ are the length and width of the $i$ th section in a flow conduit. In Figure S3-1 there are two sections along each conduit. Eq. S3-6 can be written as:

$\frac{Q L}{K D w}=\sum_{i=1}^{n} \frac{Q L_{i}}{K D w_{i}}$ 
And the equivalent conduit width can be determined as follow:

$W=\left[\frac{L}{\sum_{i=1}^{2} \frac{L_{i}}{w_{i}}}\right]$

An equation can be written for all conduits in order to determine resultant $K$ for all conduits. Total flow is the sum of flow through $m$ conduits:

$Q=\sum_{j=1}^{m} \frac{K D w_{j}}{L_{j}} \Delta h$

Eq. S3-9 can be written in term of conduits' lengths and widths:

$Q=\sum_{j=1}^{m} \frac{K D\left[\frac{L_{j}}{\frac{L_{1 j}}{w_{1 j}}+\frac{L_{2 j}}{w_{2 j}}}\right]}{L_{j}} \Delta h$

Conduit lengths and widths can be written in terms of other parameters:

$L_{1 j}=\Delta h+\frac{p}{D} \times\left(h_{0}\right)$

$L_{2 j}=p$

$w_{1 j}=\frac{D}{h_{0}} \times(d w)=d p$

$w_{2 j}=d w=\frac{h_{0}}{D} d p$

Where $\mathrm{p}$ is the horizontal distance from the outflow lateral face (Figure S3-1). For infinitely narrow conduits the conduit widths $\mathrm{w}_{1}$ and $\mathrm{w}_{2}$ can be written as $d p$ and $d w$. Eq. S3-10 can be written in integral form: 


$$
Q=K D \Delta h \int \frac{1}{\frac{L_{1 j}}{w_{1 j}}+\frac{L_{2 j}}{w_{2 j}}}
$$

and replacing S3-11 to S3-12 and integrating from 0 to $D$ :

$$
Q=K D \Delta h \int_{0}^{D} \frac{1}{\frac{\Delta h+\frac{p}{D} \times\left(h_{0}\right)}{d p}+\frac{p}{\frac{h_{0}}{D} d p}}
$$

the total flow rate $Q$ was determined as:

$$
Q=\frac{K D \Delta h}{\left(\frac{h_{0}}{D}+\frac{D}{h_{0}}\right)}\left(-\ln \left(\frac{\Delta h h_{0}}{h_{0}^{2}+D^{2}}\right)+\ln \left(\frac{\Delta h h_{0}+h_{0}^{2}+D^{2}}{h_{0}^{2}+D^{2}}\right)\right)
$$

By assuming $D=2000$

$$
Q=\frac{K \times 2000 \times \Delta h h_{0}}{\left(\frac{h_{0}^{2}+4000000}{2000}\right)}\left(-\ln \left(\frac{\Delta h h_{0}}{h_{0}^{2}+4000000}\right)+\ln \left(\frac{\Delta h h_{0}+h_{0}{ }^{2}+4000000}{h_{0}{ }^{2}+4000000}\right)\right)
$$

By dividing the flow rate by the flow cross-section horizontal velocity $\left(V_{h}\right)$ will be as follow:

$V_{h}=\left(1 /\left(2000 \times h_{0}\right)\right) \frac{K \times 2000 \times \Delta h h_{0}}{\left(\frac{h_{0}^{2}+4000000}{2000}\right)}\left(-\ln \left(\frac{\Delta h h_{0}}{{h_{0}}^{2}+4000000}\right)+\ln \left(\frac{\Delta h h_{0}+h_{0}{ }^{2}+4000000}{h_{0}{ }^{2}+4000000}\right)\right)$ 
According to S3-3 the resultant $\mathrm{K}$ is

$K_{e}=\left(1 /\left(h_{0}\right)\right) \frac{K \times 2000 \times h_{0}}{\left(\frac{h_{0}^{2}+4000000}{2000}\right)}\left(-\ln \left(\frac{\Delta h h_{0}}{h_{0}^{2}+4000000}\right)+\ln \left(\frac{\Delta h h_{0}+h_{0}{ }^{2}+4000000}{h_{0}{ }^{2}+4000000}\right)\right)$

Assume that:

$\frac{K_{e}}{K}=$ Kequiv

And based on Eq.s S3-1 and S3-2:

Kequiv $\times \frac{K \Delta h}{D^{2}}=\left(F_{l}+F_{S} \times h_{0}\right)$

and

$K=\left(F_{l}+F_{S} \times h_{0}\right) \frac{D^{2}}{\Delta h \times \text { Kequiv }}$

Therefore, if the flow in the cell be horizontal the K value is calculated by Eq. S3-4 but if the model calculated the same values for $F_{l}$ and $F_{S}$, but the flow was entered from the top surface then the $K$ for the material is determined by Eq. S3-20. Kequiv were calculated and plotted for different values of $h_{0}$ and $\Delta h$ in Figure S3-2. So, depend on the flow direction in the model cell, the $K$ value that determined by Eq.s S3-4 and S3-20 and with the same values of $F_{l}$ and $F_{S}$ can be up to 20 times different. In our model with cell dimensions $(D)$ of $2000 \mathrm{~m}$ and average $h_{0}$ and $\Delta h$ in range of 0.3 in and $20 \mathrm{~m}$, respectively, and $F_{l}$ and $F_{S}$ of both 0.01 day $^{-1}, K$ by Eq. S3-4 and S3-20 (by assuming Kequiv =10) are 0.02 and $0.002 \mathrm{~m} / \mathrm{s}$.

\section{Appendix S4 Markov Random Space}


In this study we deal with a Markov Random Space (MRS) rather than a simple Markov chain, so the dry and wet days are both extended through two spatial dimensions (x,y) through CFSR points as well as distributed over temporal dimension $(\mathrm{t})$ of days.

To generate wet and dry days in a three-dimensional space we used the method presented by Li and Zhang (2008). They combined the linear Markov chains and transfer them to a Markov Random Space by using Bayes' Theorem and one step and one-step transition probabilities. Markov chain uses one-step transition probability to assess the wet or dryness of an unknown day based on the known value of the previous day. One-step probabilities are PWW and PWD and defined as the probabilities of wet day following a wet or dry day, respectively. In Li and Zhang (2008) one dimensional one-step transition probabilities (Markov chains) in different directions combined together by Bayes' Theorem to give a single transition probability and calculate the state for the unknown neighbouring cell. They use the method for a two-dimensional spatial model and predicting layer types between boreholes. Here we used this method to predict the state (dry or wetness) of a day based on the known wetness of its neighbouring cells in a day before. So, we have two spatial dimensions (North-south direction, East-west direction) for the position of neighbouring cells and a time dimension that is one-day time lag between neighbouring cells and the unknown cell.

One-step transition probabilities between cells in different days and in different geographic directions were determined by assuming the cells in each geographic direction as a single Markov chain. For example, the transition probabilities between a cell and another cell in next day is named as "Forward" and transition between a cell and another cell in previous day is named "Backward". Also, if during the transition we move from a cell to another cell that is located in east of the starting cell we named it as an "East" transition. So, we used transitions in five spatial directions 
of North, South, East, West and Center and two temporal directions of Forward and Backward. The fifth direction or "Center" means the destination cell in transition is in the same location but in previous or next day. The combination of spatial and temporal transitions gives 10 type of transitions (North-Forward, North Backward, South-Forward, South-Backward, ...). So we can calculate the state (dry or wetness) of a day in on CFSR point by knowing the states in the CFSR points in previous days and located next to that point on its four directions or in the same location.

The one-step transition probabilities for 40 stations for the period of 1979 to 2014 for the 10 directions were calculated. The transition probabilities were determined for each month and also for the wet days following by a wet or dry day (PWW and PWD, respectively). For our study area PWD's are in range of 0.3 to 0.5 and PWW's are in range of 0.5 to 0.75 . Almost in all directions the least probabilities are around May and maximum ones are around May and March. To generate the Markov Random Space we used the method presented by Li and Zhang (2008) and Bayes' Theorem. We assumed moving to the next days is moving forward and determine the probability of wet day in an unknown day by using the following equation:

$\operatorname{Pr}(1 \mid K N, K S, K E, K W, K C)=\frac{P B 1 K N \times P B 1 K S \times P B 1 K E \times P B 1 K W \times P F K C 1}{\sum_{i=1}^{2} P B i K N \times P B i K S \times P B i K E \times P B i K W \times P F K C i}$

$K N, K S, K E, K W$ and $K C$ are the existing wetness states in neighbouring cells of previous day and $P B 1 K N$ is the north-backward transition probability of occurrence of $K N$ in north neighbouring cell conditional to occurrence of 1 in unknown cell. Accordingly, PFKCi is the transition probability of center-forward of occurrence of $i$ wetness state in unknown cell conditional to occurrence of $K C$ in neighbouring cell in center. $i=1$ and 2 are wet and dry states in unknown cell, 
respectively. We have revised HELP and replace PWW and PWD with the transition probability by Eq. S4-1and generate the wet and dry days for the prediction period for 40 CFSR points.

\section{Appendix S5 Observed versus simulated rating curves for the calibration period}

The observed versus simulated curves for 8 sub-basins are presented in Figure S5-1. 
Table S2-I Parameters that were used in model calibration

\begin{tabular}{|c|c|c|c|c|}
\hline Symbol & Definition & $\begin{array}{l}\text { Prior } \\
\text { range }\end{array}$ & Unit & Parameter Name \\
\hline gwflow_coef & Groundwater flow coefficient & $\begin{array}{ll}0.007 & \text { to } \\
0.03 & \end{array}$ & 1/day & gfGF, gfGM \\
\hline soil_rechr_max & $\begin{array}{l}\text { Maximum quantity of water in the } \\
\text { capillary reservoir where } \\
\text { evaporation and transpiration can } \\
\text { occur simultaneously (should be < } \\
\text { soil_moist_max) }\end{array}$ & $0.05-0.13$ & $\mathrm{~m}$ & $\begin{array}{l}\mathrm{rmM}, \mathrm{rmC}, \mathrm{rmR} \\
\mathrm{rmPM}, \mathrm{rmPC}, \mathrm{rmPR}\end{array}$ \\
\hline pref_flow_den & $\begin{array}{l}\text { fraction of infiltration that goes to } \\
\text { preferential flow rather than } \\
\text { capillary reservoir. Or the fraction } \\
\text { of the storage in soil (The possible } \\
\text { storage above the field } \\
\text { capacity[gravity reservoir]) } \\
\text { available for preferential flow. }\end{array}$ & $0.03-0.9$ & $\begin{array}{l}\text { Dimension } \\
\text { less }\end{array}$ & $\begin{array}{l}\mathrm{pdM}, \mathrm{pdC}, \mathrm{pdR} \\
\mathrm{pdPM}, \mathrm{pdPC}, \mathrm{pdPR}\end{array}$ \\
\hline slowcoef_lin & $\begin{array}{l}\text { Flow of water within soil or within } \\
\text { gravity reservoir downslope }\end{array}$ & $\begin{array}{ll}0.07 & \text { to } \\
0.25 & \end{array}$ & $1 /$ day & $\begin{array}{l}\text { FHU: } S I M, s I C, s I R \\
W H U: I f S T>3.5 m \\
s I M * S T / 3.5^{\#} \\
s I C^{*} S T / 3.5 \\
s I R^{*} S T / 3.5\end{array}$ \\
\hline slowcoef_sq & $\begin{array}{l}\text { Flow of water within soil or within } \\
\text { gravity reservoir downslope }\end{array}$ & $\begin{array}{ll}1.97 & \text { to } \\
11.8 & \end{array}$ & $1 / \mathrm{m}$-day & $\begin{array}{l}\text { FHU: sqM, sqC, sqR } \\
\text { WHU: If ST>3.5m } \\
\mathrm{sqM}^{*}(\mathrm{ST} / 3.5)^{\wedge} 2 \\
\mathrm{sqC}^{*}(\mathrm{ST} / 3.5)^{\wedge} 2 \\
\mathrm{sqR}^{*}(\mathrm{ST} / 3.5)^{\wedge} 2^{* * *}\end{array}$ \\
\hline fastcoef_lin & $\begin{array}{l}\text { Flow of water within soil fissures or } \\
\text { within preferential-flow reservoir } \\
\text { downslope }\end{array}$ & $\begin{array}{ll}0.006 & \text { to } \\
0.12 & \end{array}$ & $1 /$ day & $\begin{array}{l}\text { fIM, fIC, fIR } \\
\text { fIPM, fIPC, fIPR, fIMIN }\end{array}$ \\
\hline soil2gw_max & $\begin{array}{l}\text { Maximum value of soil-water } \\
\text { (gravity reservoir) excess routed } \\
\text { directly to PRMS groundwater } \\
\text { reservoir. }\end{array}$ & 0.0095 & $m$ & sxP \\
\hline fastcoef_sq & $\begin{array}{l}\text { Flow of water within soil fissures or } \\
\text { within preferential-flow reservoir } \\
\text { downslope }\end{array}$ & $\begin{array}{ll}0.03 & \text { to } \\
7.87 & \end{array}$ & $1 /$ m-day & $\begin{array}{l}\text { fsM, fsC, fsR } \\
\text { fsPM, fsPC, fsPR, fsNIN }\end{array}$ \\
\hline Soil_moist_max & $\begin{array}{l}\text { Maximum available water holding } \\
\text { capacity of capillary reservoir from } \\
\text { land surface to rooting depth of } \\
\text { the major vegetation type }\end{array}$ & 0.2 & $m$ & $120^{*}$ cpor $^{* *}$ \\
\hline
\end{tabular}




\begin{tabular}{|l|l|l|l|l|}
\hline gwsink_coef & Outflow rate from GWR to a sink & 0.0 & $\begin{array}{l}\text { Fraction/d } \\
\text { ay }\end{array}$ & $\begin{array}{l}\text { siGM, siC } \\
\text { siR, siM }\end{array}$ \\
\hline tmax_allsnow & $\begin{array}{l}\text { Precipitation is all snow when the } \\
\text { maximum daily air temperature is } \\
\text { less than tmax_allsnow }\end{array}$ & 0.59 & ' C & $\mathrm{mxsn}$ \\
\hline Op_flow_thres & $\begin{array}{l}\text { Fraction of open depression } \\
\text { storage above which surface runoff } \\
\text { occurs for each time step, any } \\
\text { water above maximum open } \\
\text { storage capacity spills as surface } \\
\text { runoff }\end{array}$ & 0.75 & $\begin{array}{l}\text { Decimal } \\
\text { fraction }\end{array}$ & Oft \\
\hline
\end{tabular}

** "gpor": That part of porosity that is related to storage of water between field capacity and saturation, and "cpor": that part of porosity that is related to storage of water between wilting point and filed capacity [total porosity = grop + cpor]

*** Eq. 50 page 56 GSFLOW manual

\$ G: Geology SG: Surficial Geology Pt: peat layer

\# ST: Sediment or HRA thickness.

Table S2-II PRMS model parameters that were not used in calibration.

\begin{tabular}{|c|c|c|c|c|}
\hline Module & Symbol & Definition & \begin{tabular}{|l|} 
Initial \\
value \\
\end{tabular} & Unit \\
\hline \multirow{4}{*}{ 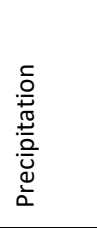 } & tmax_allrain & $\begin{array}{l}\text { Monthly minimum air temperature at an } \mathrm{HRU} \text { that } \\
\text { results in all precipitation during a day being rain. }\end{array}$ & 4.0 & ${ }^{\circ} \mathrm{C}$ \\
\hline & psta_mon & $\begin{array}{l}\text { Mean monthly precipitation at each measurement } \\
\text { station }\end{array}$ & & $\mathrm{m}$ \\
\hline & rain mon & Mean monthly rain on each $\mathrm{HRU}$ & $\ldots *$ & $\mathrm{~m}$ \\
\hline & snow mon & Mean monthly snow on each HRU & $\ldots *$ & $\mathrm{~m}$ \\
\hline \multirow{8}{*}{ 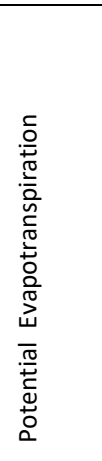 } & jh_coef_hru & Jensen-Haise constant (HRUs) & 14.5 & ${ }^{\circ} \mathrm{C}$ \\
\hline & jh_coef & Jenson-Haise temperature coefficient (Monthly) & 0.0267 & $1 /{ }^{\circ} \mathrm{C}$ \\
\hline & hs_krs & Hargreave-Samani (1982) monthly adjustment factor & 0.0135 & $\begin{array}{l}\text { decimal } \\
\text { fraction }\end{array}$ \\
\hline & rad_trncf & $\begin{array}{l}\text { Transmission coefficient for short-wave radiation } \\
\text { through winter plant canopy as a decimal fraction }\end{array}$ & 0.233 & dimensionless \\
\hline & transp_tmax & $\begin{array}{l}\text { Maximum temperature used to determine when } \\
\text { transpiration begins in an HRU }\end{array}$ & 500.0 & degree-day \\
\hline & trans_beg & Begin month for transpiration computations at $\mathrm{HRU}$ & 5 & month \\
\hline & trans end & Last month for transpiration computation at HRU & 10 & month \\
\hline & soil type & Type of soil in each HRU (Sand, loam and clay) & 1 to 3 & dimensionless \\
\hline \multirow{6}{*}{ 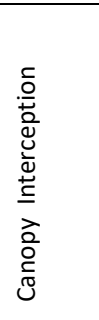 } & cov type & Bare (0), grass (1), shrub (2), trees (3), coniferous (4) & $0,3,4$ & dimensionless \\
\hline & covden_sum & Summer plant canopy density & $\begin{array}{l}0.32(\mathrm{WHU}), \\
0.62(\mathrm{WHU})\end{array}$ & $\begin{array}{l}\text { fraction of } \\
\text { area }\end{array}$ \\
\hline & covden_win & Winter plant canopy density & \begin{tabular}{|l|}
$0.32(\mathrm{WHU})$, \\
$0.62(\mathrm{WHU})$ \\
\end{tabular} & $\begin{array}{l}\text { fraction of } \\
\text { area }\end{array}$ \\
\hline & snow intcp & Maximum snow storage in plant canopy & 0.0025 & $\mathrm{~m}$ \\
\hline & srain intcp & Maximum summer rain storage in plant canopy & $1.27 \mathrm{e}-3$ & $\mathrm{~m}$ \\
\hline & wrain intcp & Maximum winter rain storage in plant canopy & $1.27 \mathrm{e}-3$ & $\mathrm{~m}$ \\
\hline \multirow{8}{*}{ 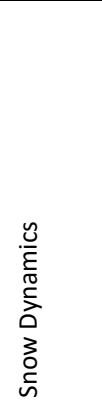 } & potet sublim & Fraction of potential evaporation form snow surface & 0.75 & dimensionless \\
\hline & den init & Density of new fallen snow & 0.1 & dimensionless \\
\hline & den max & Maximum snowpack density & 0.6 & dimensionless \\
\hline & melt force & Julian date to force snowmelt & 90 & Julian day \\
\hline & melt_look & Julian date when the snow melt start & 60 & Julian day \\
\hline & emis noppt & Emissivity of air in days without precipitation & 0.757 & dimensionless \\
\hline & settle const & Snowpack settlement-time constant & 0.1 & $1 /$ day \\
\hline & albset_sna & $\begin{array}{l}\text { Minimum snow (in water equivalent) needed to reset } \\
\text { snow albedo when snowpack is accumulating as a } \\
\text { decimal fraction. }\end{array}$ & 0.05 & dimensionless \\
\hline
\end{tabular}




\begin{tabular}{|c|c|c|c|c|}
\hline & albset_snm & $\begin{array}{l}\text { Minimum snow (in water equivalent) needed to reset } \\
\text { snow albedo when snowpack is melting as a decimal } \\
\text { fraction. }\end{array}$ & 0.2 & dimensionless \\
\hline & albset_rna & $\begin{array}{l}\text { Decimal fraction of rain in a mixed rain and snow event } \\
\text { above which snow albedo is not reset (when snow pack } \\
\text { is accumulating) }\end{array}$ & 0.8 & dimensionless \\
\hline & albset_rnm & $\begin{array}{l}\text { Decimal fraction of rain in a mixed rain and snow event } \\
\text { above which snow albedo is not reset (when snow pack } \\
\text { is melting) }\end{array}$ & 0.6 & dimensionless \\
\hline & snarea_thresh & $\begin{array}{l}\text { Maximum water equivalent threshold, water equivalent } \\
\text { less than threshold results in use the snow-covered-area } \\
\text { curve }\end{array}$ & 1.27 & $\mathrm{~m}$ \\
\hline & snarea_curve & $\begin{array}{l}\text { Snow area-depletion curve values, } 11 \text { for each curve } \\
(0.05,0.24,0.4,0.53,0.65,0.75,0.82,0.88,0.93,0.99 \\
1.0) \text { and } \\
(0.05,0.25,0.4,0.48,0.54,0.58,0.61,0.64,0.66,0.68 \text {, } \\
0.70)\end{array}$ & $\cdots$ & $\begin{array}{l}\text { decimal } \\
\text { fraction }\end{array}$ \\
\hline & hru deplcrv & Identifier of snowpack areal-depletion curve for HRU & 1 to ndepl & number \\
\hline & ndepl & Number of snow depletion curves & 2 & number \\
\hline & tstorm_mo & $\begin{array}{l}\text { Storm type in each month (0: frontal, } 1 \text { : convective) } \\
(0,0,0,0,1,1,1,1,1,0,0,0)\end{array}$ & 0 and 1 & number \\
\hline & cecn_coef & Monthly convection-condensation energy coefficient & 5.0 & $\begin{array}{l}\mathrm{Cal} /{ }^{\circ} \mathrm{C} \text { (above } \\
\text { zero) }\end{array}$ \\
\hline & snowinfil max & daily maximum snow infiltration & 0.07 & inches \\
\hline & freeh2o_cap & $\begin{array}{l}\text { Free-water holding capacity of snowpack expressed as } \\
\text { decimal fraction of total snowpack water equivalent. }\end{array}$ & 0.05 & dimensionless \\
\hline & dprst_area & Aggregate sum of surface depression areas of each HRU & $\begin{array}{l}150(15 \%): \\
\text { wetlands } \\
890: \text { mining } \\
\text { areas }\end{array}$ & acres \\
\hline & dprst_depth_average & $\begin{array}{l}\text { Average depth of storage depressions at maximum } \\
\text { storage capacity }\end{array}$ & $\begin{array}{l}1.02: \\
\text { wetlands } \\
\text { 11.43: Wet } \\
\text { tailings }\end{array}$ & $\mathrm{m}$ \\
\hline & dprst_et_coef & $\begin{array}{l}\text { Fraction of unsatisfied potential evapotranspiration to } \\
\text { apply to surface depression storage }\end{array}$ & $\begin{array}{l}0.15: \text { Wetlands } \\
0: \quad \text { Mining } \\
\text { areas }\end{array}$ & $\begin{array}{l}\text { decimal } \\
\text { fraction }\end{array}$ \\
\hline & dprst_flow_coef & $\begin{array}{l}\text { Coefficient in linear flow routing equation for open } \\
\text { surface depression for each HRU }\end{array}$ & 0.05 & fraction/day \\
\hline 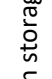 & dprst_frac_init & $\begin{array}{l}\text { Fraction of maximum surface depression storage that } \\
\text { contains water at the start of a simulation }\end{array}$ & 0 & $\begin{array}{l}\text { decimal } \\
\text { fraction }\end{array}$ \\
\hline 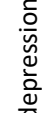 & dprst_frac_open & $\begin{array}{l}\text { Fraction of open surface depression storage area within } \\
\text { an } \mathrm{HRU} \text { that can generate surface runoff as a function of } \\
\text { storage volume }\end{array}$ & $\begin{array}{l}\text { 1: Wetlands } \\
0: \quad \text { Mining } \\
\text { areas }\end{array}$ & $\begin{array}{l}\text { decimal } \\
\text { fraction }\end{array}$ \\
\hline 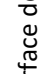 & dprst_seep_rate_clos & $\begin{array}{l}\text { Coefficient used in linear seepage flow equation for } \\
\text { closed surface depressions for each HRU }\end{array}$ & 0.0001 & fraction/day \\
\hline$\stackrel{亏}{亏}$ & dprst_seep_rate_open & $\begin{array}{l}\text { Coefficient used in linear seepage flow equation for } \\
\text { open surface depressions for each HRU }\end{array}$ & 0.0001 & fraction/day \\
\hline & sro_to_dprst & $\begin{array}{l}\text { Fraction of previous surface runoff that flows into } \\
\text { surface depression storage; the remainder flows to a } \\
\text { stream network for each HRU }\end{array}$ & $\begin{array}{l}0.3: \text { Wetlands } \\
0.95: \text { Mining } \\
\text { areas }\end{array}$ & $\begin{array}{l}\text { decimal } \\
\text { fraction }\end{array}$ \\
\hline & va_clos_exp & $\begin{array}{l}\text { Coefficient in the exponential equation relating } \\
\text { maximum surface area to the fraction that closed } \\
\text { depressions are full to compute current surface area for } \\
\text { each HRU }\end{array}$ & 1.0 & none \\
\hline & va_open_exp & $\begin{array}{l}\text { Coefficient in the exponential equation relating } \\
\text { maximum surface area to the fraction that open } \\
\text { depressions are full to compute current surface area for } \\
\text { each HRU }\end{array}$ & 1.0 & none \\
\hline & carea_max & Maximum possible area contributing in surface runoff & 0.0 & $\begin{array}{l}\text { decimal } \\
\text { fraction }\end{array}$ \\
\hline$\stackrel{+}{0}$ & imperv stor max & Maximum retention storage for HRU impervious area & 0.0 & $\mathrm{~m}$ \\
\hline$\vec{\propto}$ & hru percent imperv & Relative area of the impervious part of $\mathrm{HRU}$ & 0.0 & dimensionless \\
\hline
\end{tabular}




\begin{tabular}{|c|c|c|c|c|}
\hline \multirow{11}{*}{$\begin{array}{l}\stackrel{\Perp}{0} \\
\stackrel{0}{N} \\
\overline{\bar{D}}\end{array}$} & soil_moist_init & $\begin{array}{l}\text { Initial value of available water in the capillary reservoir } \\
\text { of the soil }\end{array}$ & $2.5 e-3$ & $\mathrm{~m}$ \\
\hline & Soil type & Sand(1), Clay (2) , Loam (3) & $1,2,3$ & dimensionless \\
\hline & soil_rechr_init & $\begin{array}{l}\text { Initial value in capillary reservoir where evaporation and } \\
\text { transpiration can occur simultaneously }\end{array}$ & 0.0 & $\mathrm{~m}$ \\
\hline & smidx_exp & $\begin{array}{l}\text { exponent for the nonlinear relation between the soil } \\
\text { moisture and surface runoff contributing area }\end{array}$ & 22.83 & $1 / \mathrm{m}$ \\
\hline & smidx_coef & $\begin{array}{l}\text { coefficient for the nonlinear relation between the soil } \\
\text { moisture and surface runoff contributing area }\end{array}$ & 0.18 & dimensionless \\
\hline & ssstor_init & $\begin{array}{l}\text { Initial storage in PRMS subsurface reservoir or gravity } \\
\text { reservoir }\end{array}$ & 0.0 & $\mathrm{~m}$ \\
\hline & ssr2gw_rate & $\begin{array}{l}\text { linear coefficient in gravity drainage from gravity } \\
\text { reservoir equation }\end{array}$ & $\begin{array}{l}5.1 \mathrm{e}-4- \\
2.5 \mathrm{e}-2\end{array}$ & inches /day \\
\hline & ssr2gw_exp & $\begin{array}{l}\text { exponent in gravity drainage from gravity reservoir } \\
\text { equation }\end{array}$ & $6.4-14.3$ & dimensionless \\
\hline & Pref flow max & Maximum storage of preferential flow reservoir & 0.254 & $\mathrm{~m}$ \\
\hline & Pref_flow_thrsh & $\begin{array}{l}\text { Storage between field capacity and maximum soil } \\
\text { saturation minus the any preferential-flow storage }\end{array}$ & $0.43-3.02$ & $m$ \\
\hline & sat_threshold & $\begin{array}{l}\text { Maximum volume of water per unit area in the soil zone. } \\
\text { It can be calculated as the sum of pref_flow_thrsh } \\
\text { and pref_flow_max. }\end{array}$ & $0.69-3.28$ & $m$ \\
\hline \multirow{2}{*}{$\begin{array}{l}\text { Ground } \\
\text { water }\end{array}$} & gwstor init & Initial storage in groundwater reservoir & 0.076 & $\mathrm{~m}$ \\
\hline & gwstormin & Minimum groundwater storage & 0.0 & $\mathrm{~m}$ \\
\hline \multirow[t]{2}{*}{$\begin{array}{l}\text { Stream } \\
\text { flow }\end{array}$} & K_coef & $\begin{array}{l}\text { Travel time of flood wave from one segment to the next } \\
\text { downstream segment }\end{array}$ & 2.0 & hours \\
\hline & $x$ coef & The amount of attenuation of the flow wave & 0.1 & dimensionless \\
\hline
\end{tabular}



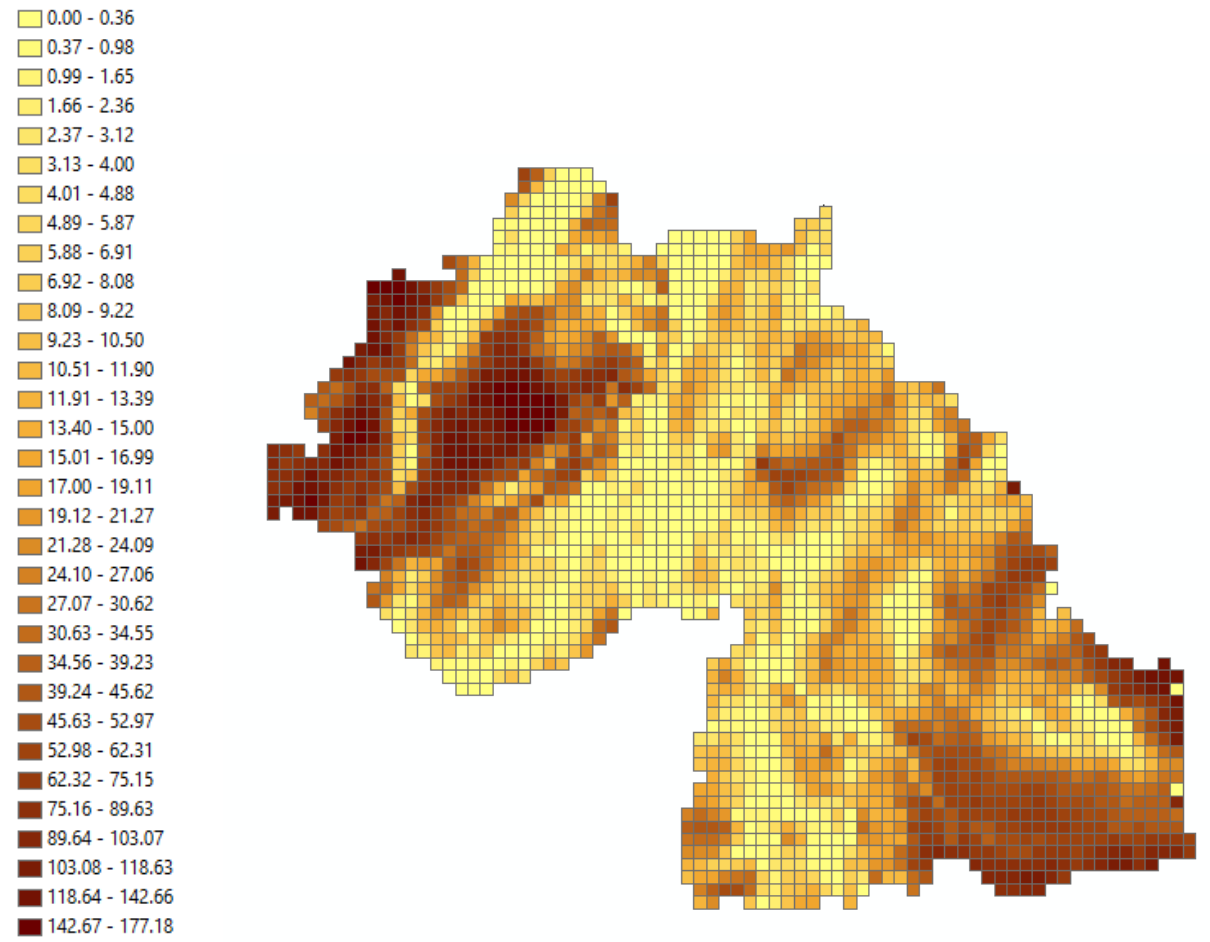

Figure S1-1 Distribution of surficial layer thicknesses (m) in the study area. 

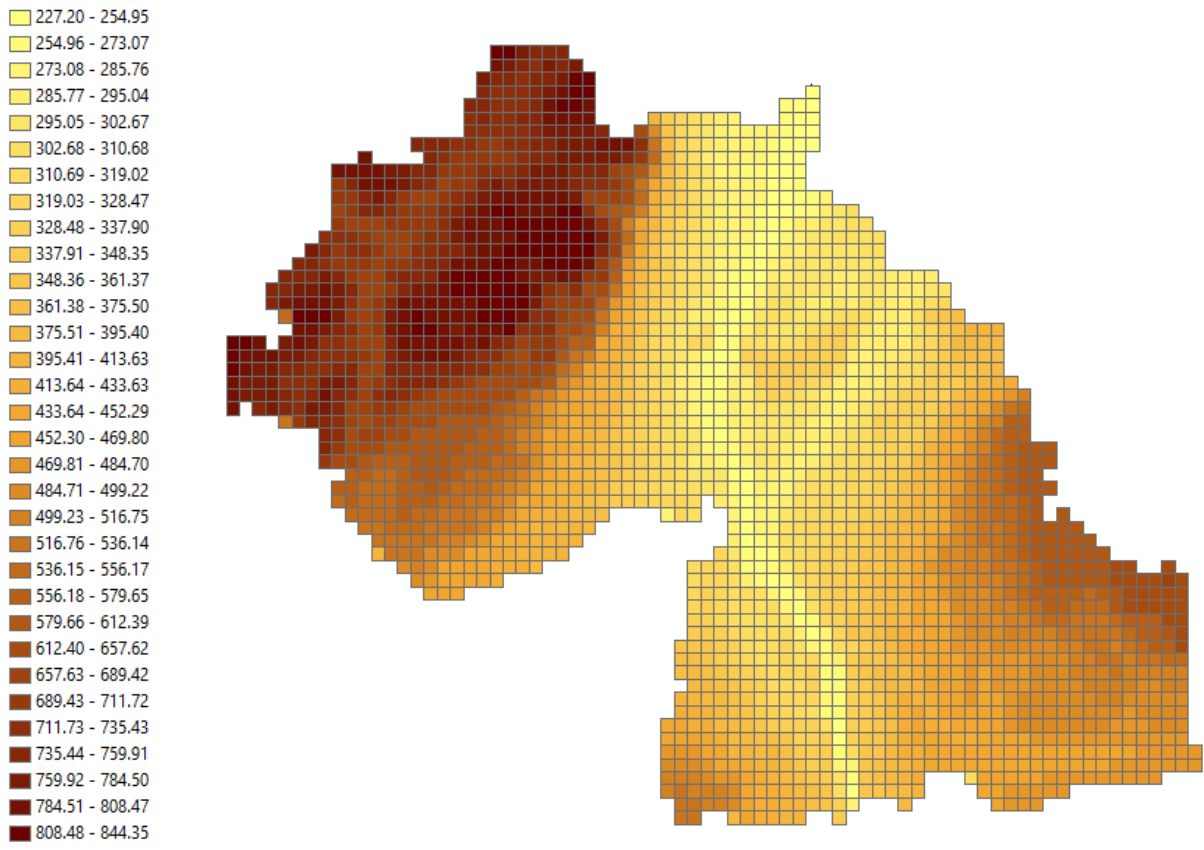

Figure S1-2 Surface topography displayed as elevation (masl) across the study area. 


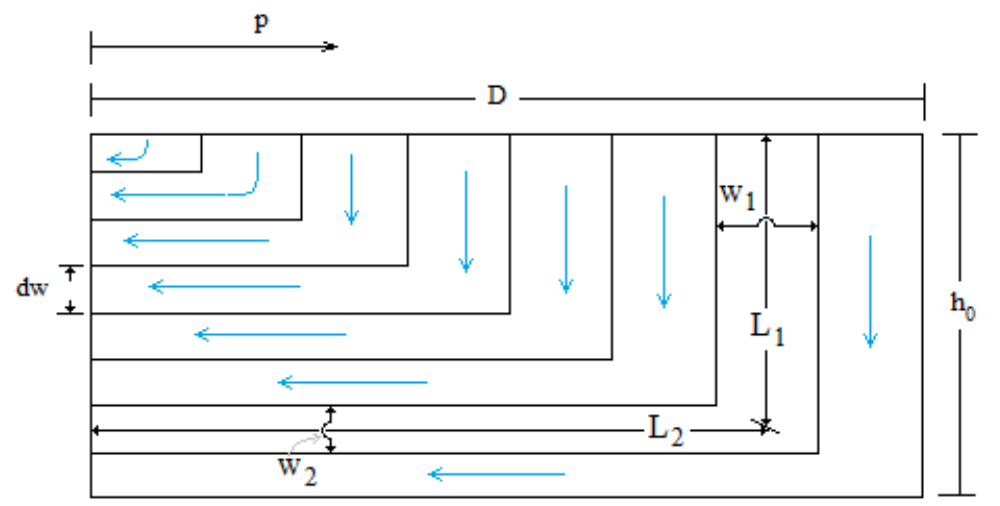

Figure S3-1 The schematic flow pipes in flow cross section. The length and width of the flow conduits are proportional to the length and width of the whole cross section. 


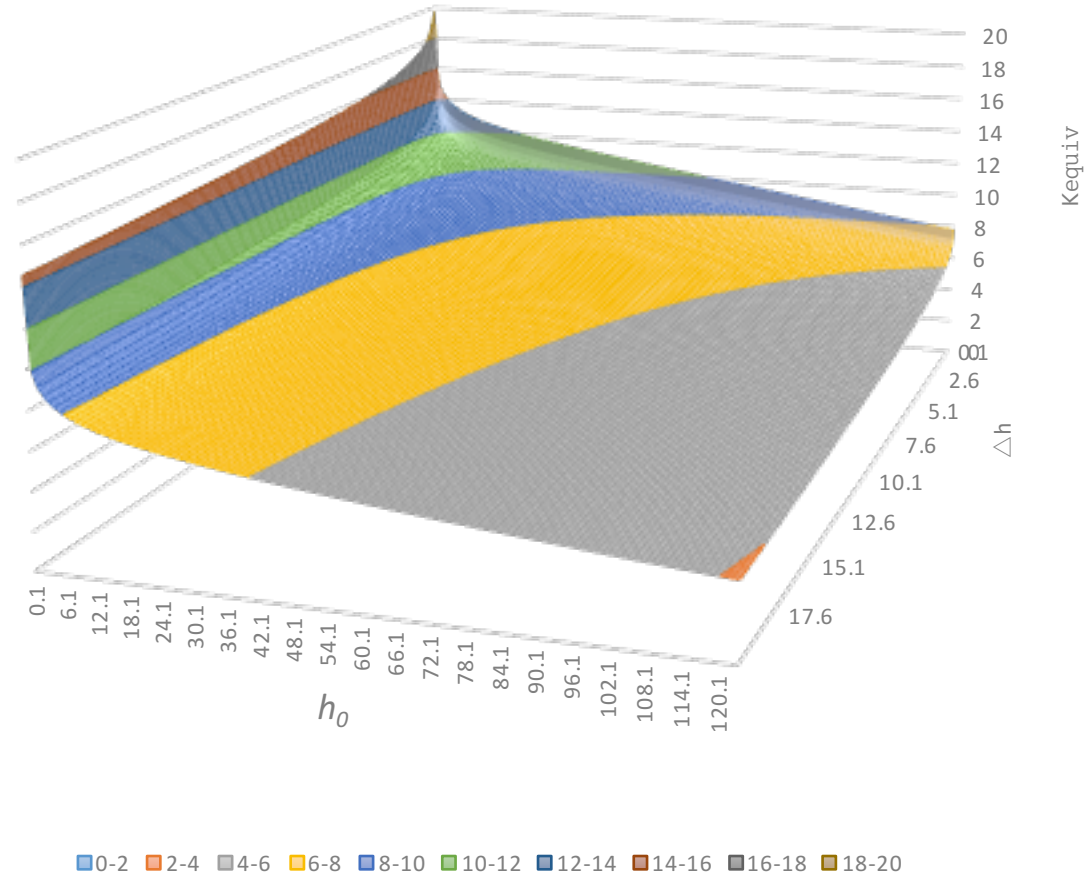

Figure S3-2 Variation of Equivalent $\mathrm{K}$ (Kequiv) versus $\Delta \mathrm{h}(\mathrm{m})$ and $\mathrm{h} 0 \mathrm{~m}$ ) for a rectangular model cell for the case of input from top and one dimensional output from one lateral aspects. Different colors show different range of values for Equivalent $\mathrm{K}$ (Kequiv, is dimensionless). 


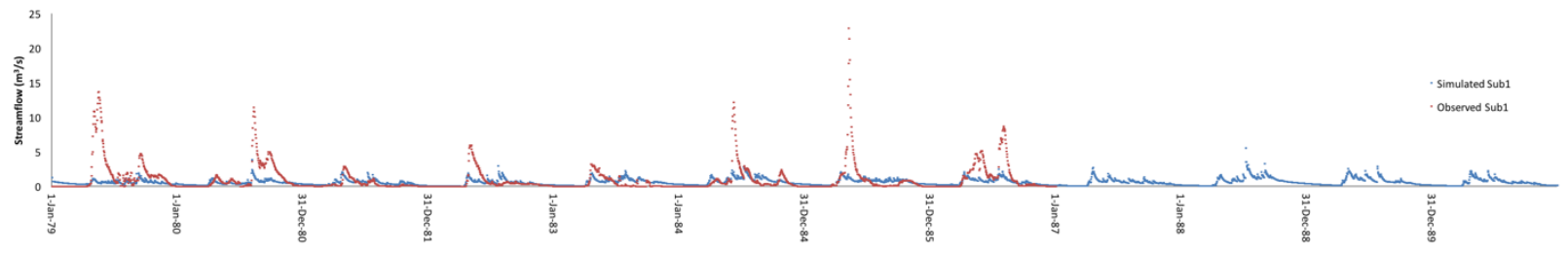

a)

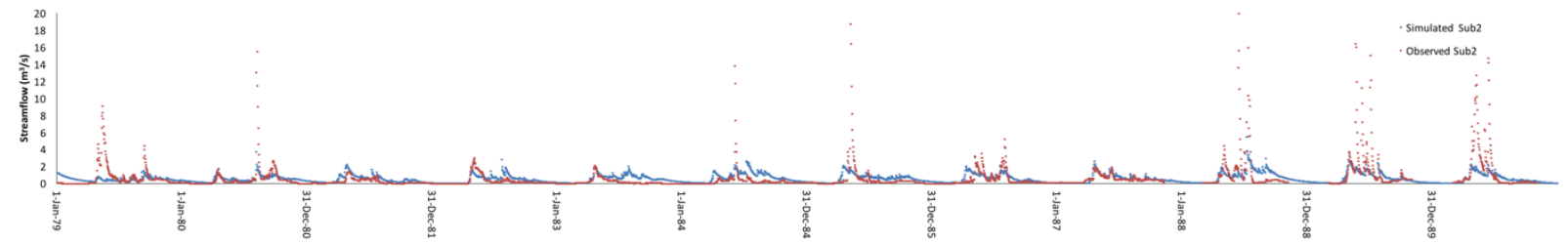

b)

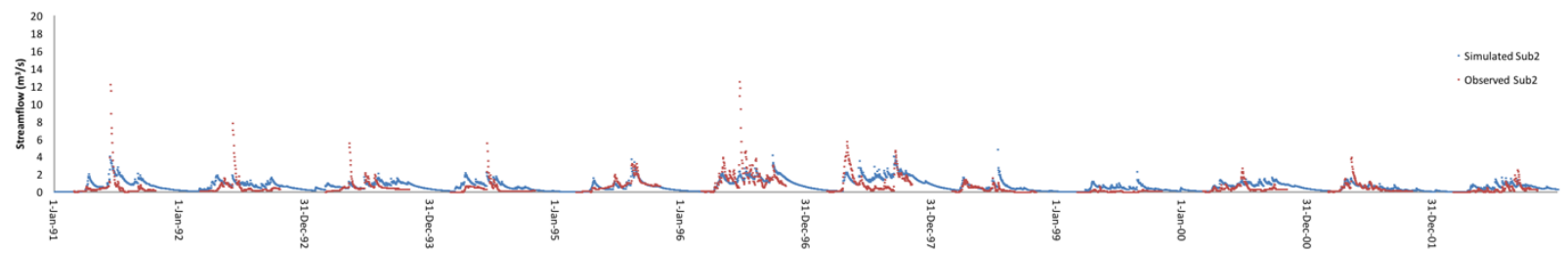

c)

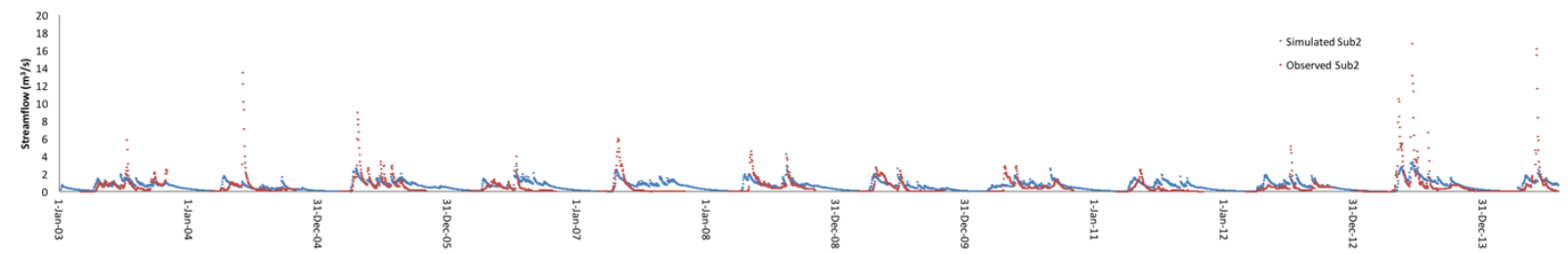

d)

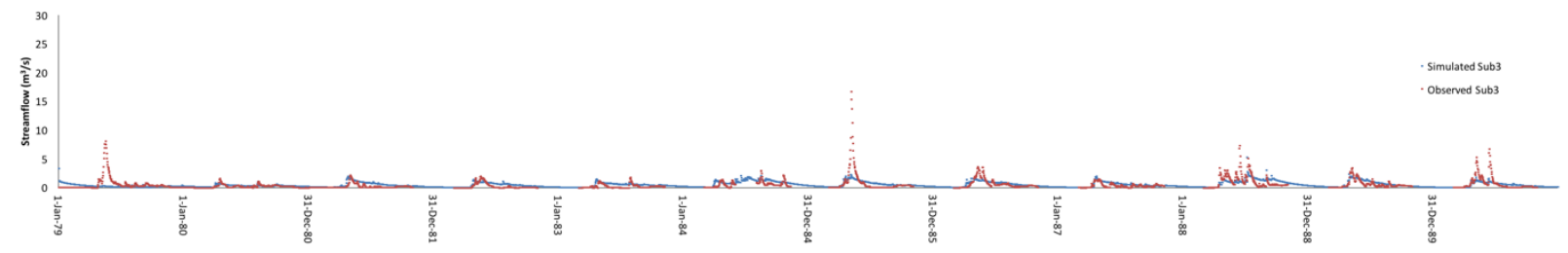

e) 


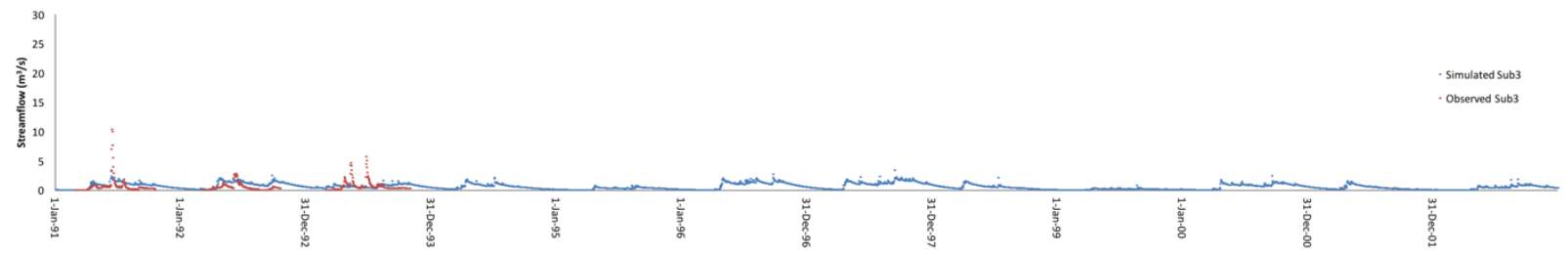

f)

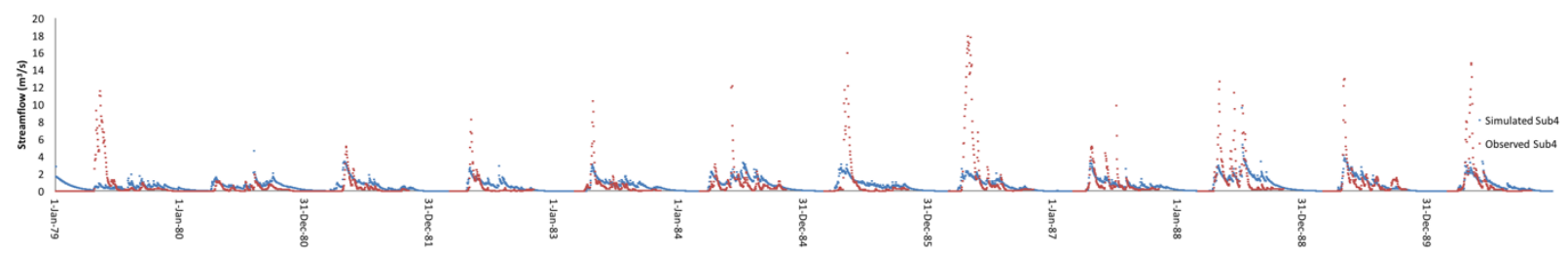

g)

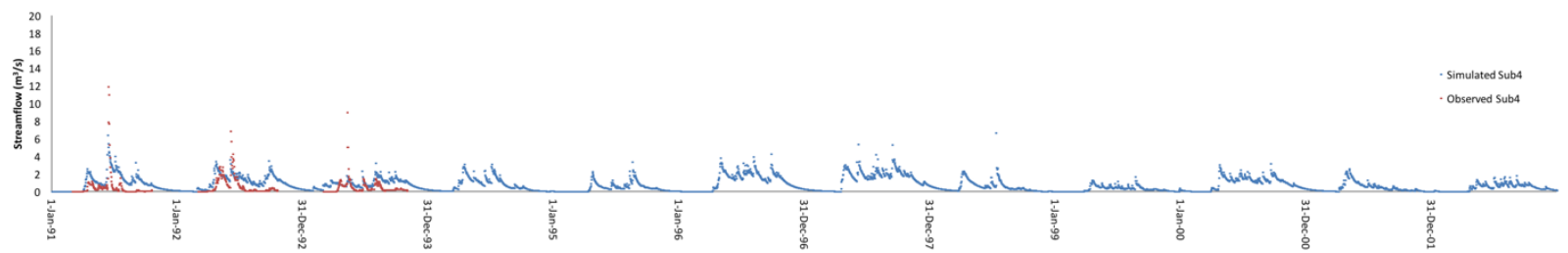

h)

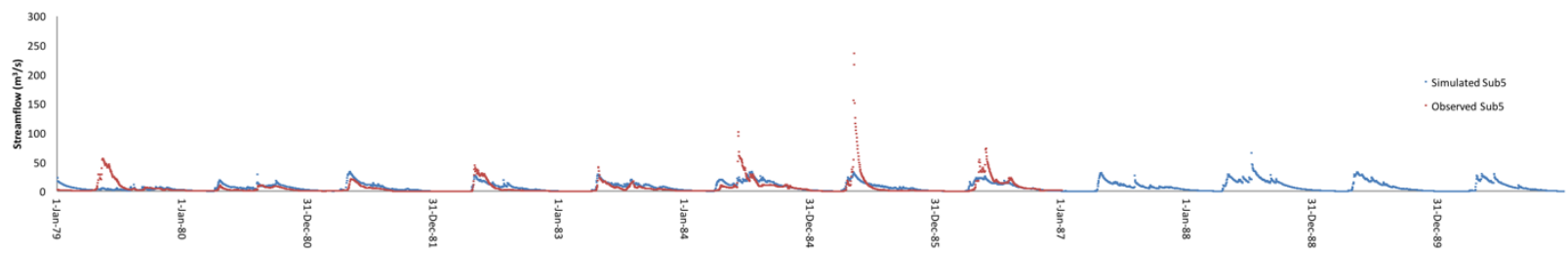

i)

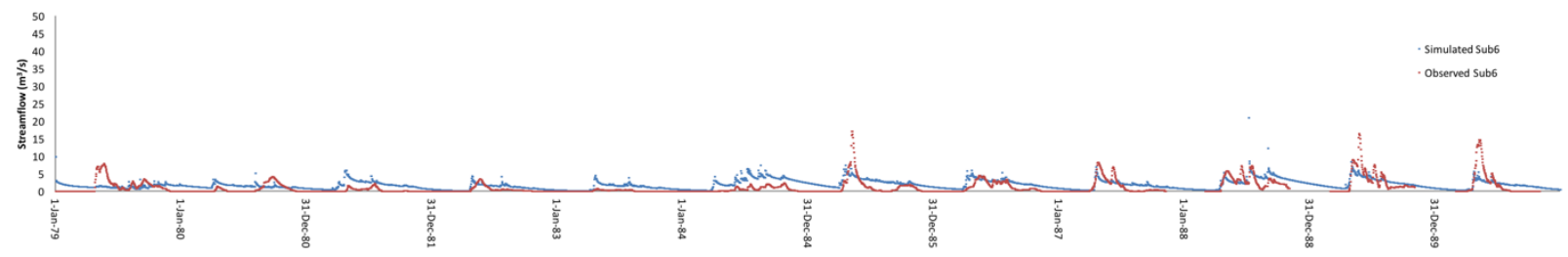

j) 


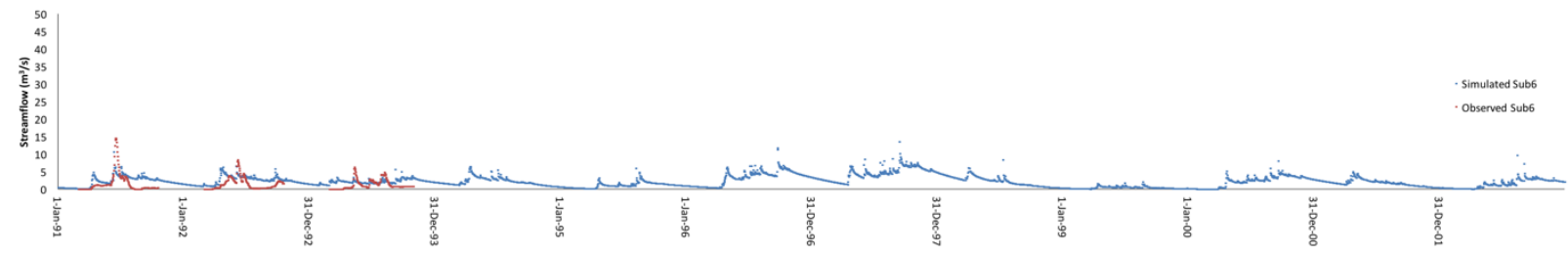

k)

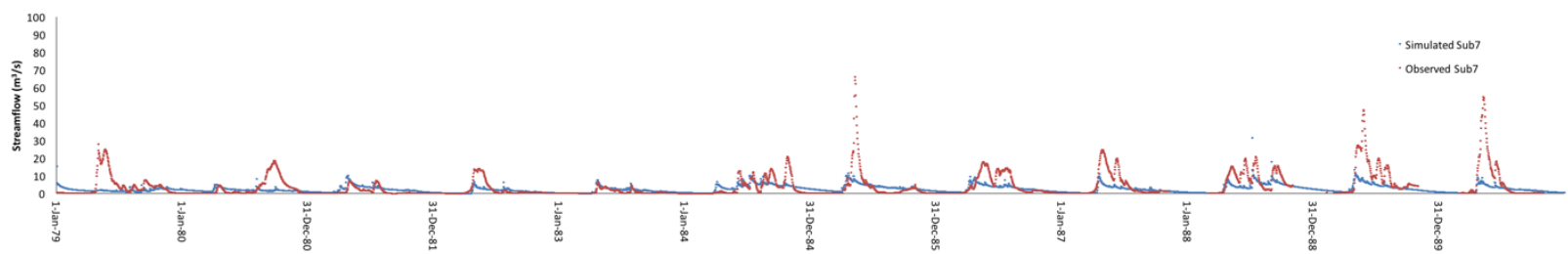

I)

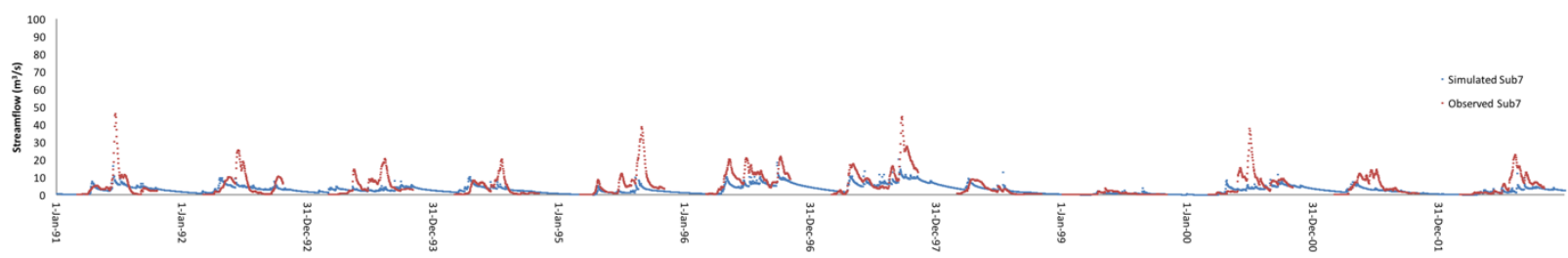

m)

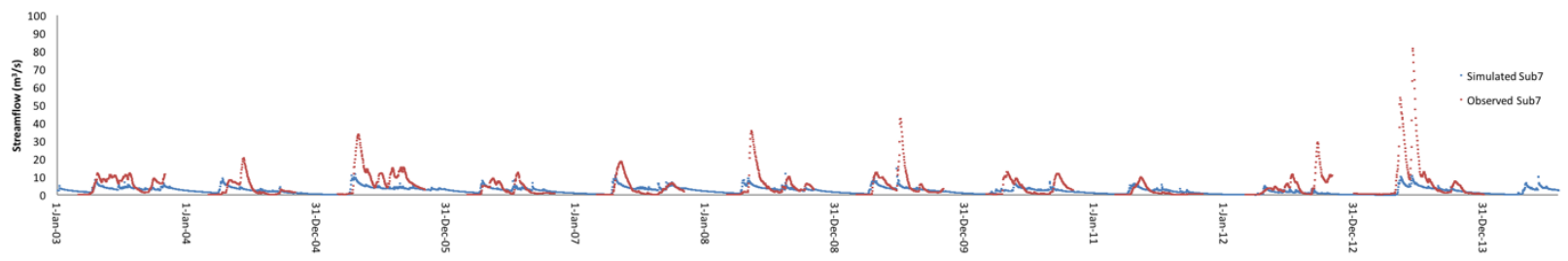

n)

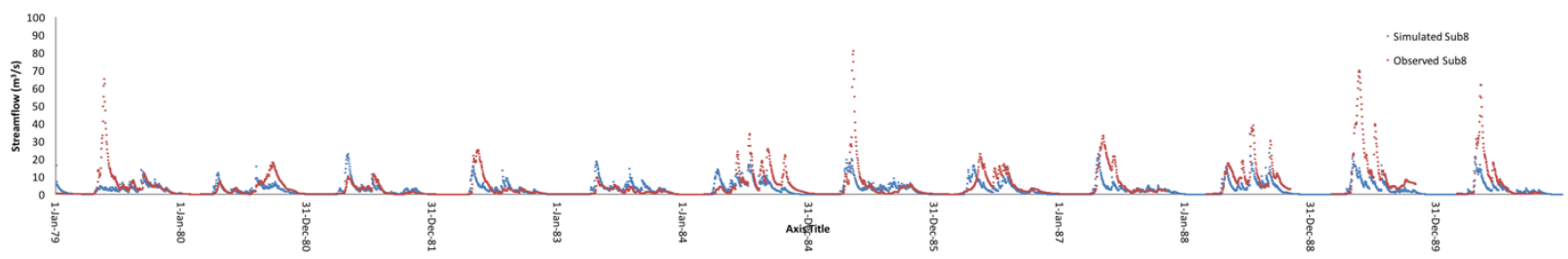

o) 


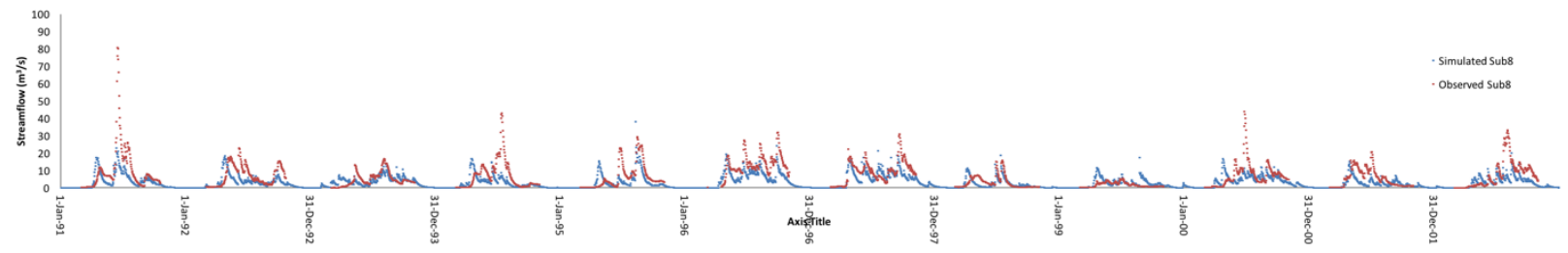

p)

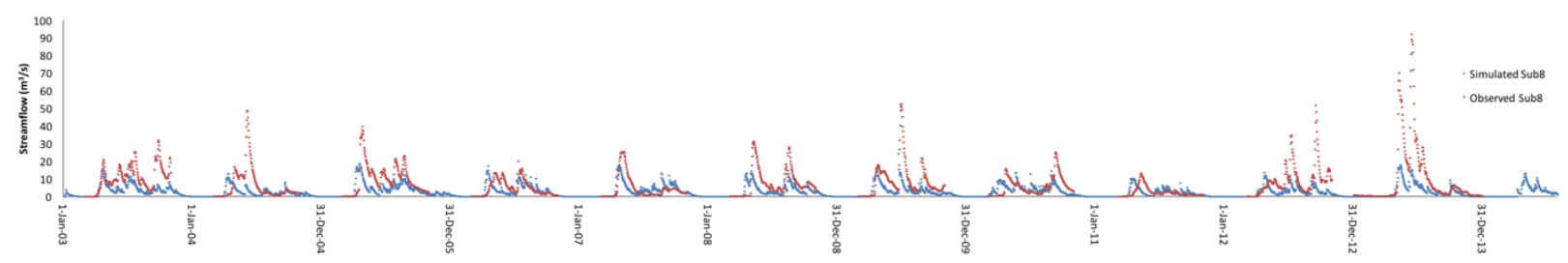

q)

Figure S5-1 Time series of observed and simulated curves for sub-basin 1. 
Table A-1 Initial values, lower and upper limits, optimal values as well as standard errors for the calibration parameters. Bold font indicates the 14 parameters with standard errors of calibration in an acceptable range, as calculated by Dynamically

Dimensioned Search (DDS).

\begin{tabular}{|c|c|c|c|c|c|c|c|}
\hline \multirow[b]{2}{*}{ PRMS name } & \multirow[b]{2}{*}{ Parameter } & \multirow{2}{*}{$\begin{array}{l}\text { Initial } \\
\text { value }\end{array}$} & \multirow[b]{2}{*}{ Lower limit } & \multirow{2}{*}{$\begin{array}{l}\text { Upper } \\
\text { limit }\end{array}$} & \multicolumn{2}{|c|}{ Calibration results } & \multirow[b]{2}{*}{ Unit } \\
\hline & & & & & $\begin{array}{c}\text { Optimal } \\
\text { values }\end{array}$ & Standard errors & \\
\hline \multirow[t]{3}{*}{ gwflow_coef } & gfGF & 0.020 & $1.00 \mathrm{E}-07$ & 0.120 & 0.120 & 1.05E-01 & 1/day \\
\hline & gfGM & 0.006 & $1.00 \mathrm{E}-07$ & 0.137 & 0.104 & 9.90E-02 & \\
\hline & $\mathrm{rmC}$ & 0.121 & $2.50 \mathrm{E}-6$ & 0.241 & 0.034 & 5.05E-01 & \\
\hline \multirow[t]{3}{*}{ soil_rechr_max } & $\mathrm{rmPM}$ & 0.128 & $2.50 \mathrm{E}-6$ & 0.241 & 0.238 & $8.66 \mathrm{E}+00$ & $\mathrm{~m}$ \\
\hline & $\mathrm{rmPC}$ & 0.049 & $2.50 \mathrm{E}-6$ & 0.241 & 0.241 & 9.27E-01 & \\
\hline & $\mathrm{rmPR}$ & 0.061 & $2.50 \mathrm{E}-6$ & 0.241 & 0.122 & $1.48 \mathrm{E}+01$ & \\
\hline \multirow{6}{*}{ pref_flow_den } & $\mathrm{pdM}$ & 0.051 & 0.002 & 0.990 & 0.003 & 4.07E-02 & \\
\hline & $\mathrm{pdC}$ & 0.043 & 0.005 & 0.990 & 0.246 & 3.76E-01 & \\
\hline & $\mathrm{pdR}$ & 0.037 & 0.005 & 0.990 & 0.006 & 8.27E-01 & dimensionless \\
\hline & pdPM & 0.915 & 0.020 & 0.990 & 0.021 & 7.40E-01 & \\
\hline & $\mathrm{pdPC}$ & 0.165 & 0.020 & 0.990 & 0.056 & 3.57E-01 & \\
\hline & pdPR & 0.454 & 0.020 & 0.990 & 0.021 & $1.02 \mathrm{E}+00$ & \\
\hline slowcoef_lin & sIR & 0.005 & 0.001 & 0.250 & 0.122 & Not_reported & 1/day \\
\hline slowcoef_sq & sqR & 7.401 & 0.004 & 27.550 & 20.393 & Not_reported & 1/m-day \\
\hline \multirow{4}{*}{ fastcoef_lin } & $\mathrm{flC}$ & 0.180 & 0.0002 & 0.700 & 0.075 & $1.10 \mathrm{E}+00$ & \\
\hline & fIPM & 0.111 & 0.0002 & 0.600 & 0.569 & $8.33 E+01$ & $1 /$ day \\
\hline & fIPC & 0.061 & 0.0002 & 0.600 & 0.047 & $1.12 \mathrm{E}+00$ & \\
\hline & fIMIN & 0.100 & 0.0002 & 0.700 & 0.110 & $2.64 \mathrm{E}+01$ & \\
\hline soil2gw_max & sxP & 0.357 & 0.000 & 0.510 & 0.323 & Not_reported & $\mathrm{m}$ \\
\hline \multirow{7}{*}{ fastcoef_sq } & fsM & 18.38 & 0.004 & 47.240 & 47.204 & $2.54 \mathrm{E}+04$ & \\
\hline & fsC & 0.866 & 0.004 & 47.240 & 3.740 & $1.01 E+02$ & \\
\hline & fsR & 19.015 & 0.004 & 47.240 & 40.275 & $1.49 E+03$ & \\
\hline & fsPM & 0.354 & 0.004 & 47.240 & 45.236 & $5.94 \mathrm{E}+04$ & 1/m-day \\
\hline & fsPC & 0.433 & 0.004 & 47.240 & 16.692 & $1.16 \mathrm{E}+03$ & \\
\hline & fsPR & 1.102 & 0.039 & 47.240 & 47.125 & $2.15 E+04$ & \\
\hline & fsNIN & 3.937 & 0.004 & 47.240 & 38.425 & $1.13 \mathrm{E}+04$ & \\
\hline \multirow[t]{2}{*}{ porosity } & cpor & 0.15 & 0.080 & 0.270 & 0.269 & $2.53 \mathrm{E}-01$ & dimensionless \\
\hline & siGM & 0.339 & 0.000 & 1.000 & 0.999 & $1.08 \mathrm{E}+01$ & \\
\hline \multirow[t]{3}{*}{ gwsink_coef } & $\mathrm{siC}$ & 0.291 & 0.000 & 1.000 & 0.029 & 9.90E-02 & Fraction/day \\
\hline & $\operatorname{siR}$ & 0.180 & 0.000 & 1.000 & 0.995 & $5.61 \mathrm{E}+01$ & \\
\hline & sim & 0.008 & 0.000 & 1.000 & 0.001 & $5.36 \mathrm{E}-02$ & \\
\hline tmax_allsnow & $\mathrm{mxsn}$ & 0.590 & -2.000 & 2.000 & 1.990 & $1.27 \mathrm{E}+01$ & ${ }^{\circ} \mathrm{C}$ \\
\hline op_flow_thres & Oft & 0.750 & 0.001 & 0.990 & 0.712 & 7.13E-01 & Decimal fraction \\
\hline
\end{tabular}




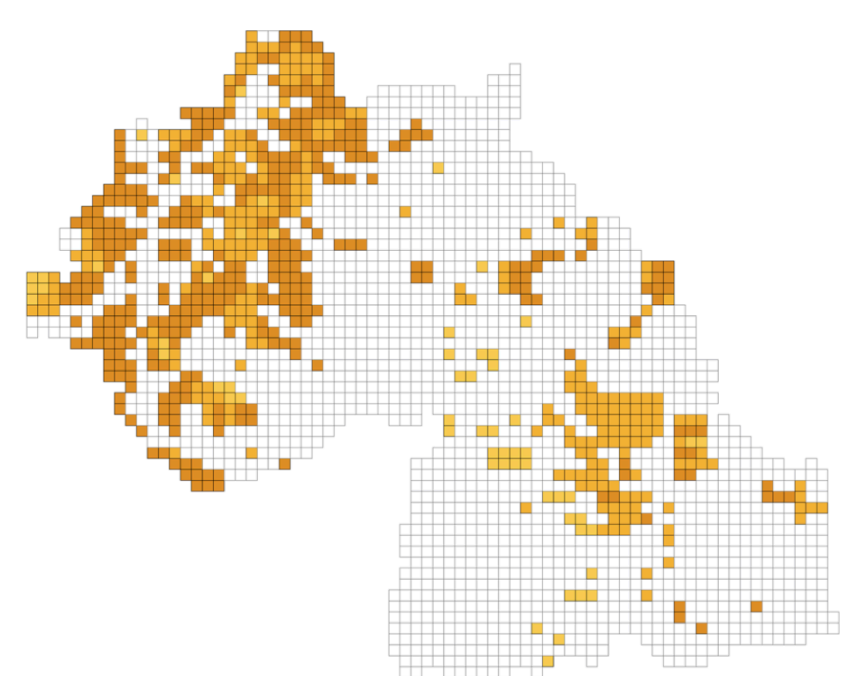

a) Median (M)
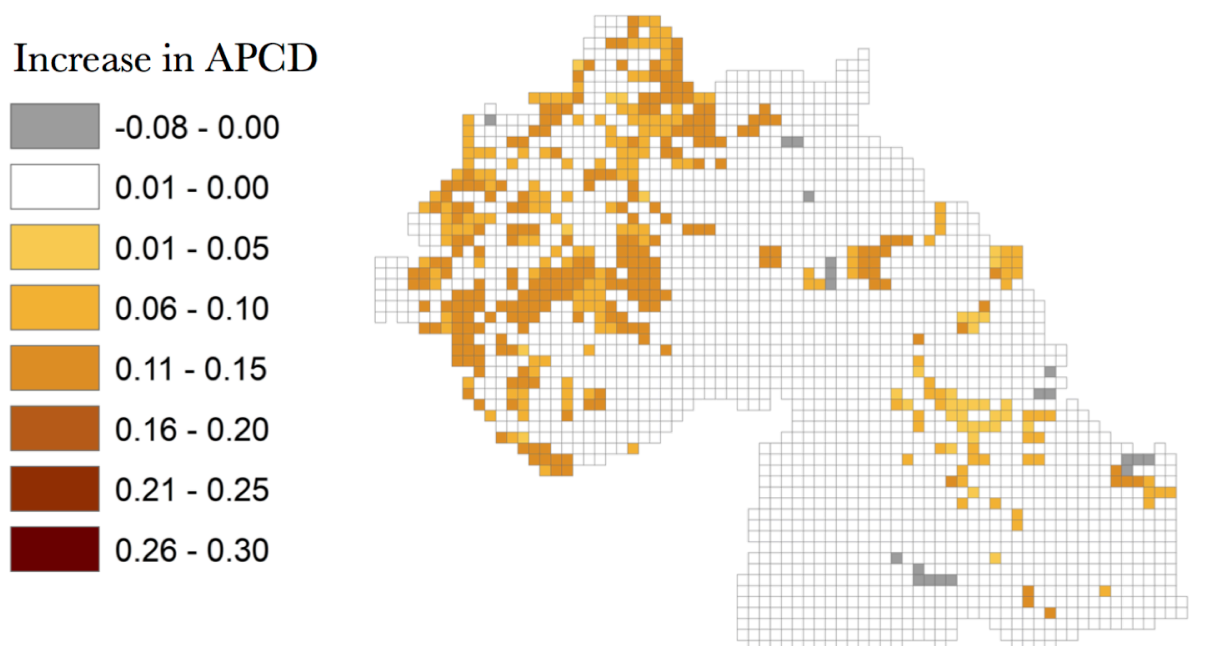

c) No change in precipitation (NP)

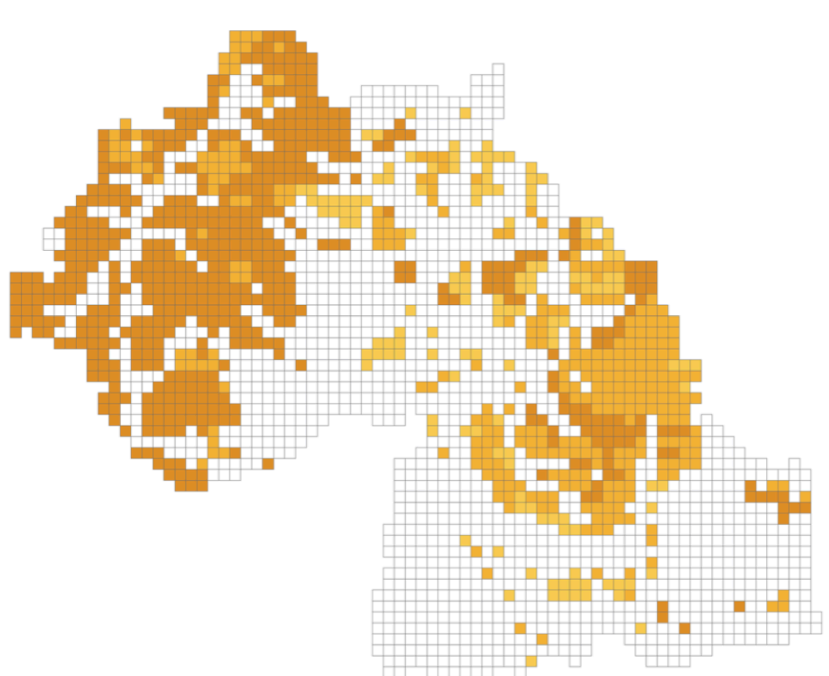

b) Double precipitation (DP)

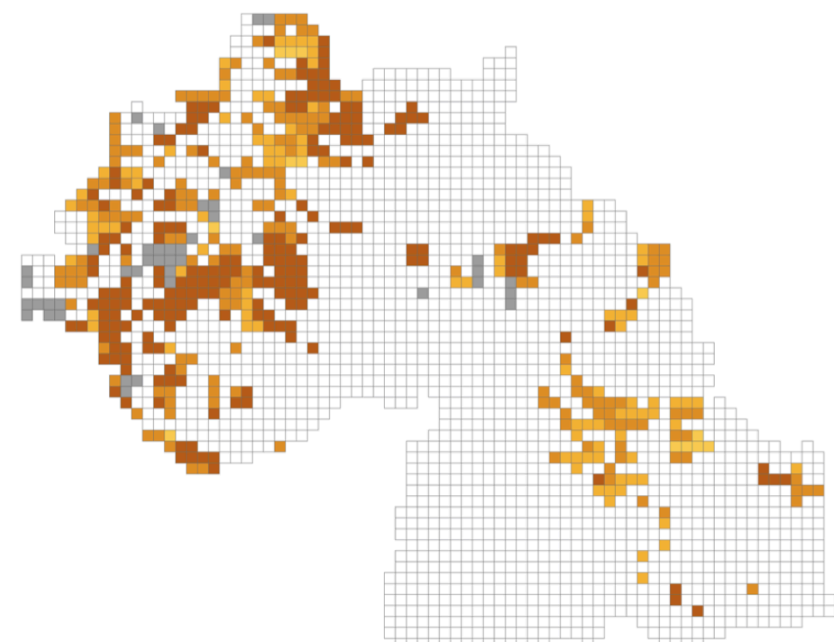

d) Double temperature (DT)

Figure 8 Increase in annual proportion of connected days in different HRUs in 2080 compared with 2016 for median (M), double precipitation (DP), no change in precipitation (NP) and double temperature (DT) scenarios. 